INSTITUTO DE PESQUISAS ENERGÉTICAS E NUCLEARES

Autarquia associada à Universidade de São Paulo

ESTUDO DO COMPORTAMENTO MECÂNICO EM TEMPERATURAS ELEVADAS DA LIGA Ti-6AI-4V APÓS TRATAMENTO SUPERFICIAL DE NITRETAÇÃO POR PLASMA

GISELE FABIANE COSTA ALMEIDA

Trabalho apresentado como parte dos requisitos para obtenção do Grau de Doutor em Ciências na Área de Tecnologia Nuclear - Materiais

Orientador:

Prof. Dr. Antonio Augusto Couto

Versão Corrigida

Versão Original disponível no IPEN

SÃO PAULO 


\section{AGRADECIMENTOS}

É difícil me lembrar de todos que contribuíram para a elaboração deste trabalho, mas espero citar pelo menos alguns nomes que foram de extrema importância. Quero agradecer:

Primeiramente a Deus, que me deu a capacidade de ser uma pessoa com a capacidade de chegar até aqui.

Ao meu orientador, o Prof. Dr. Antonio Augusto Couto, que me acompanha desde a Iniciação Científica, pela sua dedicação e ensinamentos ao longo de todos estes anos.

Ao Instituto Tecnológico de Aeronáutica (ITA) e a Universidade Federal de São Paulo (UNIFESP) pela oportunidade de utilização de suas instalações e de cursar disciplinas.

Ao Laboratório de Plasmas e Processos (LPP) do ITA, onde foram feitas as nitretações por plasma, em especial ao Prof. Dr. Argemiro S. da Silva Sobrinho, ao Prof. Dr. Marcos Massi e ao Prof. Dr. Douglas Marcel Gonçalves Leite, pelo grande apoio na parte experimental deste trabalho.

À Prof ${ }^{a}$ Dr $^{\mathrm{a}}$. Danieli Aparecida Pereira Reis e demais pesquisadores do grupo de fluência do ITA, por compartilhar seus conhecimentos na área de fluência. Não podendo deixar de citar o Prof. Dr. Carlos de Moura Neto (in memoriam).

À empresa Isoflama Ind. e Com de Equipamentos Ltda. e ao seu diretor técnico e comercial Sr. João Carmo Vendramim e ao Prof. Dr. Jan Vatavuk, pela oportunidade da visita técnica onde foi possível conhecer sobre os tratamentos superficiais em escala industrial.

Às alunas de iniciação científica, Beatriz de Pádua Severino, Mariana Ferreira Gutierrez da Silva e Giovanna Lucchesi Maset e demais funcionários dos laboratórios do IPEN pela ajuda na preparação das amostras e dedicação. Ao Prof.Dr. Nelson B. de Lima do IPEN pelas análises de Difratometria de Raios X e ao Celso Vieira Morais pelas análises do Microscópio Eletrônico de Varredura.

E à minha família, meus pais Julio Alves de Almeida e Maria Aguida da Costa Almeida, que sempre me apoiaram em todos os momentos e que sem eles seria muito mais difícil concretizar tudo isso.

Obrigada a todos! 


\title{
ESTUDO DO COMPORTAMENTO MECÂNICO EM TEMPERATURAS \\ ELEVADAS DA LIGA Ti-6AI-4V APÓS TRATAMENTO SUPERFICIAL DE NITRETAÇÃO POR PLASMA
}

\author{
Gisele Fabiane Costa Almeida
}

\begin{abstract}
RESUMO
A liga Ti-6Al-4V é uma das ligas de titânio mais suas aplicações estruturais em temperaturas elevadas são limitadas devido a sua afinidade pelo oxigênio. Um tratamento superficial que melhore a resistência à oxidação desta liga permitindo a substituição de peças que atualmente são produzidas com superligas de Ni por este material, poderia reduzir significativamente o peso destes componentes. $O$ objetivo deste trabalho é melhorar a resistência à fluência desta liga utilizando nitretação por plasma. Para homogeneizar a microestrutura do material, foi realizado um tratamento térmico a $1050^{\circ} \mathrm{C}$ por 30 minutos para obtenção da microestrutura de Widmanstätten que foi a que apresentou melhor resistência à fluência no material sem tratamento. A nitretação foi realizada variando parâmetros de processo como tempo, temperatura e mistura de gases na atmosfera. A partir dos resultados obtidos, a mistura de gás de $\operatorname{Ar}: \mathrm{N}_{2}: \mathrm{H}_{2}$ $(0,49: 0,49: 0,03)$ a $700^{\circ} \mathrm{C}$ por 4 horas foi a condição escolhida. A caracterização da camada nitretada foi realizada por técnicas de microscopia ótica e eletrônica de varredura, além de difração de raios $X$. As fases da amostra nitretada detectadas por DRX foram o $\varepsilon-\mathrm{Ti}_{2} \mathrm{~N}$ e $\delta$-TiN, além das fases $\alpha$ e $\beta$ da matriz. $A$ espessura da camada nitretada foi de cerca de $1 \mu \mathrm{m}$. Os ensaios de tração a quente foram realizados em temperaturas entre $500^{\circ} \mathrm{C}$ e $700^{\circ} \mathrm{C}$ no material com e sem nitretação e mostraram um aumento na resistência da liga nitretada de até $29 \%$ nos limites de escoamento e resistência. Os ensaios de fluência foram realizados variando a temperatura também entre 500 e $700^{\circ} \mathrm{C}$ e tensão aplicada entre 125 e $319 \mathrm{MPa}$. O resultado foi um aumento na resistência à fluência do material nitretado. Isto foi evidenciado pela diminuição da taxa de fluência secundária e também pelo aumento do tempo de ruptura do material.
\end{abstract}

Palavras-chave: Fluência, Ti-6Al-4V, nitretação por plasma. 


\title{
HIGH TEMPERATURE MECHANICAL BEHAVIOR OF THE TI-6AL-4V ALLOY AFTER PLASMA NITRIDING
}

\author{
Gisele Fabiane Costa Almeida
}

\begin{abstract}
The Ti-6Al-4V alloy is one of the most widely used titanium alloys, but its structural applications at elevated temperatures are limited because of the titanium high affinity for oxygen. A surface treatment that improves the oxidation resistance of this alloy allowing the replacement of parts that are currently produced with $\mathrm{Ni}$ based super alloys by this material could significantly reduce the weight of these components. The aim of this work is to improve the creep resistance of the Ti-6Al$4 \mathrm{~V}$ alloy using plasma nitriding. In order to homogenize the material microstructure, it was performed a heat treatment at $1050^{\circ} \mathrm{C}$ for 30 minutes to obtain the Widmanstätten microstructure, which was the that presented better resistance to creep in the no nitrided material. The nitriding was performed by varying parameters as time, temperature and gas mixture in the atmosphere during the process. The chosen condition was a gas mixture of Ar: $\mathrm{N}_{2}: \mathrm{H}_{2}(0.49$ : 0.49: 0.03 ) at $700^{\circ} \mathrm{C}$ for 4 hours. The compound layer characterization was performed by optical and scanning electron microscopy techniques and X-ray diffraction. The nitrided samples phases detected by XRD were $\varepsilon-T i_{2} N, \delta-T i N$ and the $\alpha$-Ti and $\beta$-Ti matrix phases. The layer thickness of this sample was about 1 $\mu \mathrm{m}$. The hot tensile tests were performed in a temperature range from $500^{\circ} \mathrm{C}$ to $700^{\circ} \mathrm{C}$ in nitrided and no nitrided materials and show an increase in the strength of the nitrided alloy up $29 \%$ in yield and ultimate strength. The creep tests were also performed in a temperature between 500 and $700^{\circ} \mathrm{C}$ and stress range from 125 to $319 \mathrm{MPa}$. The results showed an increase in nitrided sample creep resistance. This was evidenced by both the decrease in secondary creep rate and an increase in final creep time.
\end{abstract}

Keywords: Creep, Ti-6Al-4V, plasma nitriding. 


\section{LISTA DE FIGURAS}

Figura 1 - Materiais utilizados para a fabricação de motores a jato. 15

Figura 2 - Composição química das principais ligas de titânio em pseudodiagrama de equilíbrio de fases binário do titânio e estabilizador $\beta$

Figura 3 - seção isotérmica do Ti-Al-V versus a fase de equilíbrio nas temperaturas indicadas. $\mathrm{O}$ círculo sólido $(\bullet)$ representa a liga Ti-6AI-4V.

Figura 4 - Diagrama de fases da liga Ti-6Al-4V ilustrando as diversas microestruturas formadas a partir do tratamento térmico com diferentes taxas de resfriamento.

Figura 5 - Microestrutura de Widmanstätten típica da liga $\alpha+\beta$ (Ti-6Al-4V) resfriada lentamente a partir da temperatura de transição $\beta$ 25

Figura 6 - Diagrama de fase da liga Ti-6Al-4V ilustrando a formação da estrutura Widmanstätten. .26

Figura 7 - Variação da espessura da camada do composto versus (a) tempo e (b) temperatura de processo.

Figura 8 - Diagrama de fases do Ti-N mostrando as fases esperadas em condição de equilíbrio para diferentes teores de $\mathrm{N}_{2}$ (expresso em \% atômica) 30 Figura 9 - Representação esquemática da cinética de formação e crescimento da camada superficial durante a nitretação do titânio. .32

Figura 10 - Esquema de um ensaio de fluência típico .33

Figura 11 - Curva típica de fluência a tensão constante e temperatura elevada constante. 34

Figura 12 - Dependência da taxa de fluência estacionária com a temperatura....38 Figura 13 - Esquema das etapas realizadas para elaboração da parte experimental do trabalho 45

Figura 14 - Configuração do corpo de prova (dimensões em $\mathrm{mm}$ ) utilizado nos ensaios de fluência (ASTM INTERNATIONAL, 2011) 46

Figura 15 - Fotografia do corpo de prova utilizado nos ensaios de fluência. .47

Figura 16 - Forno tubular utilizado para realização do tratamento térmico .47

Figura 17 - Reator utilizado para processamento de materiais por plasma. .48

Figura 18 - Fonte CC utilizada para geração do plasma no reator. .48

Figura 19 - Desenho do porta amostra utilizado para nitretação. 49

Figura 20 - Fluxograma do processo de nitretação por plasma. .50 
Figura 21 - Imagem dos corpos de prova de fluência sendo nitretados por plasma.

Figura 22 - Equipamento utilizado para realização dos ensaios de fluência.

Figura 23 - Microestrutura da liga Ti-6Al-4V (a) antes e (b) depois do tratamento térmico.

Figura 24 - Fotografia das amostras nitretadas com diferentes teores de $\mathrm{N}_{2}$ (a) com $50 \%$ (b) com $25 \%$ e (c) com $75 \%$ de $\mathrm{N}_{2}$ na atmosfera nitretante. .58 Figura 25 - Micrografia óptica em campo escuro da amostra de Ti-6Al-4V nitretada por plasma.

Figura 26 - Micrografia da liga Ti-6Al-4V observada por MEV utilizando elétrons secundários. 59

Figura 27 - Micrografia da liga Ti-6Al-4V observada por MEV. 60

Figura 28 - Difratograma de raios $X$ da amostra como recebida. 61

Figura 29 - Difratograma de raios $X$ da amostra tratada por nitretação por plasma em atmosfera com $25 \%$ de $\mathrm{N}_{2}$.

Figura 30 - Difratograma de raios $\mathrm{X}$ da amostra tratada por nitretação por plasma com atmosfera com $50 \%$ de $\mathrm{N}_{2}$

Figura 31 - Difratograma de raios $\mathrm{X}$ da amostra tratada por nitretação por plasma com atmosfera com $75 \%$ de $\mathrm{N}_{2}$ .65

Figura 32 - Difratograma de raios $X$ da amostra tratada por nitretação por plasma com atmosfera com $50 \%$ de $\mathrm{N}_{2}$ (lote dos corpos de prova). 68

Figura 33 - Influência da temperatura no limite de escoamanto do material .........70

Figura 34 - Influência da temperatura no limite de resistência do material 71 Figura 35 - Curvas de tensão-deformação da liga Ti-6Al-4V obtidas no ensaio de tração a quente a $500^{\circ} \mathrm{C}$. 72

Figura 36 - Curvas de tensão-deformação da liga Ti-6Al-4V obtidas no ensaio de tração a quente a $600^{\circ} \mathrm{C}$. .72

Figura 37 - Curvas de tensão-deformação da liga Ti-6Al-4V obtidas no ensaio de tração a quente a $700^{\circ} \mathrm{C}$. .73

Figura 38 - Curvas de fluência a $600^{\circ} \mathrm{C}$ e $250 \mathrm{MPa}$ para o Ti-6Al-4V com microestrutura de Widmanstätten com e sem nitretação por plasma. .74 Figura 39 - Curvas de fluência a $500^{\circ} \mathrm{C}$ e $319 \mathrm{MPa}$ para o Ti-6Al-4V com diferentes microestruturas e tratamentos superficiais. .76 
Figura 40 - Curvas de fluência a $600^{\circ} \mathrm{C}$ e $125 \mathrm{MPa}$ para o Ti-6Al-4V com diferentes microestruturas e tratamentos superficiais.

Figura 41 - Curvas de fluência a $600^{\circ} \mathrm{C}$ e $250 \mathrm{MPa}$ para o Ti-6Al-4V com diferentes microestruturas e tratamentos superficiais.

Figura 42 - Curvas de fluência a $600^{\circ} \mathrm{C}$ e $319 \mathrm{MPa}$ para o Ti-6Al-4V com diferentes microestruturas e tratamentos superficiais. .78

Figura 43 - Curvas de fluência a $700^{\circ} \mathrm{C}$ e $319 \mathrm{MPa}$ para o Ti-6Al-4V com diferentes microestruturas e tratamentos superficiais. .78

Figura 44 - Percentual relativo do tempo dos estágios de fluência dos ensaios realizados na liga Ti-6Al-4V nitretada por plasma.

Figura 45 - Dependência do tempo de fluência primária com a tensão aplicada da liga Ti-6AI-4V a $600^{\circ} \mathrm{C}$ sem tratamento, nitretada por plasma e tratada com IIIP. 84 Figura 46 - Dependência da taxa de fluência estacionária com a tensão aplicada da liga Ti-6Al-4V a $600^{\circ} \mathrm{C}$ sem tratamento, nitretada por plasma e tratada com IIIP.

Figura 47 - Diagrama para a determinação da energia de ativação a $319 \mathrm{MPa}$ da liga Ti-6Al-4V sem tratamento, nitretada por plasma e tratada com IIIP. .86 Figura 48 - Dependência do tempo de fluência primária com a temperatura aplicada a $319 \mathrm{MPa}$. .88

Figura 49 - Dependência da taxa de fluência estacionária com a tensão aplicada de $319 \mathrm{MPa}$ para as condições Widmanstätten (sem tratamento, nitretada por plasma e com IIIP).

Figura 50 - Microscopia óptica da seção longitudinal do corpo de prova de fluência testado a $500^{\circ} \mathrm{C}$ e $319 \mathrm{MPa}$.

Figura 51 - Microscopia óptica da seção longitudinal do corpo de prova de fluência testado a $700^{\circ} \mathrm{C}$ e $319 \mathrm{MPa}$.

Figura 52 - Microscopia óptica da seção longitudinal do corpo de prova de fluência testado a $600^{\circ} \mathrm{C}$ e $125 \mathrm{MPa}$ .92

Figura 53 - Microscopia óptica da seção longitudinal do corpo de prova de fluência testado a $600^{\circ} \mathrm{C}$ e $250 \mathrm{MPa}$.

Figura 54 - Microscopia óptica da seção longitudinal do corpo de prova de fluência testado a $600^{\circ} \mathrm{C}$ e $319 \mathrm{MPa}$.

Figura 55 - Aspecto geral da superfície de fratura da liga Ti-6Al-4V com estrutura Widmanstätten após ensaio de fluência a $600^{\circ} \mathrm{C}$ e $250 \mathrm{MPa}$. 
Figura 56 - Análise fractográfica da liga Ti-6Al-4V com estrutura Widmanstätten após ensaio de fluência a $600^{\circ} \mathrm{C}$ e $250 \mathrm{MPa}$ (região interna próxima a borda). ...99 Figura 57 - Aspecto geral da superfície de fratura da liga Ti-6Al-4V após ensaio de fluência a $500^{\circ} \mathrm{C}$ e $319 \mathrm{MPa}$ e analisado por MEV. 94

Figura 58 - Aspecto geral da superfície de fratura da liga Ti-6Al-4V após ensaio de fluência a $600^{\circ} \mathrm{C}$ e (a) $125 \mathrm{MPa}$, (b) $250 \mathrm{MPa}$ e (c) 319MPa e analisado por MEV.

Figura 59 - Aspecto geral da superfície de fratura da liga Ti-6Al-4V após ensaio de fluência a $500^{\circ} \mathrm{C}$ e $319 \mathrm{MPa}$ e analisado por MEV. .96

Figura 60 - Análise fractográfica por MEV da liga Ti-6AI-4V ensaiada a $600^{\circ} \mathrm{C}$ e $125 \mathrm{MPa}$. .97

Figura 61 - Análise fractográfica por MEV da liga Ti-6Al-4V ensaiada a $600^{\circ} \mathrm{C} \mathrm{e}$ $250 \mathrm{MPa}$. 97

Figura 62 - Análise fractográfica por MEV da liga Ti-6Al-4V ensaiada a $600^{\circ} \mathrm{C} \mathrm{e}$ $319 \mathrm{MPa}$ .98

Figura 63 - Análise fractográfica por MEV da liga Ti-6Al-4V ensaiada a $700^{\circ} \mathrm{C}$ e 319MPa. .99 


\section{LISTA DE TABELAS}

Tabela 1 - Determinação do mecanismo de fluência dominante através dos valores dos parâmetros $n$ e $Q_{c}$. Adaptado de (EVANS; WILSHIRE, 1993) ............39

Tabela 2 - Composição química da amostra Ti-6Al-4V (\% em peso).....................46

Tabela 3 - Parâmetros de Nitretação das amostras .............................................51

Tabela 4 - Parâmetros utilizados na nitretação dos corpos de prova de fluência. 52

Tabela 5 - Parâmetros utilizados para os ensaios de fluência ...............................54

Tabela 6 - Resultados dos testes de tração a quente. ..........................................69

Tabela 7 - Propriedades mecânicas de tração da liga Ti-6Al-4V a temperatura ambiente.

Tabela 8 - Comparação dos valores de tensão obtidos a $600^{\circ} \mathrm{C}$ e as tensões utilizadas no ensaio de fluência.

Tabela 9 - Codificação utilizada para identificar as amostras dos ensaios de fluência. .73

Tabela 10 - Parâmetros experimentais a $600^{\circ} \mathrm{C}$ e $250 \mathrm{MPa}$ da liga Ti-6Al-4V com e sem nitretação por plasma.

Tabela 11 - Parâmetros experimentais da liga Ti-6Al-4V nitretada por plasma. ...75 Tabela 12 - Dados comparativos de fluência a 500, 600 e $700^{\circ} \mathrm{C}$ da liga Ti-6Al-4V com e sem nitretação por plasma e para diferentes microestruturas. .80

Tabela 13 - Tempos dos estágios primário, secundário, terciário e percentual relativo do tempo dos estágios de fluência.

Tabela 14 - Comparação do tempo de fluência final (tf) para condições investigadas .83

Tabela 15 - Valores do expoente de fluência primária m para a liga Ti-6AI-4V . ...85 Tabela 16 - Valores do expoente de tensão $n$ e energia de ativação $\left(Q_{c}\right)$ para a liga Ti-6Al-4V

Tabela 17 - Valores das constantes M e C para a relação Monkman-Grant. .90 


\section{LISTA DE ABREVIATURAS E/OU SIGLAS}

ASTM - American Society for Testing and Materials

CCC - Cúbico de Corpo Centrado

CFC - Cúbico de Face Centrada

CTA - Centro Técnico Aeroespacial

DCTA - Departamento de Ciência e Tecnologia Aeroespacial

DRX - Difração de raios $X$

EEL-USP - Escola de Engenharia de Lorena - Universidade de São Paulo

HC - Hexagonal Compacta

IIIP - Implantação lônica por Imersão em Plasma

IIIP-N - Implantação lônica por Imersão em Plasma de Nitrogênio

INPE - Instituto Nacional de Pesquisas Espaciais

IPEN - Instituto de Pesquisas Energéticas e Nucleares

ITA - Instituto Tecnológico de Aeronáutica

JCPDS - Joint Committee on Powder Diffraction Standards

LPP - Laboratório de Plasmas e Processos

LVDT - Linear Variable Differential Transformer

MEV - Microscopia Eletrônica De Varredura

MO - Microscopia Óptica

TBC - Thermal Barrier Coating

UNIFESP - Universidade Federal de São Paulo 


\section{SUMÁRIO}

Página

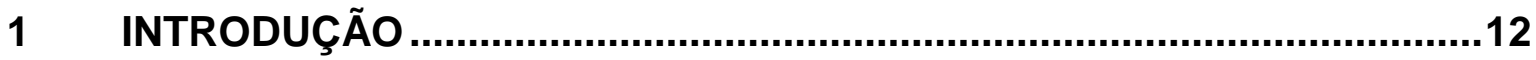

2 OBJETIVOS ...........................................................................................14

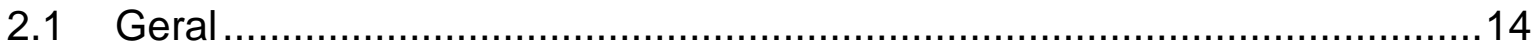

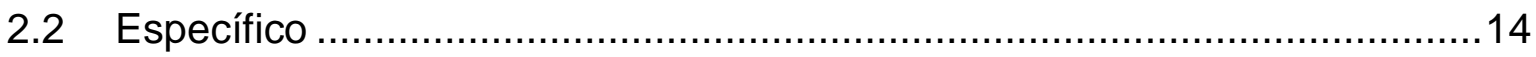

3 REVISÃO DA LITERATURA

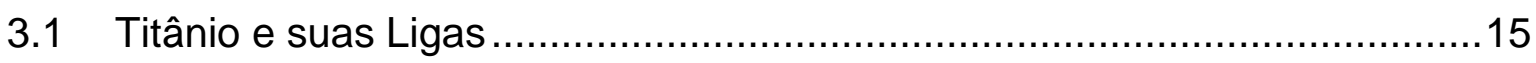

3.1.1 Metalurgia Física das Ligas de Titânio …………………………......16

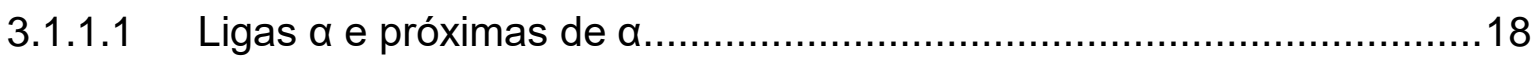

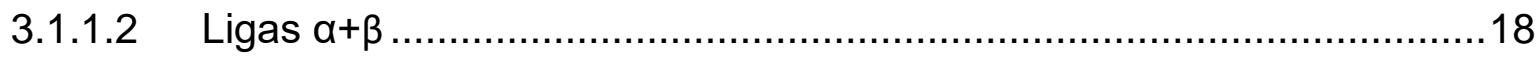

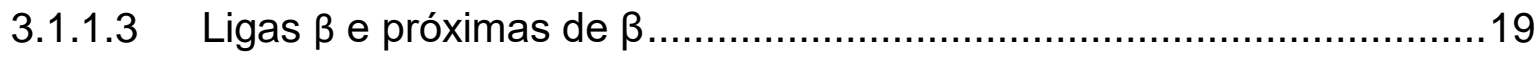

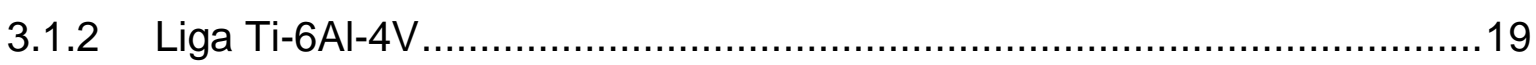

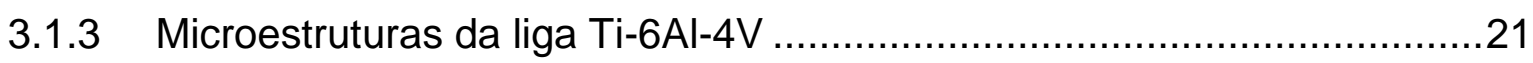

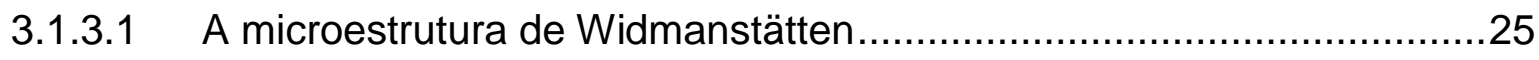

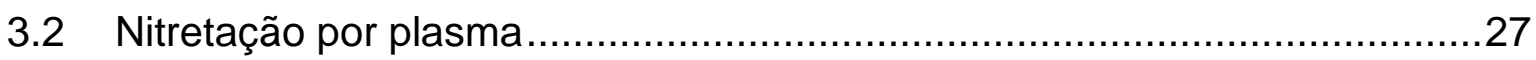

3.2.1 Parâmetros do processo de nitretação ...............................................27

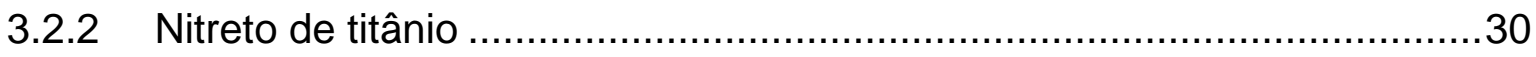

3.3 Transformações de fase durante o processo..............................................

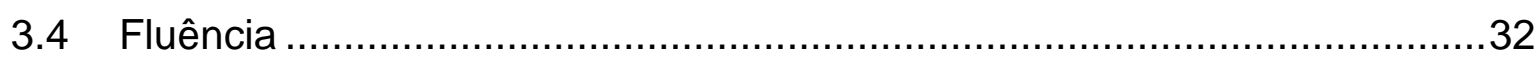

3.4.1 Mecanismos de deformação por fluência ..............................................35

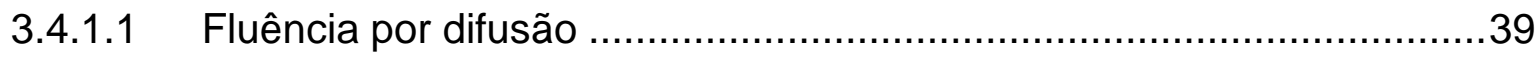

3.4.1.2 Fluência por escorregamento e escalagem das discordâncias .............41

3.4.1.3 Fluência por escorregamento de contorno de grão ................................41

3.4.2 Fluência da liga Ti-6Al-4V ............................................................... 42

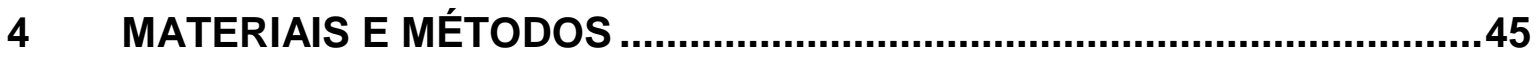

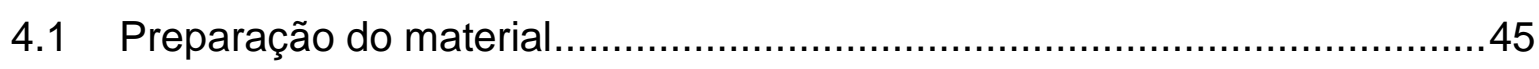

4.1.1 Amostras para definição dos parâmetros de nitretação ...........................46

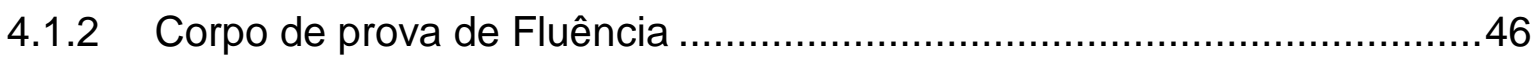

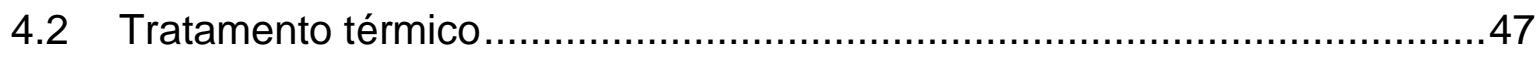

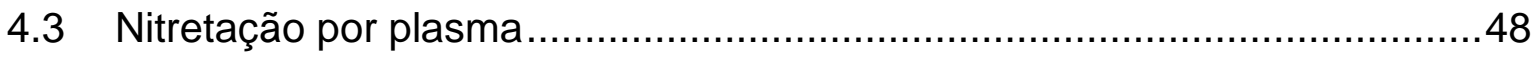

4.3.1 Equipamentos utilizados para a nitretação .............................................48 


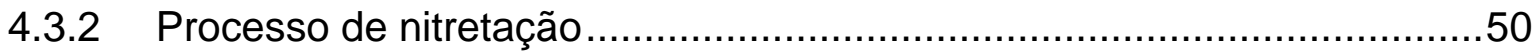

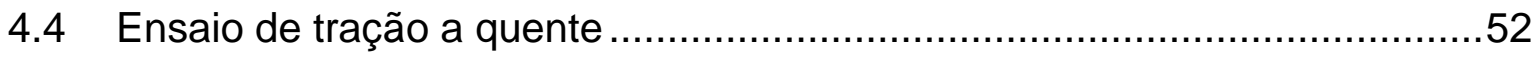

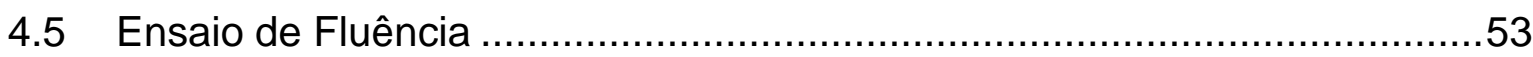

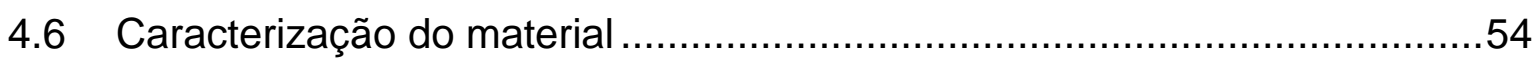

4.6.1 Análise microestrutural por Microscopia ...............................................

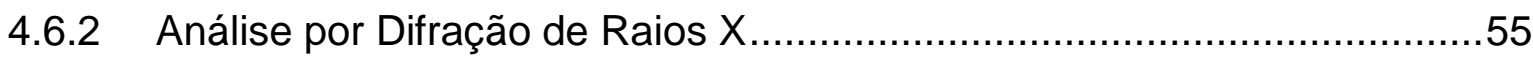

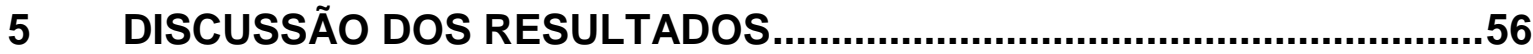

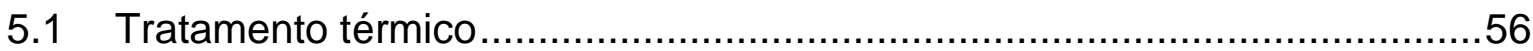

5.1.1 Caracterização da microestrutura do material.......................................56

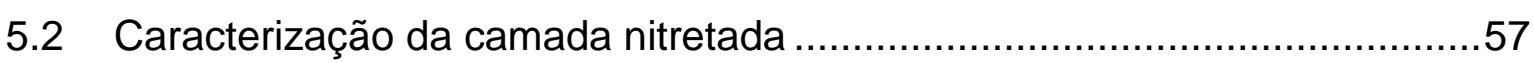

5.2.1 Microscopia Óptica (MO) e Eletrônica de Varredura (MEV) .....................58

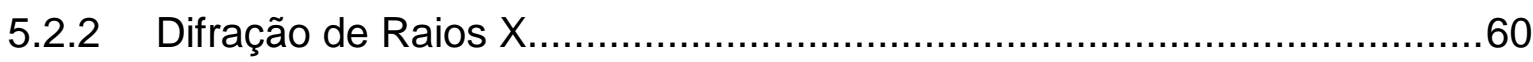

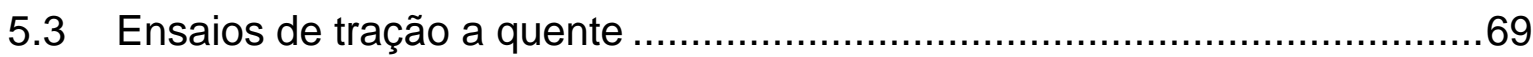

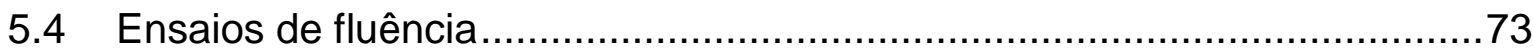

5.4.1 Ensaio preliminar de fluência da liga nitretada por plasma .....................74

5.4.2 Ensaios de fluência da liga tratada termicamente e nitretada por plasma75

5.4.2.1 Comparação dos resultados de fluência da liga Ti-6Al-4V sem

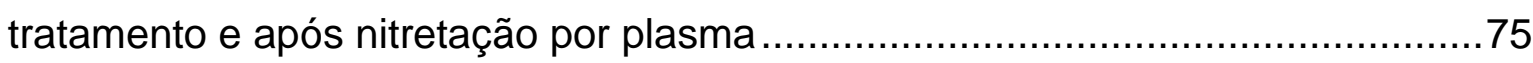

5.4.3 Comparação dos tempos de fluência da liga Ti-6Al-4V ...........................81

5.4.4 Cálculo dos expoentes de tensão e da energia de ativação ………….....83

5.4.5 Dependência do tempo de ruptura com a taxa de fluência estacionária

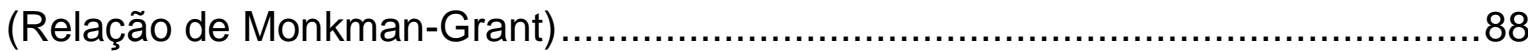

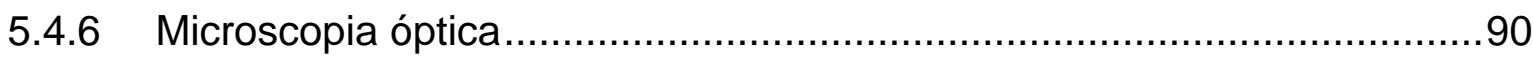

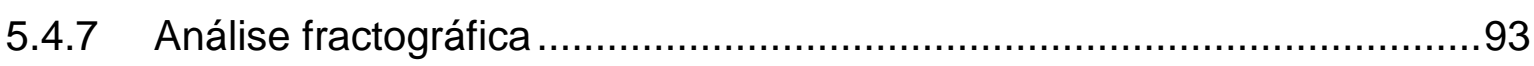

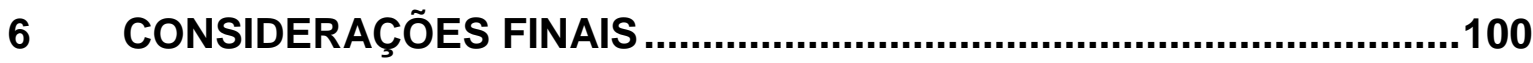

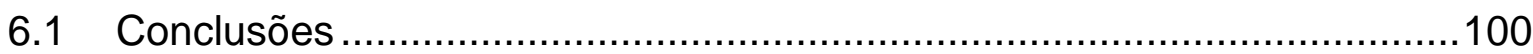

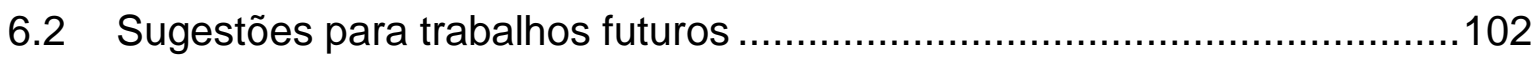

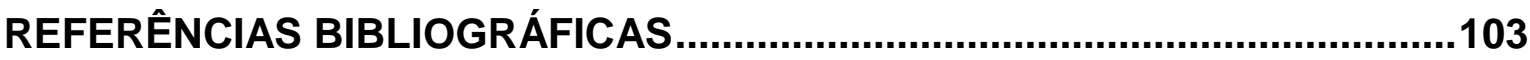




\section{INTRODUÇÃO}

O comportamento em temperaturas elevadas dos metais e de suas ligas durante a deformação é complexo e muda com os parâmetros de processamento termomecânico e com as condições de trabalho (BARBOZA, 2001). O titânio e suas ligas são excelentes materiais para aplicações como componentes estruturais, submetidos a temperaturas elevadas devido à sua alta resistência mecânica, baixa massa específica, boa resistência à corrosão e estabilidade metalúrgica. A liga Ti-6Al-4V é a mais importante das ligas de titânio utilizadas em engenharia, combinando propriedades atrativas com boa trabalhabilidade. Por isso tem sido muito utilizada na indústria aeronáutica e aeroespacial, particularmente para aplicações que requerem resistência mecânica em alta temperatura (EVANS; WILSHIRE, 1993; NORRIS, 1994).

Apesar dos notáveis avanços no desenvolvimento de ligas de titânio com alta resistência à tração, ductilidade e resistência à fluência em altas temperaturas, ocorrem limitações quanto ao seu uso em temperaturas superiores a $600^{\circ} \mathrm{C}$ (OLIVEIRA; REIS, 2009). Devido a essa limitação, diversas modificações superficiais têm sido testadas para tentar obter um aumento nas possibilidades de aplicação em temperaturas superiores. Entre elas estão os tratamentos térmicos, recobrimentos e tratamentos termoquímicos como oxidação, carbonetação e nitretação. Revestimentos de proteção podem servir como barreiras à nucleação e propagação de trincas, podendo ser usados em ligas de titânio submetidas por longo tempo a altas temperaturas. Todavia, problemas de aderência durante o ciclo térmico e a difusão dos elementos do recobrimento no substrato são as atuais dificuldades encontradas na pesquisa desses materiais (KEARNS; RESTALL, 1988).

Durante a execução desta tese de doutorado foi estudado o efeito da nitretação por plasma nas propriedades mecânicas em fluência da liga Ti-6Al-4V. Após a nitretação por plasma da liga Ti-6Al-4V em diversas condições, a caracterização microestrutural das camadas nitretadas foi realizada por microscopia óptica (MO), eletrônica de varredura (MEV) e por difratometria de raios $X(D R X)$. Os corpos de prova utilizados nos ensaios de tração a quente e fluência foram então nitretados na condição escolhida de nitretação por plasma. Os ensaios de tração a quente e de fluência foram executados na liga Ti-6Al-4V 
em condições otimizadas baseados nos resultados obtidos em trabalhos anteriores (BARBOZA, 2001; REIS, 2005). As superfícies de fratura dos corpos de prova ensaiados foram analisadas por $\mathrm{MO}$ e MEV. Os resultados foram analisados buscando correlações entre as modificações da superfície por meio do processo de nitretação e as propriedades em fluência.

O grupo de estudos de fluência formado por pesquisadores do Instituto Tecnológico de Aeronáutica (ITA), Departamento de Ciência e Tecnologia Aeroespacial (DCTA), Instituto Nacional de Pesquisas Espaciais (INPE), Escola de Engenharia de Lorena - Universidade de São Paulo (EEL-USP) e, mais recentemente, do Instituto de Pesquisas Energéticas e Nucleares (IPEN), tem estudado a fluência de ligas de titânio há vários anos (BARBOZA, 2001; REIS et al., 2003; PEREZ, 2004; REIS, 2005, 2012; SUGAHARA et al., 2010; BRIGUENTE, 2011, 2015; YOGI, 2012). Contudo, o estudo da fluência de ligas de titânio com este tratamento superficial proposto tem um caráter inovador e representa um avanço no cenário tecnológico nacional e internacional, visto a necessidade de estudo da nitretação no comportamento mecânico da liga Ti-6Al$4 \mathrm{~V}$ em temperaturas elevadas.

Existem alguns estudos sobre os efeitos da nitretação por plasma da liga Ti-6AI-4V (GRILL; RAVEH; AVNI, 1990; RAVEH et al., 1993; MOLINARI et al., 1997; RODRIGUEZ et al., 2001; RAHMAN et al., 2007; RAJASEKARAN; RAMAN, 2008; YILDIZ et al., 2008; YETIM et al., 2009; ALI; RAMAN, 2010; OLIVEIRA et al., 2011), mas relacionados principalmente com fadiga e desgaste. Quanto ao efeito da nitretação por plasma desta liga nas propriedades mecânicas em fluência, não existem estudos específicos na literatura e é a contribuição inédita deste doutorado.

A liga de Ti-6Al-4V é utilizada em componentes da seção fria de motores de turbinas a gás, nos estágios de compressão até uma temperatura máxima de aproximadamente $315^{\circ} \mathrm{C}$. Como a seção fria pode alcançar temperaturas de operação de até $490^{\circ} \mathrm{C}$, os discos e palhetas dos últimos estágios de compressão são produzidos a base de superligas de Ni com o dobro de massa específica, devido à baixa resistência à oxidação do titânio sem tratamento superficial em temperaturas mais elevadas (BRIGUENTE, 2015). Portanto, uma possível substituição de material poderia trazer uma redução no peso da turbina. 


\section{OBJETIVOS}

\subsection{Geral}

Estudar o efeito da nitretação por plasma nas propriedades mecânicas em temperaturas elevadas da liga Ti-6Al-4V, buscando uma melhora nestas propriedades para possibilitar uma aplicação mais ampla deste material. Este estudo busca obter correlações entre os parâmetros do processo de nitretação por plasma e a microestrutura, a resistência mecânica em tração em temperaturas elevadas e principalmente as propriedades mecânicas em fluência.

\subsection{Específico}

Portanto, esta tese de doutorado tem como objetivos específicos:

- Realizar a nitretação superficial por plasma na liga Ti-6Al-4V, analisando a camada formada por meio de técnicas de microscopia óptica e eletrônica e também por difração de raios $X$ e escolher a melhor condição de tratamento.

- Efetuar ensaios de tração a quente no material com e sem nitretação nas temperaturas de 500, 600 e $700^{\circ} \mathrm{C}$.

- Executar ensaios de fluência na modalidade de carga constante no material nitretado por plasma nas condições:

- $319 \mathrm{MPa}$ a $500^{\circ} \mathrm{C}$;

- 125 a $319 \mathrm{MPa}$ a $600^{\circ} \mathrm{C}$;

- $319 \mathrm{MPa}$ a $700^{\circ} \mathrm{C}$;

- Caracterizar o material após a realização dos ensaios por meio de técnicas de microscopia óptica e eletrônica.

- Analisar o comportamento mecânico deste material em alta temperatura, em tração e principalmente em fluência.

- Determinar os parâmetros de fluência para poder compreender os mecanismos de fluência predominantes no material nitretado por plasma. 


\section{REVISÃO DA LITERATURA}

\subsection{Titânio e suas Ligas}

O titânio é amplamente distribuído no Universo. É abundante na Terra e tem sido detectado em meteoritos, na lua, no sol e em outras estrelas. A sua concentração de cerca de $0,6 \%$ dentro da crosta terrestre o torna o quarto metal mais abundante depois do ferro, alumínio e magnésio (BOYER; COLLINGS; WELSCH, 1993; BELL; DONG, 2000). Sua quantidade é 20 vezes maior do que a do cromo, 30 vezes maior do que o níquel, 60 vezes maior do que o cobre, 100 vezes maior do que o tungstênio e 600 vezes maior do que o molibdênio (BOYER; COLLINGS; WELSCH, 1993). Por causa das propriedades tribológicas pobres do titânio e suas ligas, tratamentos termoquímicos superficiais, tais como diferentes tipos de nitretação são recomendados para aumentar a gama de aplicações médicas e industriais (ZHECHEVA et al., 2005).

O titânio e as suas ligas são excelentes para aplicações como em componentes estruturais submetidos a altas temperaturas devido a sua alta resistência, baixa massa específica, boa resistência à corrosão e estabilidade metalúrgica. A sua alta resistência à fluência é de grande importância para uso em motores (BOYER, 1996; DALTON, 2013), nos mais modernos motores de aviões, as peças de ligas de titânio perfazem 25 a 30\%, principalmente no compressor e na turbina. O titânio é o material mais escolhido para peças de motores que operam até $1.100^{\circ} \mathrm{F}\left(593^{\circ} \mathrm{C}\right)$ (INTERNATIONAL TITANIUM ASSOCIATION, 2011). A Figura 1 mostra os materiais utilizados na fabricação de um motor a jato.

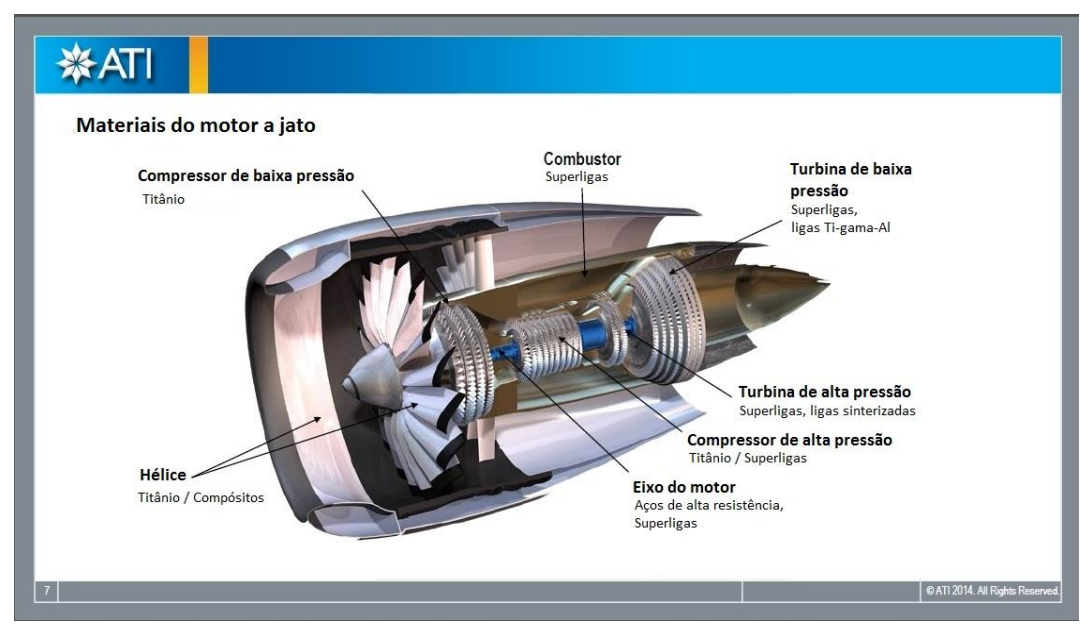

Figura 1 - Materiais utilizados para a fabricação de motores a jato.

Fonte: Adaptado de (DALTON, 2013) 
O uso do titânio só é limitado pelo seu custo mais elevado em relação às ligas de alumínio e aos aços, ficando restrito a aplicações mais especiais (BOYER, 1996). Além disso, a afinidade com o oxigênio é um dos principais fatores que limitam sua aplicação como um material estrutural em altas temperaturas. A alta solubilidade sólida do oxigênio no titânio resulta na perda de material e na formação de uma camada frágil e de alta dureza durante a exposição ao ar em temperaturas elevadas. Têm sido observados avanços no desenvolvimento de ligas de titânio com o objetivo de aumentar as propriedades de fluência, embora a oxidação superficial limite o seu emprego em temperaturas superiores a $600^{\circ} \mathrm{C}$ (SRIVATSAN, 1990; SECO; IRISARRI, 2001; SILVA et al., 2010).

A reatividade do titânio e suas ligas com o nitrogênio é similar a sua ação com o oxigênio, onde uma camada de óxido é formada na superfície como um nitreto (ABKOWITZ; BURKE; HILTZ JR., 1955). Porém neste caso a camada formada pode servir como proteção contra a oxidação superficial.

De acordo com os últimos dados do Serviço Geológico dos EUA, em 2013, aproximadamente $73 \%$ do titânio metálico consumido nos Estados Unidos foi utilizado em aplicações aeroespaciais e os $27 \%$ restantes utilizado em "armamentos, processos químicos, peças para marinha, biomateriais, geração de energia, artigos esportivos e outras aplicações”(“Mineral Commodity Summaries 2014", 2014). Uma das características que mais tem contribuído para o crescimento do seu uso para fins estruturais refere-se ao seu alto ponto de fusão. Sua utilização concentra-se em componentes aeroespaciais, onde as resistências à fluência, à fadiga e à degradação são consideradas essenciais, sendo a liga Ti6Al-4V uma das ligas mais utilizadas. (SUGAHARA et al., 2009).

\subsubsection{Metalurgia Física das Ligas de Titânio}

O titânio é um metal de transição com uma camada incompleta em sua estrutura eletrônica, o que possibilita que ele forme solução sólida com muitos elementos substitucionais.

As ligas de titânio podem ser classificadas em três tipos dependendo da sua estrutura a temperatura ambiente. Estes tipos de liga podem incluir as ligas $\alpha$, as ligas $\beta$ e as ligas $\alpha+\beta$, dentro da última categoria existem as subclasses próxima de $\alpha$ e próxima de $\beta$, que se referem a ligas com 
composições que as colocam perto dos limites de fase para $\alpha /(\alpha+\beta)$ ou $(\alpha+\beta) / \beta$, respectivamente. (BOYER, 1996; ZHECHEVA et al., 2005).

As ligas de titânio mais utilizadas são mostradas no formato de um pseudodiagrama de fases na Figura 2, que mostra a interação entre os elementos estabilizadores da fase $\alpha$ e da fase $\beta$. No eixo $x$ é apresentada a concentração de estabilizantes da fase $\beta$ e no eixo y a dependência com a temperatura. As linhas Ms e Mf se referem, respectivamente, ao início e ao fim da transformação martensítica induzida por altas taxas de resfriamento.

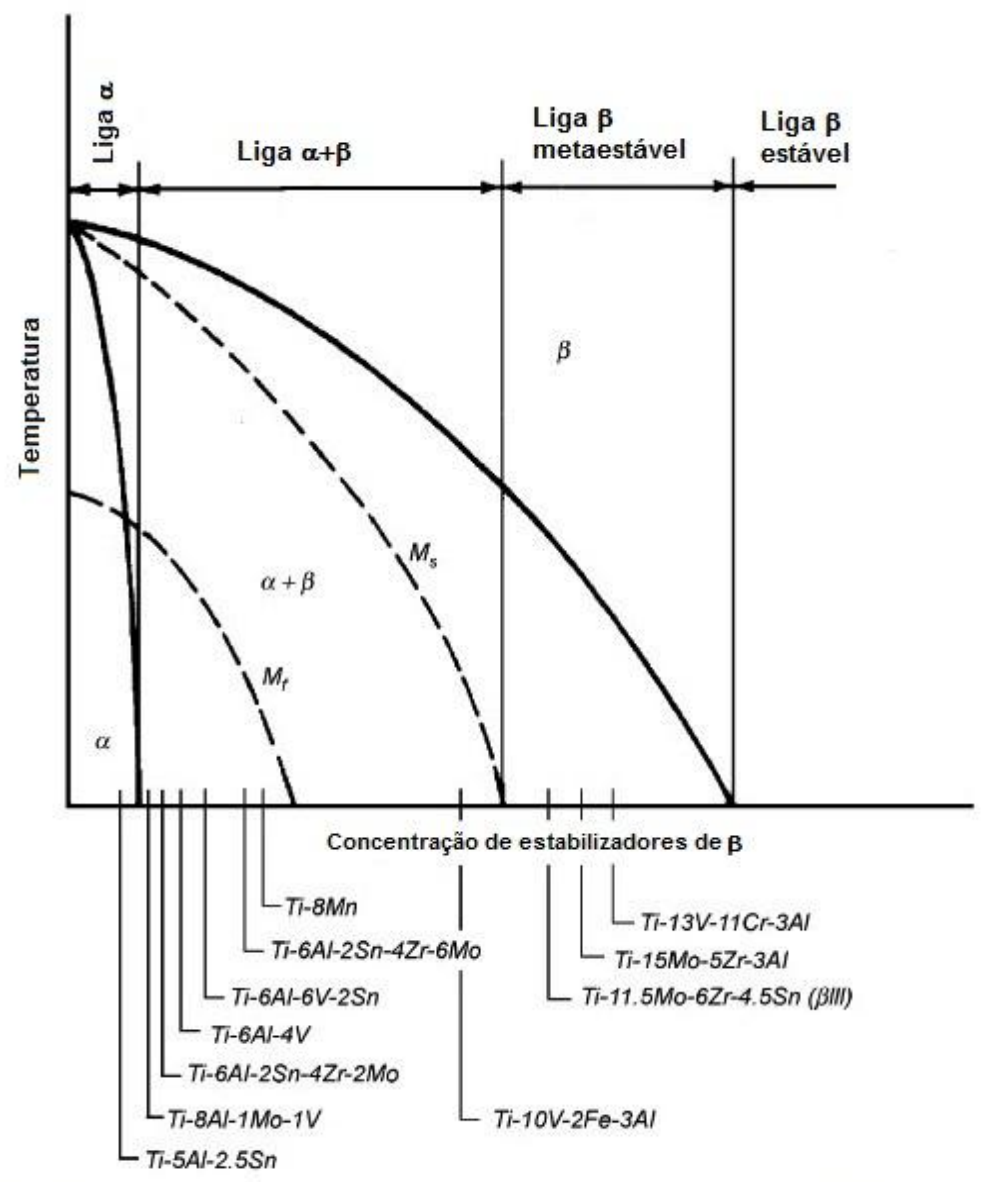

Figura 2 - Composição química das principais ligas de titânio em pseudodiagrama de equilíbrio de fases binário do titânio e estabilizador $\beta$.

Fonte: Adaptado de (NISHIMURA; MIZOGUCHI; ITOH, 1984)

A fase $\alpha$ do titânio tem estrutura hexagonal compacta $(\mathrm{HC})$ e é estável até $883^{\circ} \mathrm{C}$, a partir desta temperatura essa estrutura transforma-se em cúbica de corpo centrado (CCC), fase $\beta$, que é estável até a temperatura de fusão $\left(1668^{\circ} \mathrm{C}\right)$ (BOYER; COLLINGS; WELSCH, 1993). Esta temperatura de transformação pode ser alterada através da adição de elementos de liga. Os elementos estabilizadores da fase $\alpha$, dentre os quais se destacam Al, Ga, O, N, C elevam 
essa temperatura, ao passo que elementos estabilizadores da fase $\beta$, como $V$, $\mathrm{Mo}, \mathrm{Nb}, \mathrm{Fe}, \mathrm{Cr}$, Ni diminuem esta temperatura. Alguns outros elementos como $\mathrm{Sn}$ e $\mathrm{Zr}$ são neutros, e não estabilizam a fase $\alpha$ ou a fase $\beta$, entretanto formam solução sólida com o titânio (JOSHI, 2006). Com a manipulação das fases presentes através de adições de elementos de liga e de tratamentos termomecânicos pode ser desenvolvida uma grande variedade de ligas, proporcionando uma quantidade inumerável de combinações de resistência e ductilidade (INTERNATIONAL TITANIUM ASSOCIATION, 2011).

\subsubsection{Ligas $\alpha$ e próximas de $\alpha$}

O alumínio é o estabilizador da fase $\alpha$ de maior importância comercial e está presente na maioria das ligas comerciais de titânio, com teores restritos a 7\% para evitar a formação da fase $\mathrm{Ti}_{3} \mathrm{Al}$ que leva a uma severa fragilização (JOSHI, 2006).

As ligas a não são tratáveis termicamente e possuem geralmente boa soldabilidade. Elas têm baixa a média resistência; razoavelmente boa ductilidade e possuem excelentes propriedades mecânicas em aplicações em temperaturas criogênicas. As ligas próximas de $\alpha$ com pequenas adições de estabilizadores de $\beta$, entre $1 \%$ a $2 \%$, oferecerem resistência à fluência a alta temperatura e uma ótima resistência à oxidação. Ligas a são utilizadas em peças forjadas, como carcaças de motores de turbinas a gás e anéis. Ligas próximas de a são usadas para a fuselagem e componentes estruturais, tubos sem costura e aplicações em temperatura moderadamente alta, tais como lâminas de compressor de motores a jato (JOSHI, 2006; INTERNATIONAL TITANIUM ASSOCIATION, 2011).

\subsubsection{Ligas $\alpha+\beta$}

As ligas $\alpha+\beta$ contém uma quantidade maior de estabilizadores de $\beta$, entre 4 a $6 \%$, e constituem a maior parte das ligas de titânio atuais, incluindo a liga Ti-6Al-4V, que é utilizada em diversas aplicações. Estas ligas são tratáveis termicamente e possuem maior soldabilidade. Seus níveis de resistência são de médio a alto. Suas qualidades de forjamento a quente são boas, mas a resistência à fluência a alta temperatura não é tão boa quanto na maioria das ligas a. Proporcionam excelentes combinações de resistência, dureza e resistência à corrosão. Aplicações típicas incluem lâminas e discos de turbinas de 
motores a jato e compressores, componentes de aeronaves estruturais e trens de pouso, equipamentos de processo químico, componentes marinhos e implantes cirúrgicos. (JOSHI, 2006; INTERNATIONAL TITANIUM ASSOCIATION, 2011)

\subsubsection{Ligas $\beta$ e próximas de $\beta$}

Em ligas contendo entre 10 a $15 \%$ de estabilizadores de $\beta$, a fase $\beta$ a temperatura ambiente se encontra numa condição metaestável. Esta fase metaestável pode se transformar em finas placas de fase a do tipo Widmanstätten em uma matriz enriquecida de $\beta$ através de um tratamento de envelhecimento. Estas ligas possuem alta resistência e excelentes temperabilidade e forjabilidade, além de uma melhor tenacidade a fratura do que as ligas $\alpha+\beta$. Sua aplicação tem aumentado em peças estruturais de aeronaves.

As adições mais altas (30\%) de estabilizadores de $\beta$ resultam na retenção da fase $\beta$ estável a temperatura ambiente, porém estas ligas possuem alta densidade e baixa ductilidade, o que restringe sua utilização em aplicações muito específicas onde são necessárias altas resistências à temperaturas elevadas e à corrosão. (JOSHI, 2006)

\subsubsection{Liga Ti-6Al-4V}

A liga Ti-6Al-4V é uma das ligas de titânio mais utilizadas devido à menor densidade do que o titânio puro, mas com propriedades mecânicas e físicas mais favoráveis para aplicações aeronáuticas e como biomaterial (BERBERICH et al., 2001; LAKSHMI; ARIVUOLI; GANGULI, 2002; FOUQUET et al., 2004a, 2004b; MA; XU; JIE, 2004). Este material tem uma estrutura de duas fases: uma fase hexagonal $\alpha-\mathrm{Ti}$ com alumínio em solução sólida e uma fase $\beta$-Ti com o vanádio estabilizando o reticulado cúbico de corpo centrado. Esta estrutura bifásica contribui para uma resistência mecânica mais elevada comparada com o titânio puro Ti (BERBERICH et al., 2000). As fases em condição de equilíbrio em várias temperaturas estão indicadas na Figura 1Figura 3 que mostra o diagrama de fases ternário do Ti-Al-V e marca o ponto referente à liga Ti-6Al-4V em cada temperatura (BOYER; COLLINGS; WELSCH, 1993). 

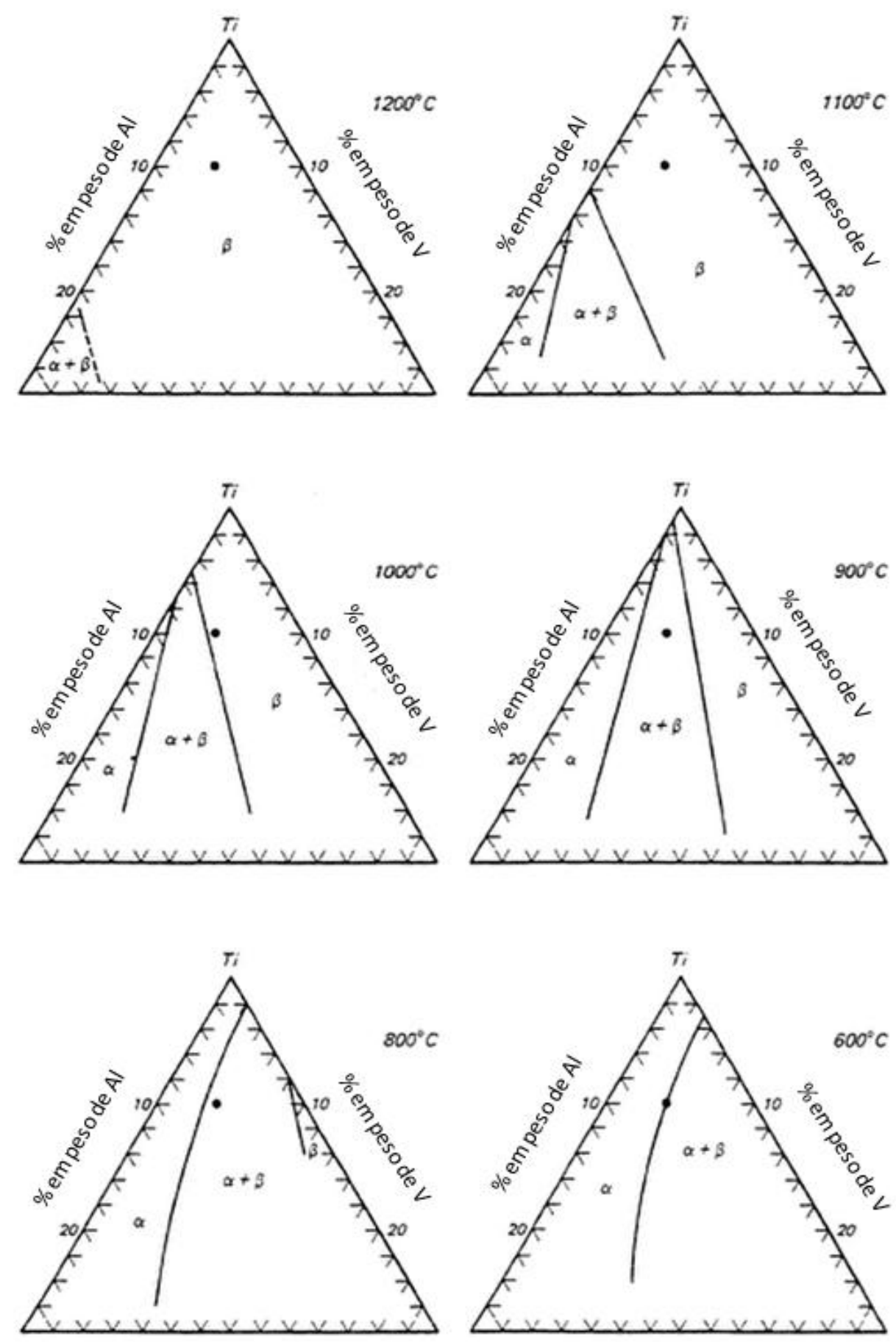

Figura 3 - seção isotérmica do Ti-Al-V versus a fase de equilíbrio nas temperaturas indicadas. O círculo sólido $(\bullet)$ representa a liga Ti-6Al-4V.

Fonte: Adaptado de (BOYER; COLLINGS; WELSCH, 1993)

Tratamentos superficiais tais como a nitretação, têm sido investigados como possíveis soluções para a melhoria das propriedades desta liga (ITOH et al., 1999; GALLIANO et al., 2001; OHRING, 2002; FOUQUET et al., 2004a; PÉREZ, 2005). A nitretação modifica a estrutura da superfície pela formação de 
diferentes fases cristalinas tais como $\mathrm{Ti}_{2} \mathrm{~N}$ e TiN (ITOH et al., 1999; BERBERICH et al., 2000; GALLIANO et al., 2001; OHRING, 2002; MA; XU; JIE, 2004; PÉREZ, 2005). A presença destas fases cristalinas resulta em aumento de dureza do material (EROLA, 1988).

Em geral, as ligas próximas de a tem melhor resistência à fluência, seguidas pelas ligas $\alpha+\beta$, e por último as ligas $\beta$. Uma melhor resistência à fluência pode ser obtida alterando a estrutura equiaxial para uma acicular pelo processamento de $\beta$ ou pelo tratamento térmico a temperatura elevada no campo $\alpha+\beta$. A taxa de fluência (mínima) no estado estacionário pode ser corelacionada com a quantidade de a primária (BOYER; COLLINGS; WELSCH, 1993).

\subsubsection{Microestruturas da liga Ti-6Al-4V}

Tratamentos térmicos podem ser realizados para se alterar as características mecânicas e estruturais de uma liga, de forma a alterar a resistência à fluência de um material.

Sendo uma liga $\alpha+\beta$, o Ti-6Al-4V pode apresentar diferentes frações volumétricas das fases $\alpha$ e $\beta$, dependendo do tratamento térmico e do teor intersticial (de oxigênio principalmente). $A$ fase $\beta$ é estável a temperatura ambiente somente se enriquecida com mais de $15 \%$ de vanádio. Tal enriquecimento é obtido quando a liga é resfriada lentamente ou recozida abaixo de aproximadamente $750^{\circ} \mathrm{C}\left(1400^{\circ} \mathrm{F}\right)$. O Ti-6Al-4V resfriado lentamente contém aproximadamente $90 \%$ em volume da fase $\alpha$.

Além disso, a liga Ti-6Al-4V pode adquirir uma grande variedade de microestruturas com diferentes arranjos geométricos das fases $\alpha$ e $\beta$, dependendo em particular do tratamento termomecânico. Estas diferentes "morfologias" e microestruturas podem ser grosseiramente classificadas em três diferentes categorias: lamelar, equiaxial, ou uma mistura de ambas (bimodal) (BOYER; COLLINGS; WELSCH, 1993).

Microestruturas lamelares podem ser facilmente controladas por tratamento térmico. $O$ resfriamento lento a partir da região de duas fases acima da temperatura de transição $\beta$ conduz a nucleação e crescimento da fase $\alpha$ na forma de placas a partir do contorno de grão da fase $\beta$. A estrutura lamelar resultante é bastante grosseira e normalmente referenciada como $\alpha$ em placas. $O$ resfriamento ao ar resulta em fase a mais fina e em forma de agulhas 
referenciada com a acicular. Certas taxas de resfriamento intermediárias desenvolvem uma estrutura de Widmanstätten. Têmpera em água a partir do campo da fase $\beta$ seguido de um recozimento na região $\alpha+\beta$ leva a uma estrutura lamelar muito mais fina. Têmperas em temperaturas acima de $900^{\circ} \mathrm{C}\left(1650^{\circ} \mathrm{F}\right)$ resultam em estrutura $\mathrm{HC}$ de martensita em forma de agulhas ( $\alpha$ '), enquanto a têmpera a partir de temperaturas variando entre $750^{\circ} \mathrm{C}$ a $900^{\circ} \mathrm{C}\left(1308\right.$ a $\left.1650^{\circ} \mathrm{F}\right)$ produz uma estrutura ortorrômbica de martensita ( $\alpha$ ").

Microestruturas equiaxiais são obtidas por um extenso trabalho mecânico ( $>75 \%$ de redução) do material no campo da fase $\alpha+\beta$, onde 0 rompimento da fase a lamelar em a equiaxial depende do processo exato de deformação (exemplo ver Figura 4). Um recozimento subsequente a aproximadamente $700^{\circ} \mathrm{C}\left(1300^{\circ} \mathrm{F}\right)$ produz a estrutura chamada "laminada e recozida", que é muito dependente do trabalho anterior. Uma estrutura equiaxial mais reprodutível é obtida por um recozimento de recristalização de $4 \mathrm{~h}$ a temperatura de $925^{\circ} \mathrm{C}\left(1700^{\circ} \mathrm{F}\right)$ seguido de resfriamento lento. A estrutura resultante é razoavelmente grosseira com grãos da fase $\alpha$ com aproximadamente 15-20 $\mu \mathrm{m}$.

Microestruturas tipo bimodal consistem de grãos isolados da fase $\alpha$ primária em uma matriz da fase $\beta$ transformada. Estas microestruturas são melhores obtidas por um recozimento de $1 \mathrm{~h}$ a $955^{\circ} \mathrm{C}\left(1750^{\circ} \mathrm{F}\right)$ seguido de têmpera em água (ou mais frequentemente de resfriamento ao ar) e envelhecimento a $600^{\circ} \mathrm{C}\left(1100^{\circ} \mathrm{F}\right)$. O tamanho de grão da fase primária $\alpha$ resultante é usualmente entre 15-20 $\mu \mathrm{m}$ em uma estrutura como "solubilizada e envelhecida". O envelhecimento em aproximadamente $650^{\circ} \mathrm{C}\left(1200^{\circ} \mathrm{F}\right)$ também pode produzir precipitados da fase $\alpha$ na fase $\beta$ previamente temperada. (BOYER; COLLINGS; WELSCH, 1993).

A Figura 4 mostra esquematicamente as microestruturas formadas após tratamentos térmicos em diversas temperaturas e taxas de resfriamento. 


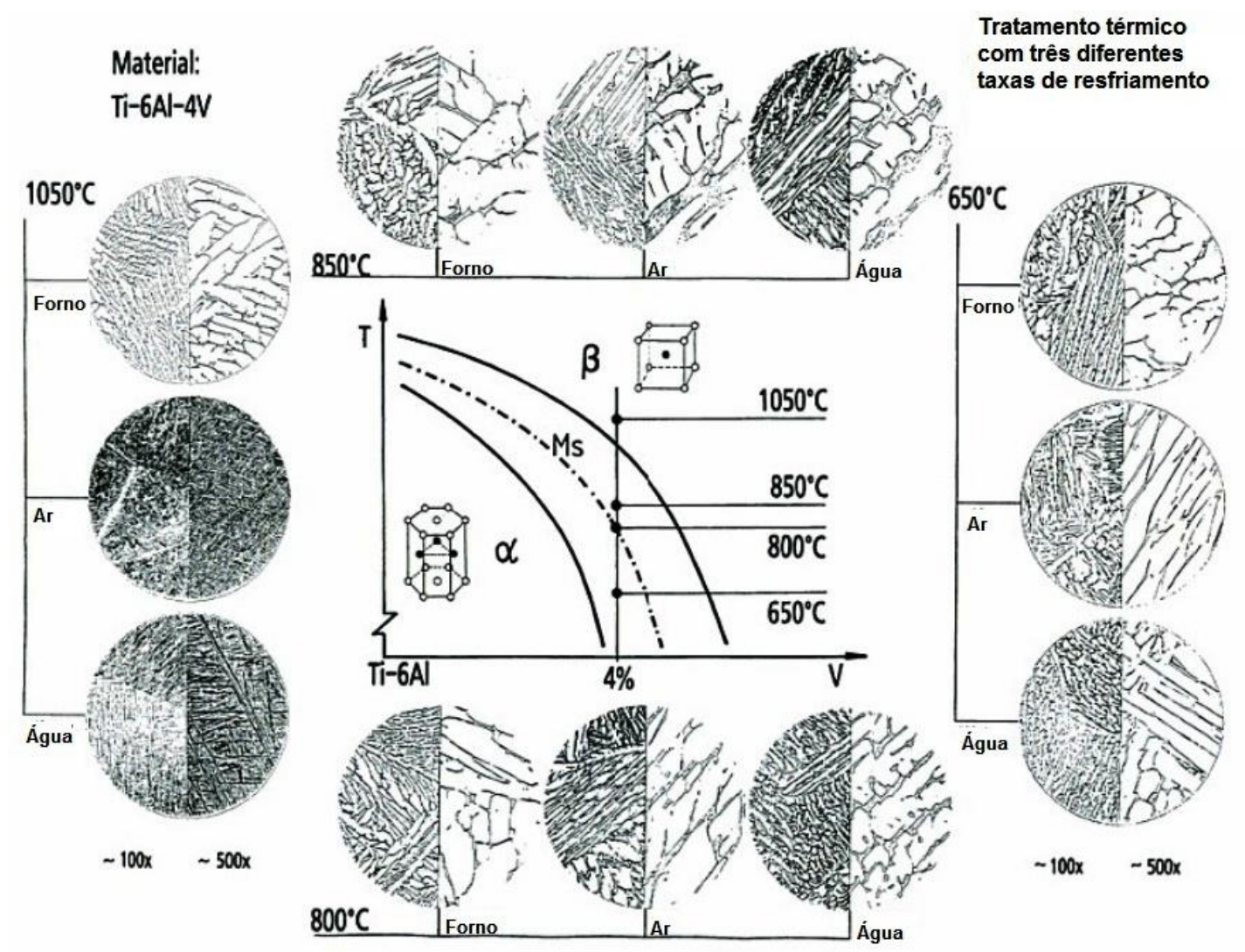

Figura 4 - Diagrama de fases da liga Ti-6Al-4V ilustrando as diversas microestruturas formadas a partir do tratamento térmico com diferentes taxas de resfriamento.

Fonte: Adaptado de (BOYER; COLLINGS; WELSCH, 1993).

A microestrutura equiaxial é resultado de um processo de recristalização e em geral resulta em maiores ductilidade e resistência à fadiga, por outro lado nas microestruturas lamelares se obtém elevadas tenacidade à fratura e resistência à fluência (MATSUMOTO et al., 2011). A decomposição da fase $\beta$ pode se dar por um processo de difusão (nucleação e crescimento) dando origem a uma microestrutura de Widmanstätten, ou por um processo sem difusão (transformação martensítica) (GIL et al., 2001).

Diferentes tipos de martensitas podem ser formados, dependendo da composição química e da temperatura de têmpera, elas são designadas por martensita a' e martensita $\alpha^{\prime \prime}$. Após a têmpera a partir da temperatura de transição $\beta$ (cerca de $980^{\circ} \mathrm{C}$, ou $1796^{\circ} \mathrm{F}$ ), a estrutura é toda formada por martensita $\alpha$ ' ou $\alpha$ " com uma pequena quantidade de $\beta$ (embora em algumas ligas a fase $\beta$ não é observada). A presença de algum $\beta$ na estrutura após a têmpera a partir da temperatura de transição é devido ao fato que a temperatura do fim da transformação martensitica, Mf, é abaixo da temperatura ambiente $\left(25^{\circ} \mathrm{C}\right.$, ou 
$77^{\circ} \mathrm{F}$ ) para estas ligas. Isto ocorre porque o vanádio é um estabilizador da fase $\beta$, e a adição de $4 \%$ de $\mathrm{V}$ em uma liga Ti-6\%Al é suficiente para colocar Mf abaixo de $25^{\circ} \mathrm{C}\left(77^{\circ} \mathrm{F}\right)$. Assim, após a têmpera até $25^{\circ} \mathrm{C}\left(77^{\circ} \mathrm{F}\right)$, nem toda a fase $\beta$ é convertida em $\alpha$ ' ou $\alpha$ ". (DONACHIE, 2000)

Martensita hexagonal compacta ( $\left.\alpha^{\prime}\right)$ é obtida pela têmpera a aproximadamente $900^{\circ} \mathrm{C}\left(1650^{\circ} \mathrm{F}\right)$ e tem uma microestrutura acicular e algumas vezes lamelar fina. Ela é cristalograficamente relacionada com a fase a e tem parâmetros de rede similares aos da fase $\alpha$.

Martensita ortorrômbica ( $\alpha$ ") é uma martensita bastante suave que é formada durante a têmpera da fase $\beta$ com $10 \pm 2 \%$ em peso de vanádio. Ela ocorre quando a liga Ti-6Al-4V é temperada em temperaturas entre 750 e $900^{\circ} \mathrm{C}$ $\left(1380\right.$ e $\left.1650^{\circ} \mathrm{F}\right)$. A martensita $\alpha "$ pode também ser formada como um produto da tensão induzida pela deformação da fase $\beta$ metaestável.(BOYER; COLLINGS; WELSCH, 1993)

Devido aos grãos maiores e com formato acicular da estrutura martensítica é possível aumentar a resistência à fluência obtendo-se maiores valores de tempo de fluência primária, redução da taxa de fluência estacionária e maior tempo para ruptura comparada com o material sem tratamento. Essa maior resistência pode ser associada às "agulhas" da estrutura martensítica, que agem como obstáculos à movimentação de discordâncias e ao seu maior tamanho médio de grão, que pode diminuir a deformação por fluência devido à redução do escorregamento no contorno de grão. (BRIGUENTE et al., 2013).

A microestrutura martensítica é obtida pelo tratamento térmico a temperatura de $1.050^{\circ} \mathrm{C}$ (acima da temperatura de transformação de $\beta$ ) por 30 minutos, seguido por têmpera em água. Já para a obtenção da estrutura de Widmanstätten, as amostras devem ser mantidas a temperatura de $1.050^{\circ} \mathrm{C}$ por 30 minutos e resfriados dentro do forno (VENKATESH et al., 2001).

Trabalhos anteriores mostram que a resistência à fluência da liga Ti$6 \mathrm{Al}-4 \mathrm{~V}$ é mais alta quando o material possui a microestrutura de Widmanstätten (CORTEZ et al., 2007; SUGAHARA et al., 2008, 2009; YOGl et al., 2008; YOGl; SUGAHARA, 2008; BRIGUENTE, 2011; YOGI, 2012) A microestrutura obtida através do resfriamento mais lento dentro da região das duas fases resulta em uma estrutura lamelar mais grossa com boa resistência a fluência onde as interfaces $\alpha / \beta$ agem como obstáculos ao escorregamento das discordâncias. $O$ 
maior tamanho médio de grão diminui a deformação por fluência devido à redução do escorregamento nos contornos de grão, fontes de discordâncias e difusão de oxigênio ao longo dos contornos de grão (VENKATESH et al., 2001).

Devido a isso, a microestrutura de Widmanstätten foi escolhida para se estudar os efeitos da nitretação por plasma em relação à resistência à fluência neste trabalho.

\subsubsection{A microestrutura de Widmanstätten}

Quando liga Ti-6Al-4V é resfriada lentamente a partir da região $\beta$, a fase $\alpha$ começa a se formar abaixo da temperatura de transição de $\beta$, que é cerca de $980^{\circ} \mathrm{C}\left(1796^{\circ} \mathrm{F}\right)$. A fase $\alpha$ formada se apresenta em forma de placas, com uma relação cristalográfica com $\beta$ na qual é formada (BARBOZA et al., 2006). As placas da fase $\alpha$ se formam com seu plano basal (empacotamento compacto) paralelo com um plano especial da fase $\beta$ (MATHISEN, 2012). Devido ao resfriamento lento, forma-se um núcleo da fase $\alpha$, e por causa da estreita correspondência atômica ao longo deste plano comum, a fase a engrossa relativamente devagar perpendicularmente a este plano mais cresce rapidamente paralelamente a ele. Desta forma, as placas se desenvolvem. Porque existem seis conjuntos de planos não paralelos de crescimento em um determinado grão $\beta$, uma estrutura de placas da fase $\alpha$ é formada, composta por seis conjuntos não paralelos (YANG; HAO, 1999). A microestrutura de Widmanstätten desenvolvida é mostrada na Figura 5 (DONACHIE, 2000).

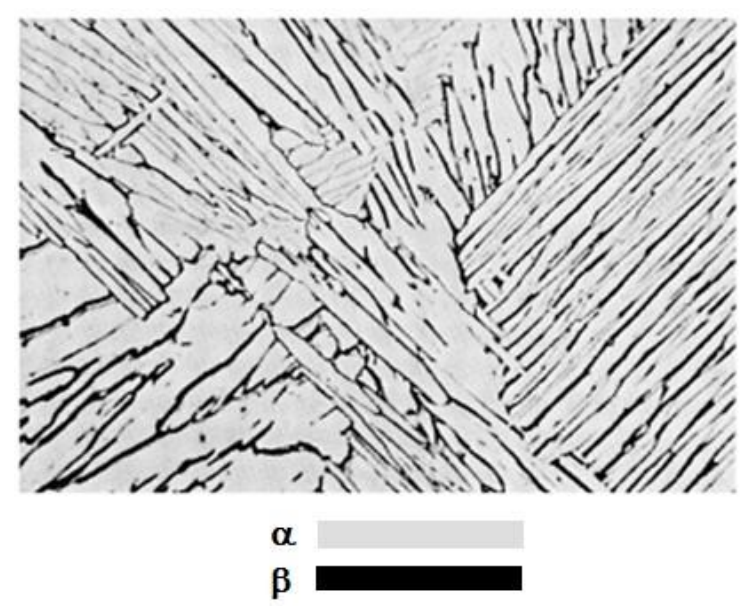

Figura 5 - Microestrutura de Widmanstätten típica da liga $\alpha+\beta$ (Ti-6Al-4V) resfriada lentamente a partir da temperatura de transição $\beta$.

Fonte: Adaptado de (DONACHIE, 2000) 
O processo de formação é mostrado esquematicamente na Figura 6, é utilizado um diagrama de fase com composição constante de $6 \%$ de Al para ilustrar a formação da fase $\alpha$ após o resfriamento. As regiões escuras são da fase $\beta$ formada entre as placas da fase $\alpha$. A microestrutura consiste de placas paralelas de $\alpha$ delineadas pela fase $\beta$ entre elas. Onde placas da fase $\alpha$ formadas paralelas a um plano específico de $\beta$ se encontram com placas da fase $\alpha$ formadas em outros planos, existe um contorno de grão de alto ângulo que revela uma linha que os separa. Esta morfologia microestrutural, consiste deste conjunto de placas paralelas que foram formadas com uma relação cristalográfica com a fase da qual elas foram formadas, é chamada de estrutura de Widmanstätten (DONACHIE, 2000).

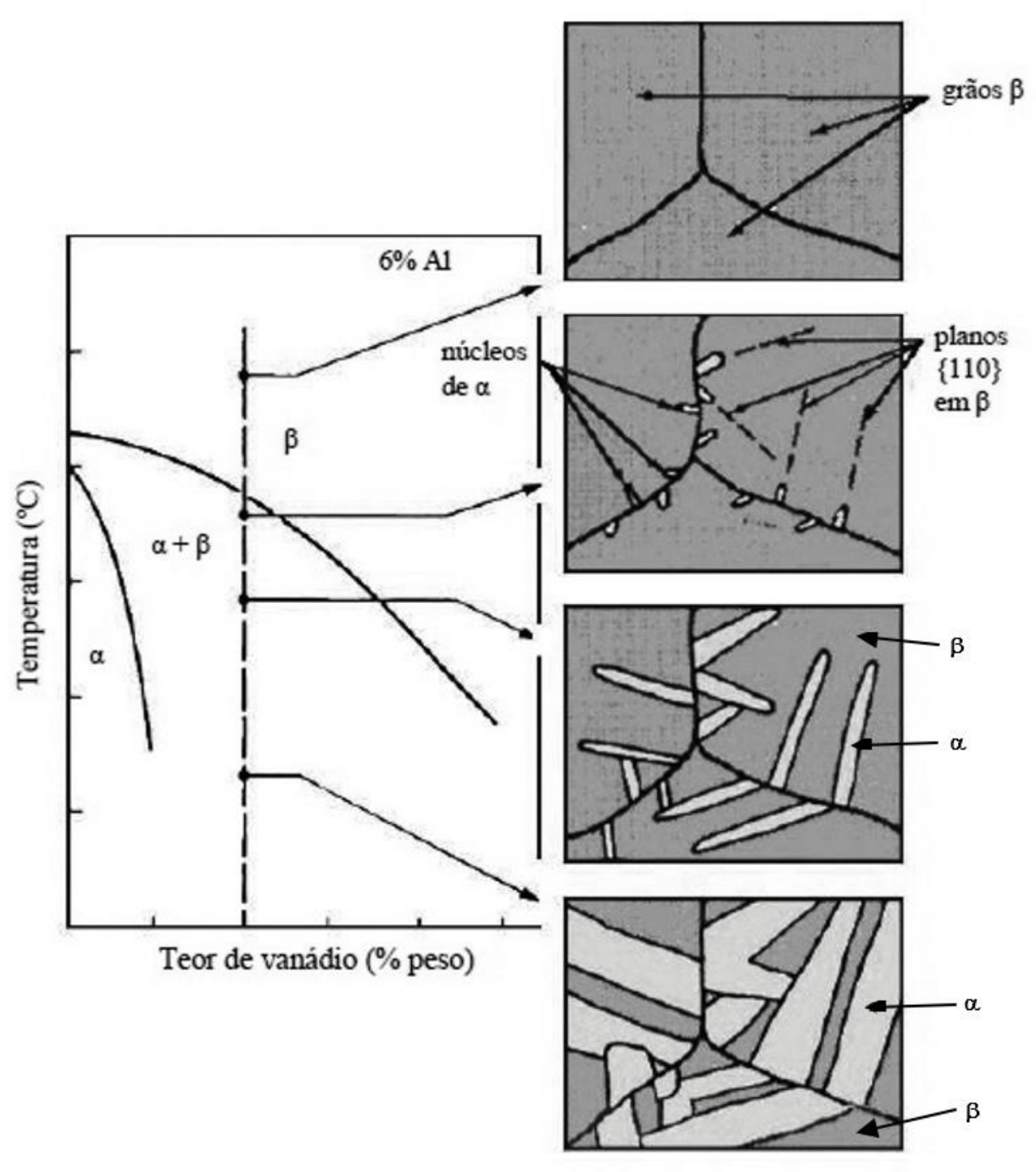

Figura 6 - Diagrama de fase da liga Ti-6Al-4V ilustrando a formação da estrutura Widmanstätten.

Fonte: Adaptado de (DONACHIE, 2000) 


\subsection{Nitretação por plasma}

Várias formas de nitretação têm sido investigadas para melhorar as propriedades superficiais das ligas à base de titânio, tais como nitretação a gás (ZHECHEVA; MALINOV; SHA, 2006; SHA et al., 2008; YASAVOL; MAHBOUBI, 2012), nitretação a laser (YILBAS; SHUJA; HASHMI, 2003; REIS, 2012) e várias formas de nitretação assistidas por plasma (CZERWIEC; MICHEL; BERGMANN, 1998; MISHRA et al., 2003; EL-HOSSARY et al., 2005; KASHAEV; STOCK; MAYR, 2005). A nitretação por plasma das ligas de titânio mostraram várias vantagens sobre outros métodos, dentre elas o fato da pulverização catódica simultaneamente limpar a superfície exposta à nitretação por plasma e, como resultado, as camadas produzidas por esta técnica conterem menos impurezas do que aquelas produzidas pela nitretação a gás (ROLIŃSKI, 1989; ROLINSKI et al., 1998). Possibilitando trabalhar de forma eficiente em temperaturas menores que as utilizadas em outros métodos convencionais, evitando modificações na microestrutura e nas propriedades mecânicas do substrato, além de permitir um melhor recobrimento superficial em formas complexas (FOUQUET et al., 2004a). A eficiência de custos e desempenho das peças também é beneficamente afetada pelo tempo de tratamento reduzido e pela maior dureza das camadas formadas (ZHECHEVA et al., 2005; FARÈ et al., 2012).

\subsubsection{Parâmetros do processo de nitretação}

A nitretação por plasma é um processo de tratamento superficial, que é amplamente utilizado para melhorar a resistência ao desgaste, à fadiga e à corrosão das peças industriais (YASAVOL; MAHBOUBI, 2012).

O efeito da nitretação nas propriedades superficiais do titânio e suas ligas é uma função muito complexa dos parâmetros do processo. Os parâmetros mais importantes dependem do tipo de nitretação, no caso da nitretação por plasma são citados a temperatura, o tempo, a misturas de gases, a pressão e os parâmetros elétricos como os mais importantes (ZHECHEVA et al., 2005).

Entre eles, parece que a temperatura da amostra desempenha o papel mais significativo (DA SILVA et al., 1999). Segundo Fernandes (2006), nas amostras nitretadas, a principal fase cristalina desenvolvida é a $\varepsilon-\mathrm{Ti}_{2} \mathrm{~N}$ tetragonal, que se correlaciona com a análise da composição. Traços de nitreto de titânio $\delta$ TiN cúbicos nanocristais podem também estar presentes, mas apenas na 
temperatura mais alta de nitretação. Uma ligeira mudança na fase $\varepsilon-T_{2} \mathrm{~N}$, de cerca de $0,10^{\circ}$, parece ocorrer a $700^{\circ} \mathrm{C}$, o que possivelmente foi devido à tensão gerada pelo grande espessura de nitreto (FERNANDES et al., 2006).

Os efeitos da temperatura, tempo e atmosfera do gás sobre a nitretação por plasma da liga Ti-6Al-4V são complexos. O nitrogênio puro, uma mistura de nitrogênio e hidrogênio, uma mistura de nitrogênio e argônio e uma mistura de todos os três gases em várias proporções têm sido utilizados como atmosfera para a nitretação por plasma (RAAIF et al., 2007; RAHMAN et al., 2007; LIMA, 2010; HOSSEINI; AHMADI, 2013; POHRELYUK; TKACHUK; PROSKURNYAK, 2013; TANG et al., 2013). As funções da adição do hidrogênio no plasma é a de capturar os átomos de oxigênio presentes na atmosfera reduzindo as impurezas (MICHEL; CZERWIEC; GANTOIS, 1995) e também porque a presença do hidrogênio diminui a energia necessária para a produção de átomos de nitrogênio via dissociação molecular por colisão, já que os íons de $\mathrm{H}^{+}$, que têm menor massa e maior energia cinética do que os íons $\mathrm{N}^{+}$nas mesmas condições de pressão, tensão e temperatura, podem se dissociar em moléculas $\mathrm{N}_{2}$ e espécies de $\mathrm{NH}_{x}$ através da colisão em energias mais baixas para produzir átomos de nitrogênio ativos (BINGZHONG; YINGZHI, 1987).

A nitretação por plasma realizada a temperaturas elevadas (cerca de $850^{\circ} \mathrm{C}$ ) pode degradar as propriedades de resistência a fadiga do Ti-6Al-4V. Isto tem sido atribuído ao crescimento de grão durante o processo e a formação da uma camada de compostos com baixa resistência à fratura. Nitretação a temperatura mais baixa (abaixo de $600^{\circ} \mathrm{C}$ ) tem sido proposto para superar este problema (ALI et al., 2010).

Estudos indicam que tanto o aumento do tempo de nitretação por plasma quanto o aumento da temperatura do processo levam a um aumento da profundidade de difusão e da espessura da camada de compostos. A variação da espessura da camada de composto versus o tempo do processo de 2 a $10 \mathrm{~h}$ (a uma temperatura constante de $800^{\circ} \mathrm{C}$ ) para a liga Ti-6Al-4V é mostrada na Figura 7 (a). $\mathrm{O}$ efeito da temperatura de processo de $700-850^{\circ} \mathrm{C}$ (com tempo constante de $10 \mathrm{~h}$ ), na espessura da camada de compostos é demonstrado na Figura 7(b). Como é evidente, o efeito da temperatura é significativamente maior do que do tempo de processo. Além disso, a espessura da camada em função do tempo de processo (Figura 7(a)) é uma curva de forma parabólica. Assim, no caso de 
nitretação por plasma de Ti-6Al-4V, o crescimento da camada exterior (a uma temperatura constante) segue a regra de difusão parabólica que é a mesma tendência que o crescimento da camada do composto de nitretação por plasma do ferro puro, conforme apresentado pela equação 1 :

$$
x=K .(D . t)^{0,5}
$$

Onde, $x, D$ e $t$ são respectivamente, a espessura da camada, o coeficiente de difusão e o tempo de processo e $K$ é uma constante. Assim, aumentando o tempo de nitretação por plasma reduz a taxa de crescimento da camada de composto de uma forma parabólica. Por outro lado, a espessura da camada em função da temperatura do processo (Figura 7(b)) é semelhante a uma curva exponencial. Isto indica que a taxa de crescimento da camada externa é proporcional ao aumento da temperatura.
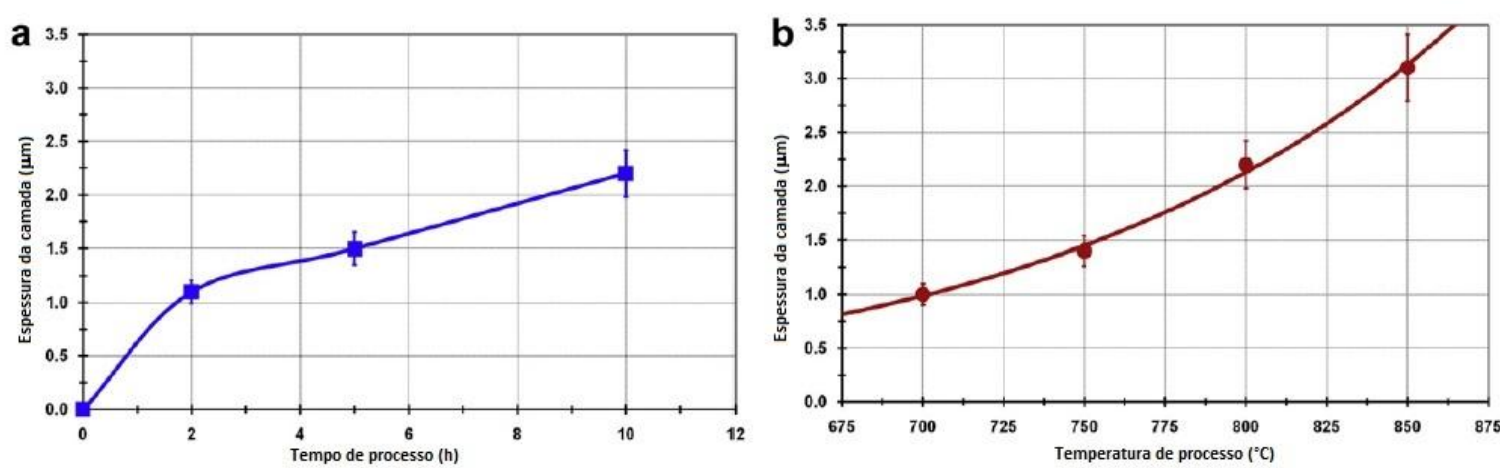

Figura 7 - Variação da espessura da camada do composto versus (a) tempo e (b) temperatura de processo.

Fonte: Adaptado de (HOSSEINI; AHMADI, 2013).

O crescimento da camada de compostos é um processo de difusão e é relativa à difusividade dos elementos, especialmente nitrogênio e alumínio. A difusividade, coeficiente de difusão, está relacionada com a temperatura do processo de acordo com a equação exponencial de Arrhenius (Equação 2):

$$
D=D_{0} . \exp \{-Q /(R . T)\}
$$

Sendo $Q$, a energia de ativação, $R$ a constante universal dos gases e $T$ a temperatura absoluta. Portanto, a taxa de crescimento da camada de composto aumenta exponencialmente com a elevação da temperatura (HOSSEINI; AHMADI, 2013). 


\subsubsection{Nitreto de titânio}

No que diz respeito a seus efeitos na transformação alotrópica, os elementos de liga no titânio são classificados como estabilizadores da fase $\alpha$ ou estabilizadores da fase $\beta$. O nitrogênio, assim como o oxigênio e o alumínio são elementos estabilizadores da fase $\alpha$ (ASM INTERNATIONAL, 1991).

No diagrama de fases do titânio-nitrogênio mostrado na Figura 8 pode se encontrar as seguintes fases em condições de equilíbrio: a fase a com estrutura cristalina hexagonal compacta $(\mathrm{HC})$ abaixo de $883^{\circ} \mathrm{C}$ para uma vasta gama de composições; a fase $\beta$ com estrutura cúbica de corpo central (CCC) acima de $883^{\circ} \mathrm{C}$ para uma vasta gama de composições; a fase $\mathrm{Ti}_{2} \mathrm{~N}$ com estrutura tetragonal, também conhecida com fase $\varepsilon$; e a fase TiN com estrutura cúbica de face centrada (CFC), também conhecida com fase $\delta$, ambas também para uma vasta gama de composições (MOLARIUS, 1985).

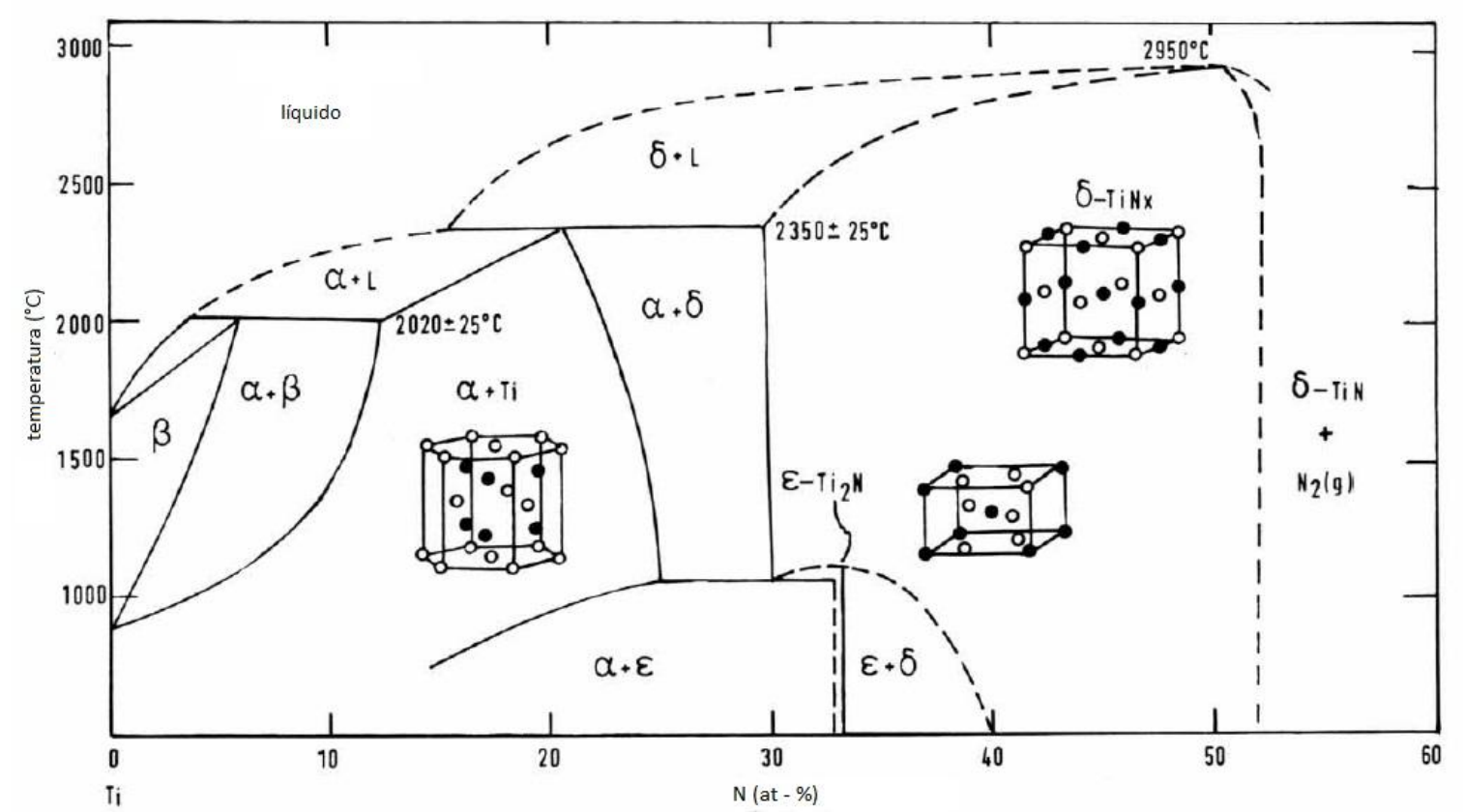

Figura 8 - Diagrama de fases do Ti-N mostrando as fases esperadas em condição de equilíbrio para diferentes teores de $\mathrm{N}_{2}$ (expresso em \% atômica)

Fonte: Adaptado de (MOLARIUS, 1985).

A liga de Ti-6Al-4V nitretada por plasma apresenta maior dureza superficial e tensão residual compressiva mais elevada em comparação com o material não nitretado, o que segundo vários autores (FU et al., 1998; GOLDEN et al., 2007; RAJASEKARAN; RAMAN, 2008; MORITA; ASAKURA; KAGAYA, 2014) seria benéfico para as propriedades mecânicas do material, podendo ter contribuído com o aumento da resistência à fluência do material. 
Devido à aplicação do nitreto de titânio em revestimentos decorativos, também tem se estudado a cores deste tipo de nitreto e consegue-se relacionar as cores com a estequiometria da camada de $\mathrm{Ti}_{\mathrm{x}} \mathrm{N}_{\mathrm{y}}$. As cores variam do cinza metálico até o dourado e finalmente marrom avermelhado com o aumento do fluxo de $\mathrm{N}_{2}$, esta variação de cores pode ser explicada pelo modelo de Drude, que relaciona o comprimento de onda com o percentual refletido. O dourado indica um valor do padrão estequiométrico TiN, o cinza abaixo do valor estequiométrico e o vermelho acima (ROQUINY; BODART; TERWAGNE, 1999). Isso pode ser explicado devido a relação $\mathrm{N}_{2} /$ Ti modificar a densidade de elétrons livres do filme depositado, levando a respostas diferentes da superfície quando radiações de comprimentos de onda incidem sobre ela (ALVES; DAMIÃO; FONTANA, 2004).

Outros autores também associam a formação do composto estequiométrico, TiN, a coloração dourada (BELL et al., 1986; LAKSHMI; ARIVUOLI; GANGULI, 2002; RAHMAN et al., 2007; LISIECKI; KLIMPEL, 2008).

\subsection{Transformações de fase durante o processo}

O modelo baseia-se em regras de reação de difusão e é aplicável para temperaturas de nitretação abaixo da transição $\beta$. Se o material de titânio está num ambiente contendo nitrogênio ativo a uma temperatura elevada, uma transferência de massa de nitrogênio a partir do meio para o sólido ocorre. 0 nitrogênio absorvido na superfície difunde para o titânio formando uma solução intersticial de nitrogênio na fase $\alpha \mathrm{HC}$ do titânio (Figura 9 parte superior). A camada superficial formada é chamada de zona de difusão $(\alpha(N))$. Este processo pode continuar enquanto a matriz de titânio a pode dissolver nitrogênio na interface atmosfera de nitrogênio/sólido (onde a concentração de nitrogênio é a mais elevada). Se a concentração de nitrogênio na interface gás/metal torna-se maior do que a fase a é capaz de manter em solução intersticial, a reação na interface ocorre levando à formação de uma nova fase $\mathrm{Ti}_{2} \mathrm{~N}$ (Figura 9 parte central). Há um salto na concentração de nitrogênio na superfície da amostra, e, como resultado, a camada de nitreto total consiste de uma camada de composto $\left(\mathrm{Ti}_{2} \mathrm{~N}\right)$ na parte superior e uma zona de difusão por baixo. Seguindo as mesmas regras, quando a concentração de nitrogênio na interface gás/metal torna-se maior do que o aceitável em $\mathrm{Ti}_{2} \mathrm{~N}$, há uma transformação de fase na superfície da amostra e $0 \mathrm{Ti}_{2} \mathrm{~N}$ se transforma em TiN (Figura 9 parte inferior). A subcamada, 
com apenas nitretos de titânio ( $\mathrm{TiN}$ e $\left.\mathrm{Ti}_{2} \mathrm{~N}\right)$, forma a camada de composto, enquanto que $\alpha(N)$ representa a zona de difusão (ZHECHEVA et al., 2005).

$$
\alpha-\mathrm{Ti} \rightarrow \alpha(\mathrm{N})-\mathrm{Ti} \rightarrow \mathrm{Ti}_{2} \mathrm{~N} \rightarrow \mathrm{TiN}
$$

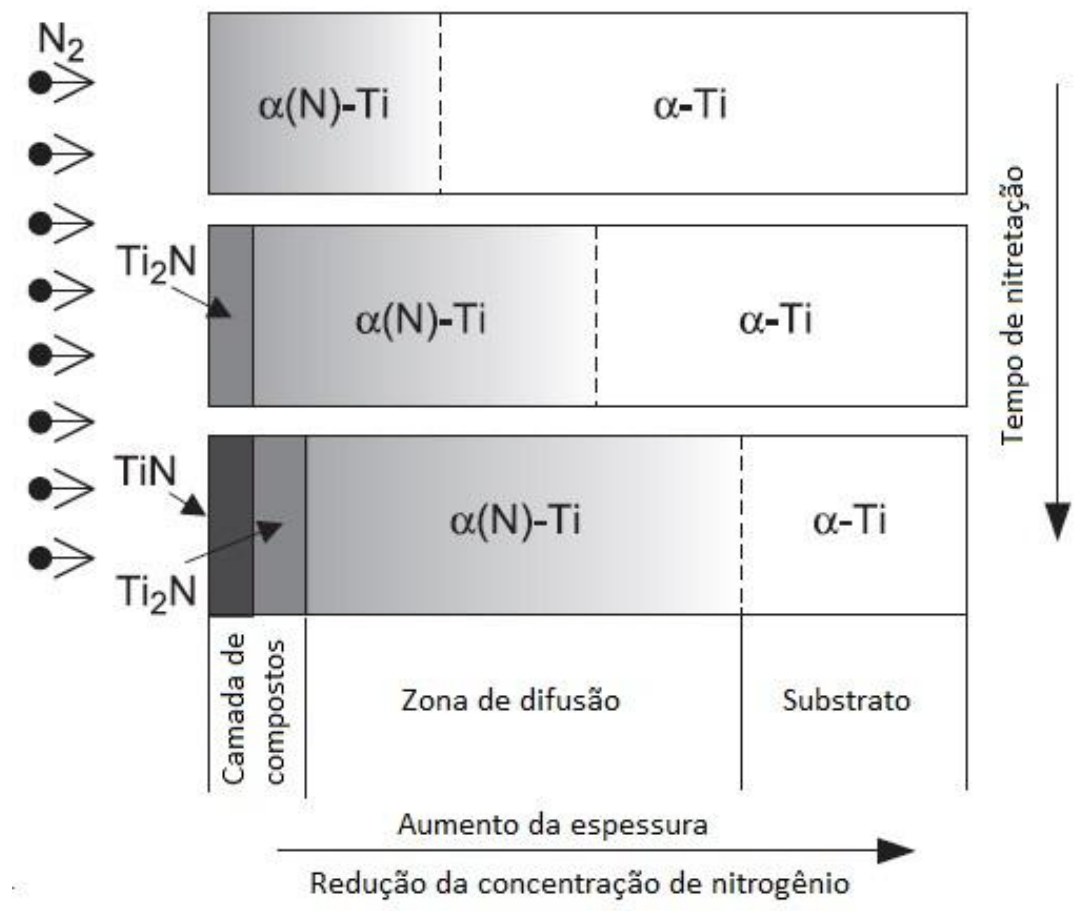

Figura 9 - Representação esquemática da cinética de formação e crescimento da camada superficial durante a nitretação do titânio.

Fonte: Adaptado de (ZHECHEVA et al., 2005)

\subsection{Fluência}

A importância técnica do fenômeno de fratura por fluência tornou-se evidente a partir da metade do século XX, sendo reconhecida como um dos maiores problemas da área industrial, devido ao crescente nível de exigência das condições de operação empregadas em usinas de geração de energia, instalações químicas e em componentes estruturais desenvolvidos junto às indústrias aeroespaciais (ES-SOUNI, 2001b; SECO; IRISARRI, 2001; NABARRO, 2002; PAULA et al., 2002). Dessa maneira, os estudos dos materiais usados nesses componentes exigem, cada vez mais, sofisticações tecnológicas, aprimoramentos nos ensaios experimentais (destrutivos e não destrutivos), e uma constante busca de uma vasta base de dados. Tais bases, associadas a métodos matemáticos e computacionais, podem conduzir a um melhor entendimento de todos os fenômenos estruturais que podem ocorrer nos materiais, quando, por 
exemplo, submetidos a tensões em regimes de temperaturas elevadas (BARBOZA, 2001; BARBOZA; MOURA NETO; SILVA, 2004).

Fluência é a deformação lenta e contínua de um sólido com o tempo quando o mesmo é submetido a uma tensão constante. No caso dos metais a fluência normalmente ocorre a temperaturas acima de 0,3/0,4 $T_{f}$, em que $T_{f}$ é a temperatura de fusão em graus Kelvin (MEETHAM; VAN DE VOORDE, 2000). Tipicamente, a resistência à fluência de um sólido é estimada pelo cálculo da taxa de deformação secundária e avaliada como função da carga ou tensão aplicada. Para tanto é aplicada uma carga estática sobre uma amostra em temperaturas elevadas, medindo-se a deformação como função do tempo, o ensaio típico de fluência é mostrado na Figura 10.

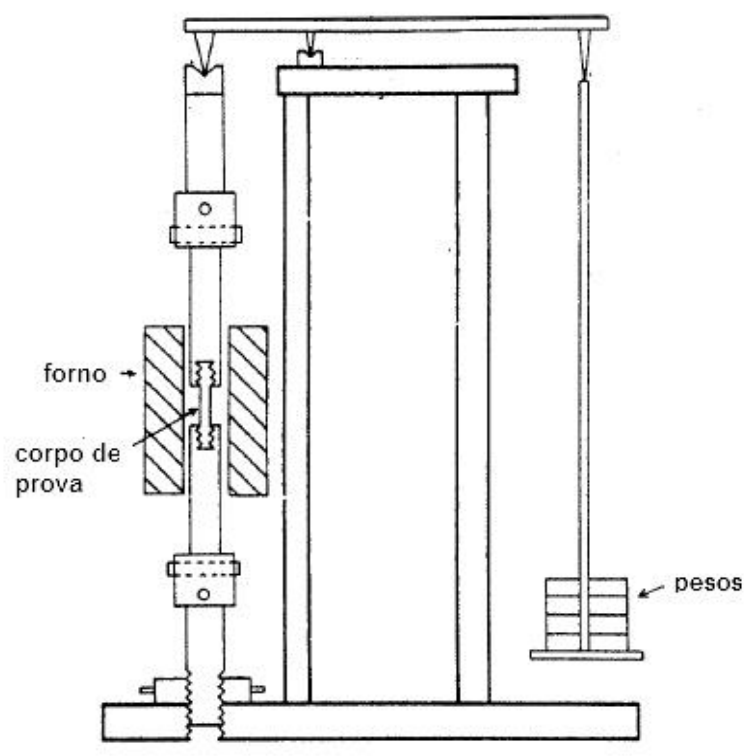

Figura 10 - Esquema de um ensaio de fluência típico Fonte: Adaptado de (EVANS; WILSHIRE, 1993)

A deformação resultante é plotada versus tempo, onde três regiões são tipicamente observadas, a primária, secundária e terciária, como mostrado na Figura 11. A taxa mínima de fluência $\Delta \varepsilon / \Delta t$ é a inclinação da reta da região secundária e o tempo de ruptura $t_{f}$ é o tempo total do ensaio até a ruptura (ANDRADE, 1910; BARSOUM, 2003). 


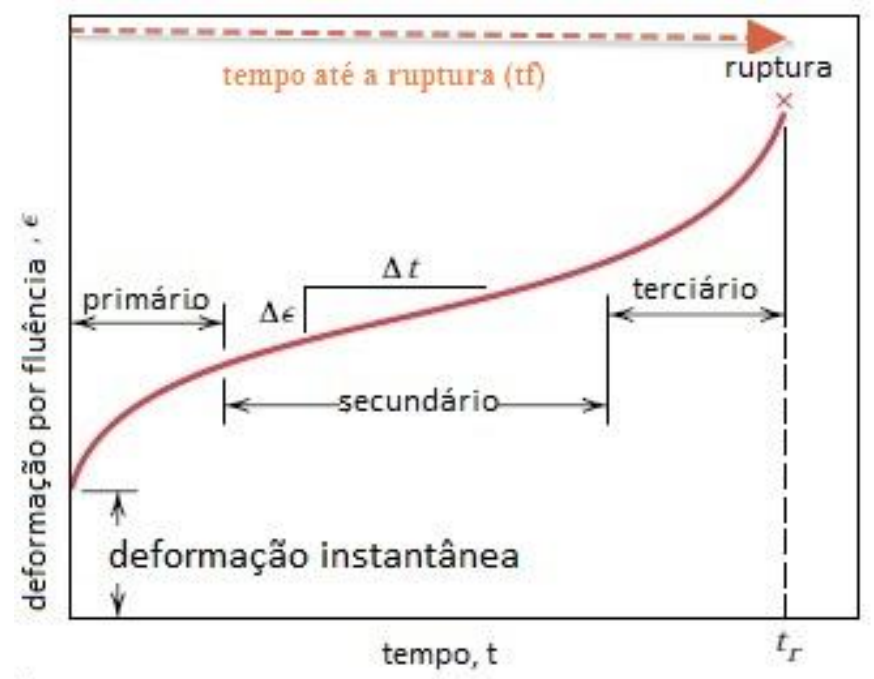

Figura 11 - Curva típica de fluência a tensão constante e temperatura elevada constante.

Fonte: Adaptado de (EVANS; WILSHIRE, 1993; CALLISTER; RETHWISCH, 2012)

Observa-se na Figura 11 que na primeira região existe uma resposta quase instantânea, a taxa de deformação é bastante rápida, seguida de uma diminuição da taxa de deformação com o tempo até um valor constante. A segunda região é onde a deformação aumenta linearmente com o tempo. Esta região é chamada de estado estacionário ou estágio de fluência secundária e, do ponto de vista prático, é a mais importante. Já a terceira região é chamada de estágio de fluência terciária, onde a taxa de deformação aumenta rapidamente com o tempo, até a ocorrência da falha catastrófica. O aumento da temperatura e/ou tensão resulta no aumento da deformação instantânea e nas taxas de fluência no estado estacionário, e uma diminuição no tempo para falha (DUSHMAN; DUNBAR; HUTHSTEINER, 1944; NABARRO, 2002).

Em condições reais de serviço, os componentes de uma forma geral operam em regime complexo de tensão e temperatura, sendo projetados para tempos de serviços da ordem de 50.000 a 100.000 horas. Entretanto, ao nível laboratorial, os ensaios de fluência são realizados por períodos mais curtos de tempo, surgindo, portanto a necessidade de técnicas de extrapolação dos resultados obtidos para situações reais de trabalho (VISWANATHAN; FOULDS, 1998). No caso específico dos metais, a complexidade metalúrgica de muitas ligas comerciais exige um conhecimento exato dos micromecanismos que controlam o processo de fluência, tanto para a elaboração de equações 
constitutivas, quanto para as técnicas de extrapolação utilizadas (EYLON et al., 1984).

Os métodos mais comuns de avaliação de comportamento de um sólido cristalino em alta temperatura envolvem, geralmente, procedimentos gráficos e analíticos, por meio de análises estatísticas ou pela elaboração de equações empíricas simples que relacionam a deformação ou a taxa de fluência à tensão e temperatura constante. Com esses procedimentos e pela forma como os dados geralmente são apresentados, a ênfase é dada somente para a fase secundária, é comum a perda de uma gama de informações sobre o fenômeno, resumindo-se aos valores de taxa mínima, tempo de ruptura e deformação correspondente á fratura final. De forma preponderante resulta na perda de informações relativas às regiões primária e terciária, as quais dominam o comportamento em muitas ligas metálicas em engenharia (GARDNER, 1994; ES-SOUNI, 2001a; TANG; NAKAZAWA; HAGIWARA, 2002; PITT; RAMULU, 2004; CALLISTER; RETHWISCH, 2012).

\subsubsection{Mecanismos de deformação por fluência}

O comportamento dos materiais metálicos em alta temperatura está intimamente relacionado com a presença de imperfeições cristalinas, devido à maior mobilidade atômica, e consequentemente aos processos que envolvem o fenômeno da difusão. A capacidade de movimentação de discordâncias aumenta com a elevação da temperatura, podendo ativar outros mecanismos responsáveis pelo processo de deformação, possibilitando a operação de novos sistemas de escorregamento e a deformação localizada ao longo dos contornos de grão. As condições ambientais, como meios agressivos, exercem uma forte influência na grande maioria das ligas, principalmente quando conjugadas com processos que envolvem a instabilidade metalúrgica, conduzindo um componente estrutural a uma possível falha prematura (BARBOZA, 2001).

Após a deformação inicial do material inicia-se a fluência primária, caracterizada por uma região onde a taxa de fluência diminui com o tempo devido ao aumento da resistência à fluência ou encruamento (DIETER, 1988; REEDHILL; ABBASCHIAN; ABBASCHIAN, 2009; CALLISTER; RETHWISCH, 2012).

O encruamento que ocorre nesse estágio é resultado do movimento e interação de discordâncias. O escorregamento dessas discordâncias é impedido 
por barreiras como precipitados, contornos de grão, florestas ou empilhamento de discordâncias, entre outras. A restrição à movimentação das discordâncias aumenta as tensões internas no material e com isso diminui a taxa de deformação por fluência. A recuperação acontece devido à ativação térmica das discordâncias, entretanto essa recuperação é pequena, pois o mecanismo de interseção das discordâncias com as barreiras é o fator controlador desse estágio (ES-SOUNI, 2000).

O parâmetro mais utilizado do estágio primário é o $t_{p}$, que é definido como o tempo correspondente ao início do estágio secundário. Esse parâmetro é descrito como:

$$
t_{p}=B_{0} \sigma^{-m} \exp \left(Q_{p} / R T\right)
$$

Onde: $B_{0}$ e $m$ são constantes dependentes da microestrutura, temperatura e tensão aplicada;

$R$ é a constante universal dos gases;

$T$ é a temperatura absoluta $(K)$;

$Q_{p}$ é a energia de ativação para a região primária (HAYES, 1996).

Em seguida, na fluência secundária ou estacionária, a taxa de deformação é muito pequena e a inclinação da curva é aproximadamente constante devido a dois fenômenos competitivos, encruamento e recuperação. Em geral, esse estágio apresenta uma duração mais longa em relação aos demais (DIETER, 1988; REED-HILL; ABBASCHIAN; ABBASCHIAN, 2009; CALLISTER; RETHWISCH, 2012). A taxa de encruamento é equilibrada pela taxa de recuperação que significa a libertação de discordâncias das barreiras (empilhamentos de discordâncias, precipitados entre outras) pela escalagem ou escorregamento com desvio. A escalagem de discordâncias requer uma maior energia de ativação sendo o processo controlador da velocidade de fluência. Além disso, como esse processo depende da temperatura, quanto maior a temperatura, maior é a recuperação e o estágio secundário apresenta uma menor duração. $\mathrm{A}$ escalagem de discordâncias é feita por absorção e emissão de lacunas. Assim sendo, para haver a escalagem é necessário vencer uma barreira energética maior e, portanto, quanto maior é a energia de ativação, mais resistente o material em fluência. Outro processo que contribui para a resistência à fluência nesse estágio é o processo de escorregamento de contornos de grão. 0 escorregamento é um processo que ocorre na direção dos contornos de grão e 
que pode criar lacunas que facilitam a escalagem das discordâncias (MEYERS; CHAWLA, 1982; DIETER, 1988; BLUM, 2001).

Uma relação muito utilizada para descrever o comportamento em fluência em temperaturas elevadas, acima de aproximadamente $0,3 \mathrm{Tf}$, relaciona a dependência da taxa de fluência estacionária com a tensão aplicada $\sigma$, sendo representada pela lei de potência, reconhecida universalmente como Lei de Norton:

$$
\dot{\varepsilon}_{s}=B \sigma^{n}
$$

onde:

B é uma constante característica do material;

n é o expoente de tensão;

$\dot{\varepsilon}_{s}$ é a taxa de fluência estacionária (EVANS; WILSHIRE, 1993)

$\mathrm{O}$ coeficiente $\mathrm{B}$ e $\mathrm{O}$ expoente de tensão $\mathrm{n}$ dependem da temperatura, composição e microestrutura do material, e do nível de tensão aplicado. (BRÅTHE; JOSEFSON, 1979)

A natureza termicamente ativada da fluência torna esse processo outro exemplo de comportamento de Arrhenius, podendo ser representada pela Equação 5:

$$
\dot{\varepsilon}_{s}=B_{0} \sigma^{n} \exp \left(-Q_{c} / R T\right)
$$

onde:

$B_{0}=$ fator dependente da tensão e da estrutura do material;

$Q_{c}=$ energia de ativação para fluência; e

$R=$ constante universal dos gases

Os valores de $B_{0}$ e $Q_{c}$ podem ser obtidos graficamente por meio de um conjunto de ensaios à tensão ou carga constantes a partir do gráfico do logaritmo da taxa de fluência em estado estacionário em função do inverso da temperatura absoluta (Figura 12). A extensão dos dados de alta temperatura no curto prazo permite a previsão do comportamento de fluência no longo prazo em temperaturas de serviço mais baixas. 


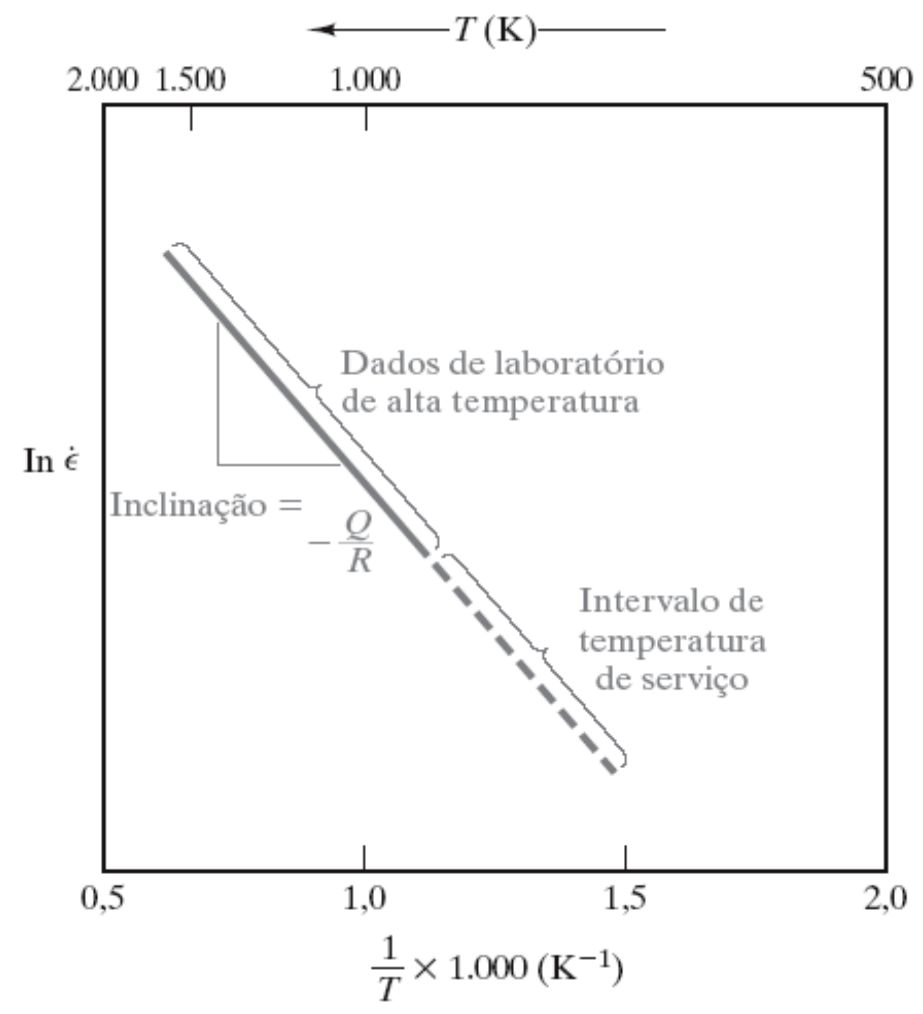

Figura 12 - Dependência da taxa de fluência estacionária com a temperatura Fonte: (EVANS; WILSHIRE, 1993; SHACKELFORD, 2012)

Todos os mecanismos podem apresentar contribuições ao longo dos três estágios da fluência (primário, secundário e terciário) e através dos valores dos parâmetros n e $Q_{c}$ podemos determinar o mecanismo de fluência dominante.

A Tabela 1 mostra a correlação do mecanismo de fluência dominante através dos valores dos parâmetros n e Qc. 
Tabela 1 - Determinação do mecanismo de fluência dominante através dos valores dos parâmetros n e $Q_{c}$. Adaptado de (EVANS; WILSHIRE, 1993)

\begin{tabular}{|c|c|c|c|c|}
\hline Mecanismo de Fluência & Temperatura & Tensão & $\begin{array}{l}\text { Valor } \\
\text { de } n\end{array}$ & $\begin{array}{l}\text { Valor } \\
\text { de Qc }\end{array}$ \\
\hline $\begin{array}{c}\text { Alta temperatura } \\
\text { Deslizamento e escalagem } \\
\text { de discordâncias }\end{array}$ & $\begin{array}{c}\text { Cerca de } \sim 0,7 \\
\mathrm{~T}_{\mathrm{f}}\end{array}$ & $\begin{array}{c}\text { Intermediária / } \\
\text { alta }\end{array}$ & $>3$ & $\sim Q_{\mathrm{SD}}$ \\
\hline $\begin{array}{c}\text { Baixa temperatura } \\
\text { Deslizamento e escalagem } \\
\text { de discordâncias }\end{array}$ & $\sim 0,4$ até $0,7 \mathrm{~T}_{\mathrm{f}}$ & $\begin{array}{c}\text { Intermediária / } \\
\text { alta }\end{array}$ & $>3$ & $Q_{\text {CORE }}$ \\
\hline $\begin{array}{c}\text { Alta temperatura } \\
\text { Fluência por difusão } \\
\text { (Nabarro-Herring) }\end{array}$ & $\begin{array}{c}\text { Cerca de } \sim 0,7 \\
\mathrm{~T}_{\mathrm{f}}\end{array}$ & Baixa & $\sim 1$ & $Q_{S D}$ \\
\hline $\begin{array}{l}\text { Baixa temperatura } \\
\text { Fluência por difusão } \\
\text { (mecanismo de Coble) }\end{array}$ & $\sim 0,4$ até $0,7 \mathrm{~T}_{\mathrm{f}}$ & Baixa & $\sim 1$ & $Q_{G B}$ \\
\hline
\end{tabular}

Quando a fluência por difusão é dominante ( $m=2$ ou 3), a taxa de fluência $\left(\dot{\varepsilon}_{S}\right)$ aumenta com a diminuição do tamanho de grão;

Quando a fluência por movimento de discordância é dominante $(\mathrm{m} \approx 0),\left(\dot{\varepsilon}_{s}\right)$ não é afetada pelo tamanho de grão;

\subsubsection{Fluência por difusão}

Ensaios mecânicos são geralmente conduzidos a uma taxa de deformação constante a baixas temperaturas, e a deformação plástica é então obtida exclusivamente através da movimentação das discordâncias. A forma da curva de tensão-deformação nestas condições é determinada pela dificuldade das discordâncias de se moverem através da rede cristalina.

Em temperaturas elevadas, experiências de laboratório tomam geralmente a forma de ensaios de fluência em que a amostra cristalina é submetida a uma 
tensão constante (ou carga). Nestas condições, a taxa de difusão é suficientemente rápida para que seja possível, pelo menos em princípio, atingir deformações plásticas permanentes unicamente pela difusão da tensão dirigida das vacâncias, este processo é denominado de fluência por difusão.

$\mathrm{Na}$ prática, contudo, a fluência por difusão só é importante a tensões baixas quando as taxas de deformação forem extremamente lentas e quando o tamanho do grão é pequeno. Em condições normais de fluência, quando as taxas de deformação são razoavelmente rápidas, a deformação é novamente alcançada através do movimento de discordâncias no interior da rede cristalina, coforme apresentado nas equações 6 e 7 (LANGDON, 1984).

$$
\begin{aligned}
& \dot{\varepsilon}_{s}=A \frac{D G b}{k T}\left(\frac{b}{d}\right)^{p}\left(\frac{\sigma}{G}\right)^{n} \\
& D=D_{0} \exp \left(-\frac{Q_{c}}{R T}\right)
\end{aligned}
$$

Onde
$A$ : constante adimensional
$D$ : coeficiente de difusão
$D_{0}$ : difusidade
$\sigma:$ tensão aplicada
G: módulo de elasticidade transversal
$b$ : vetor de Burgers
k: constante de Boltzman
$Q_{c}$ : energia de ativação para fluência
$R$ : constante universal dos gases
$T$ : temperatura absoluta
d: tamanho médio de grão

pe $n$ : constantes (mecanismos intragranulares ou intergranulares)

Existem dois mecanismos de fluência por difusão, dependendo se os caminhos da difusão são predominantemente através dos contornos de grão, um denominado de mecanismo de fluência de Coble (favorecido a temperaturas mais baixas), outro através dos próprios grãos, denominado mecanismo de fluência de Nabarro-Herring (favorecido a temperaturas mais elevadas).

Para o mecanismo de Nabarro-Herring a taxa de fluência estacionária pode ser expressa como é mostrado na equação 8: 


$$
\dot{\varepsilon}_{s}=\frac{A D_{v} G b}{k T}\left(\frac{b}{d}\right)^{2}\left(\frac{\sigma}{G}\right)
$$

Onde:

$\mathrm{D}_{v}$ : coeficiente de autodifusão

Para o mecanismo de Coble a taxa de fluência estacionária pode ser expressa como é mostrado na equação 9 :

$$
\dot{\varepsilon}_{s}=\frac{A D_{c g} G b}{k T}\left(\frac{b}{d}\right)^{3}\left(\frac{\sigma}{G}\right)
$$

Onde:

$D_{c g}$ : coeficiente de difusão ao longo dos contornos granulares

\subsubsection{Fluência por escorregamento e escalagem das discordâncias}

As discordâncias desempenham um papel muito importante na deformação plástica de materiais cristalinos em todas as temperaturas. Em baixas temperaturas, a plasticidade é conseguida pelo deslizamento das discordâncias enquanto que a temperaturas elevadas, em condições de fluência, as discordâncias sofrem deslizamento e também escalagem. Embora seja possível alcançar uma deformação plástica por fluência unicamente pela difusão dirigida da tensão das vacâncias, como na fluência por difusão, este processo é relativamente pouco importante exceto em tensões muito baixas quando o tamanho do grão é pequeno. Sob todas as outras condições, a deformação é conseguida pelo movimento de discordâncias (LANGDON, 1984).

Neste caso a taxa de fluência estacionária pode ser expressa como apresentado na equação 10:

$$
\dot{\varepsilon}_{s}=A D_{v} \frac{G b}{k T}\left(\frac{\sigma}{G}\right)^{n}
$$

\subsubsection{Fluência por escorregamento de contorno de grão}

Neste mecanismo, o processo de deformação ocorre com a movimentação relativa entre grãos de um metal policristalino, através da ação de um componente cisalhante de tensão atuando de forma descontínua e irregular, tornando-se mais efetivo com o aumento da temperatura e redução da taxa de deformação (BARBOZA, 2001). Ação combinada do movimento de discordâncias e mecanismos de difusão. O papel mais importante desempenhado pelo 
deslizamento dos contornos de grão está relacionado com o início da fratura intergranular. Uma maneira de acomodar a deformação nos contornos de grão em temperaturas altas é através da formação de dobras no final de um contorno de grão.

A taxa mínima de fluência ao longo dos contornos de grão $\left(\dot{\boldsymbol{\varepsilon}}_{s g}\right)$ pode ser expressa conforme apresentado na equação 11:

$$
\dot{\varepsilon}_{s g}=\left(\frac{A D_{c g} G b}{k T}\right)\left(\frac{b}{d}\right)\left(\frac{\sigma}{G}\right)
$$

onde:

$D_{c g}=$ coeficiente de difusão nos contornos de grãos

$d=$ diâmetro do grão

$k=$ constante de Boltzman

\subsubsection{Fluência da liga Ti-6Al-4V}

A natureza da oxidação pode ter uma influência importante sobre as propriedades em temperaturas elevadas (GARCÍA-ALONSO et al., 2003; GÜLERYÜZ; CIMENOĞLU, 2005; JANUSZEWICZ; SINIARSKI, 2006). Uma camada fina de óxido normalmente conduzirá a um aumento na resistência mecânica, mas a penetração intergranular do óxido geralmente implica em um decréscimo no tempo de ruptura por fluência e fratura intergranular. A vida em serviço de um material é bastante reduzida quando este deve operar em atmosfera de combustão de gases quentes ou em meios corrosivos.

Estudos recentes de difusão de oxigênio podem ser correlacionados com tamanho de grão e microestrutura do material. O aumento dos níveis de oxigênio é associado com o aumento de microdureza e diminuição da ductilidade do titânio (TEOH, 2000). Tais estudos são escassos na literatura e justificariam as respostas dos dados de fluência pela capacidade de oxidação de cada microestrutura. Com o propósito de se projetar novas ligas de titânio com melhores propriedades e para aperfeiçoar as condições de processamento de forjamento a quente da liga Ti-6Al-4V é necessário entender os mecanismos associados à deformação em temperaturas elevadas (ZHECHEVA et al., 2005).

A temperatura e a duração dos tratamentos foram os parâmetros estudados. Estes tratamentos modificam a estrutura da superfície pela formação de diferentes fases cristalinas tais como $\mathrm{Ti}_{2} \mathrm{~N}, \mathrm{TiN}$ e $\alpha-\mathrm{Ti}(\mathrm{N}, \mathrm{O})$ (solução sólida de 
nitrogênio no titânio) (REIS, 2005; YILDIZ et al., 2008). A presença das fases cristalinas resulta em aumento da dureza do material (REIS et al., 2005) e pode consequentemente aumentar suas propriedades de resistência à corrosão e ao desgaste em muitos ambientes agressivos (EL-HOSSARY et al., 2005).

Estudo realizado referente à microestrutura e ao tamanho de grão da liga Ti-6Al-4V em relação a fluência mostram que as taxas de fluência da liga com microestrutura Widmanstätten com tamanho de grão médio de $395 \mu$ m chegam a ser duas ordens de grandeza menor do que a as taxas do material com microestrutura equiaxial e tamanho de grão médio de $10 \mu \mathrm{m}$. Aparentemente, esta maior resistência à fluência, pode ser atribuída as interfaces de $\alpha / \beta$ agindo como obstáculos ao movimento de discordância e ao maior tamanho médio de grão, o que reduz o escorregamento no contorno de grão, as fontes de discordâncias e a taxa de difusão do oxigênio ao longo dos contornos de grão (SUGAHARA et al., 2010).

Comparações entre a microestrutura martensítica e equiaxial demonstram também que o maior tamanho médio de grão da estrutura martensítica e com formato acicular também exercem um papel significativo em relação à resistência à fluência da liga Ti-6Al-4V. Essas estruturas mais "agulhadas" agem como obstáculo ao movimento das discordâncias e o maior tamanho do grão diminui a deformação por fluência devido à redução do escorregamento no contorno de grão (BRIGUENTE et al., 2013).

Segundo estudos realizados por outros autores (CORTEZ et al., 2007; YOGI; SUGAHARA, 2008; DE MELO; REIS; MOURA NETO, 2009; SUGAHARA et al., 2009, 2010; OLIVEIRA, 2010; BRIGUENTE, 2011, 2015; REIS, 2012; CABESTRÉ, 2013), nota-se que as estruturas Widmanstätten e Martensita apresentam melhor resistência à fluência do que o material sem tratamento.

Em um estudo realizado com a liga Ti-6Al-4V tratada termicamente $\mathrm{e}$ submetida à Implantação lônica por Imersão a Plasma de Nitrogênio (IIIPN) e exposta a condições de fluência às temperaturas de $500^{\circ} \mathrm{C}$ e $600^{\circ} \mathrm{C}$ mostrou que a estrutura com menores taxas de fluência secundária foi a de Widmanstätten. Verificou-se ainda que a associação do IIIP ao tratamento térmico promoveu um aumento na resistência a fluência quando comparado com a liga somente tratada termicamente (YOGI, 2012). 
Outro trabalho em que foi utilizado recobrimento como forma de barreira térmica - TBC (Thermal Barrier Coating) o material com estrutura Widmanstätten também apresentou melhor resistência à fluência (BRIGUENTE, 2011).

Após toda esta pesquisa, este trabalho foi direcionado para tentar melhorar ainda mais os resultados em relação à fluência tratando termicamente o material para se alcançar uma estrutura Widmanstätten e ainda modificar a superfície por nitretação por plasma com o objetivo de analisar o efeito deste tratamento superficial nas propriedades da liga Ti-6Al-4V, esta proposta foi escolhida devido a importância tecnológica desta liga em aplicações a temperaturas elevadas onde a melhora da resistência à fluência é muito importante. 


\section{MATERIAIS E MÉTODOS}

Para realização do trabalho foram realizadas várias etapas que estão resumidas em um fluxograma mostrado na Figura 13.

Preparação para os testes de nitretação (corte, lixamento e polimento)

Confecção dos corpos de prova de fluência

Tratamento térmico (obtenção da microestrutura Widmanstätten)

MO (identificação da microestrutura)

Nitretatação por plasma (variando a proporção dos gases na atmosfera)

Observação da camada nitretada (MO e MEV)

Análise DRX (camada nitretada)

Determinação da melhor condição de nitretação

Nitretação dos corpos de prova na condição escolhida

Ensaio de tração a quente e de fluência do material nitretado

Análise dos resultados obtidos (MO, MEV)

Figura 13 - Esquema das etapas realizadas para elaboração da parte experimental do trabalho.

\subsection{Preparação do material}

A liga de titânio Ti-6Al-4V utilizada foi fornecida em barras cilíndricas de 15 $\mathrm{mm}$ de diâmetro, adquiridas junto à Empresa Multialloy Eng. Mat. Ltda. na condição forjada e recozida a $800^{\circ} \mathrm{C}$ durante 2 horas e resfriada ao ar. A composição química fornecida pelo fabricante é mostrada na Tabela 2 e atende aos requisitos da norma ASTM B265 (AMERICAN SOCIETY FOR TESTING AND MATERIALS (ASTM), 2015). 
Tabela 2 - Composição química da amostra Ti-6Al-4V (\% em peso)

\begin{tabular}{cccccccccc}
\hline Elementos & Al & $\mathbf{V}$ & $\mathbf{F e}$ & $\mathbf{O}$ & $\mathbf{N}$ & $\mathbf{H}$ & $\mathbf{C}$ & Outros & $\mathbf{T i}$ \\
\hline Teor (\% & 5,5 a & 3,5 & Max. & Max. & Max. & Max. & Max. & Max. & \\
em peso) & 6,75 & a & 0,4 & 0,2 & 0,05 & 0,125 & 0,1 & 0,4 & Balanço \\
& & 4,5 & & & & & & & \\
\hline
\end{tabular}

\subsubsection{Amostras para definição dos parâmetros de nitretação}

A barra foi cortada em discos com aproximadamente $2 \mathrm{~mm}$ de espessura em uma cortadeira Isomet. As amostras foram preparadas seguindo os procedimentos usuais de metalografia (embutimento, lixamento e polimento com sílica coloidal). A seguir foi retirado o embutimento para a realização dos teste no reator de plasma.

\subsubsection{Corpo de prova de Fluência}

Para realização dos ensaios de fluência foi necessário confeccionar os corpos de prova e tratar os mesmo por nitretação por plasma.

$\mathrm{Na}$ Figura 14 é apresentada a forma e as dimensões dos corpos de prova que foram utilizados nos ensaios de fluência. Os corpos de prova foram confeccionados de acordo com as especificações, sistemas de garras e extensômetros disponíveis conforme mostra a Figura 15.
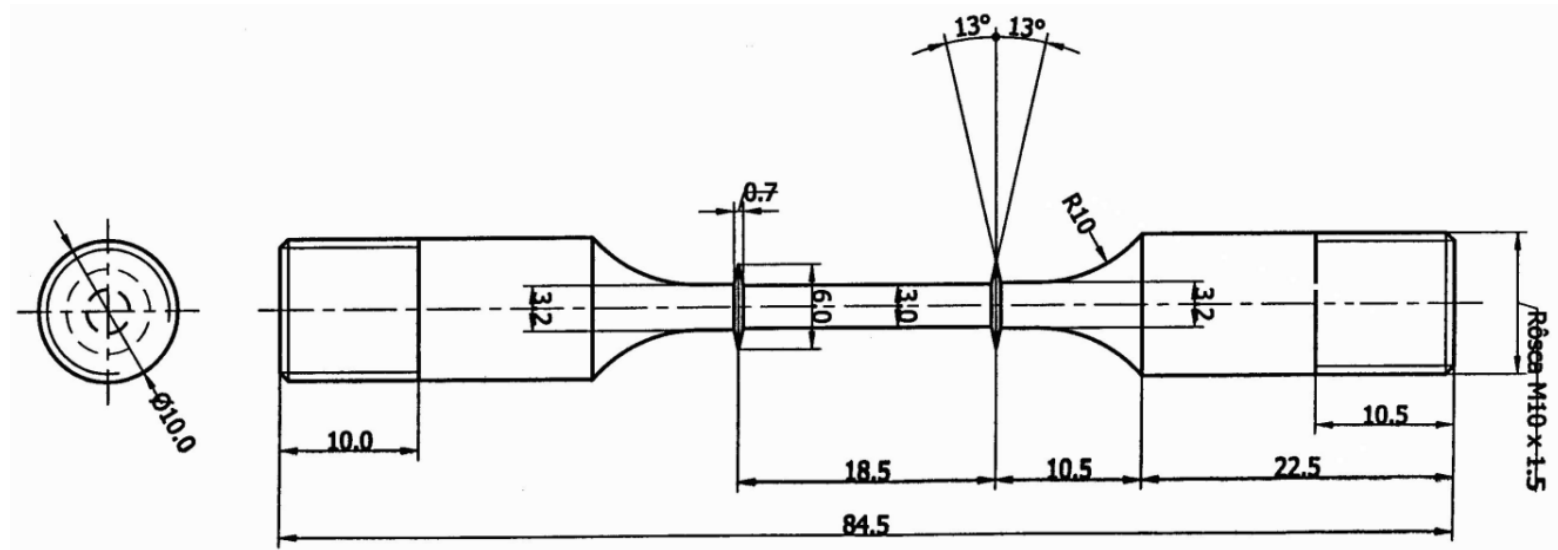

Figura 14 - Configuração do corpo de prova (dimensões em $\mathrm{mm}$ ) utilizado nos ensaios de fluência (AMERICAN SOCIETY FOR TESTING AND MATERIALS (ASTM), 2011). 
Figura 15 - Fotografia do corpo de prova utilizado nos ensaios de fluência.

\subsection{Tratamento térmico}

Todo o material em forma de pastilha para testes e caracterizações e também os corpos de prova de fluência foram submetidos ao tratamento térmico para homogeneização da microestrutura de todo o lote. O forno utilizado foi da marca Jung modelo LT3101301 pertencente ao Laboratório de Metalografia da Universidade Presbiteriana Mackenzie mostrado na Figura 16. Para evitar a oxidação do material foi adicionado um fluxo constante de argônio na atmosfera durante todo o tratamento.

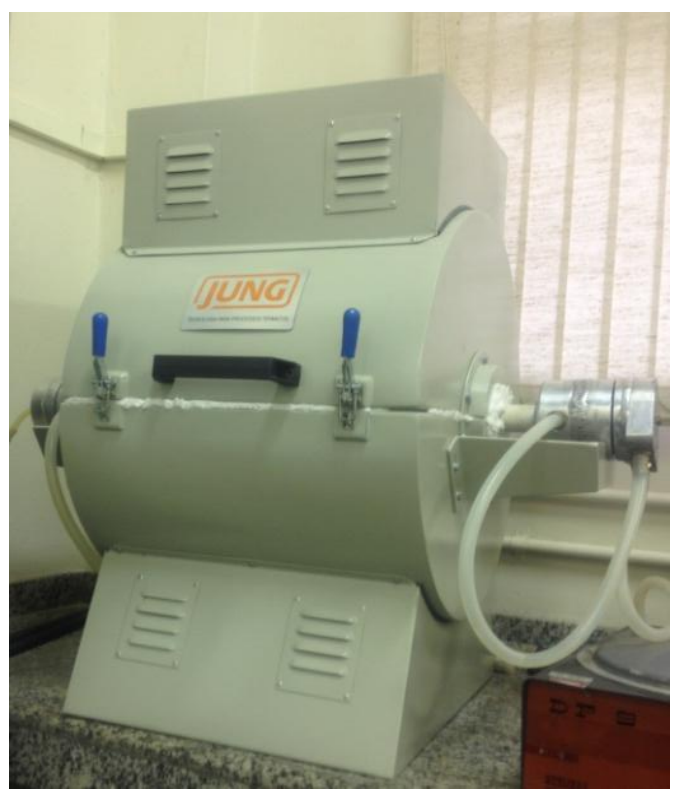

Figura 16 - Forno tubular utilizado para realização do tratamento térmico

O forno foi aquecido a uma taxa de $20^{\circ} \mathrm{C} / \mathrm{min}$ até a temperatura de $1050^{\circ} \mathrm{C}$ e esta temperatura foi mantida por 30 minutos. Após o tempo estipulado o material foi resfriado dentro do forno a uma velocidade de $6^{\circ} \mathrm{C}$ por minuto e mantido dentro do forno até a temperatura ambiente. 


\subsection{Nitretação por plasma}

O tratamento superficial de nitretação por plasma das amostras da liga de Ti-6Al-4V foi realizado no Laboratório de Plasmas e Processos (LPP) do Instituto Tecnológico de Aeronáutica (ITA), em um reator experimental desenvolvido pelo professor Dr. Argemiro S. da Silva Sobrinho. A seguir são descritos os equipamentos utilizados no processo.

\subsubsection{Equipamentos utilizados para a nitretação}

O reator utilizado para os experimentos é constituído de uma câmara hermética de forma cilíndrica com quatro janelas para observação do processo como é mostrado na Figura 17.

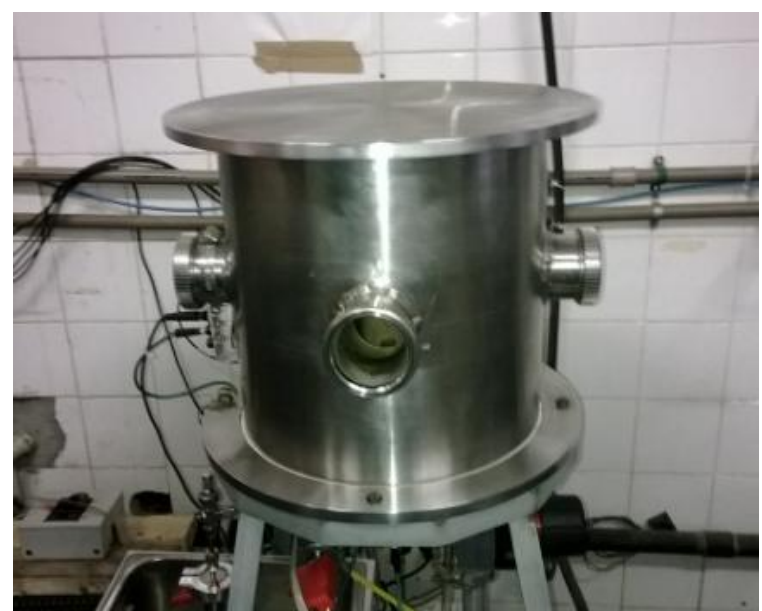

Figura 17 - Reator utilizado para processamento de materiais por plasma.

Para geração do plasma os eletrodos no interior da câmara foram ligados a uma fonte de alimentação CC da marca Supplier, modelo FCC 1000100i, com tensão ajustável de 0 a $1000 \mathrm{~V}$, potência de 10,00 kW e corrente ajustável de 0 a $10 \mathrm{~A}$, conforme é mostrado na Figura 18.

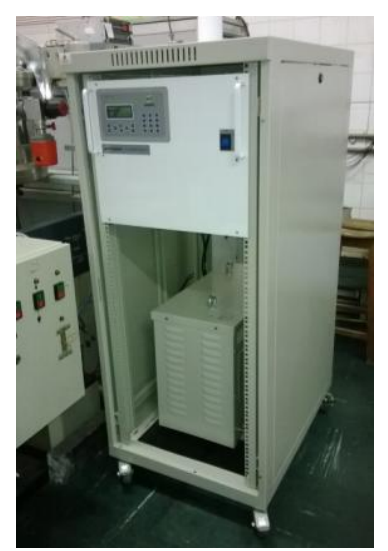

Figura 18 - Fonte CC utilizada para geração do plasma no reator. 
Para redução da pressão interna da câmara foi utilizado um sistema de vácuo constituído por uma bomba de vácuo mecânica rotativa da marca Edwards, modelo E2M18. Ao redor da câmara também existem entradas para conexão de gases, medidores de pressão e termopar. Para o controle da temperatura dentro da câmara foi utilizado um termopar tipo $\mathrm{K}$ conectado ao porta amostra e ligado a um termômetro digital da marca Minipa modelo MT-510.

A leitura da pressão dentro da câmera do reator foi realizada utilizandose um sensor de pressão da marca Edwards. Foram utilizados três tipos de gases dentro do reator, $\mathrm{Ar}, \mathrm{H}_{2}$ e $\mathrm{N}_{2}$, os quais tiveram seu fluxo controlado por um controlador de fluxo de massa de quatro canais da marca MKS Instruments, modelo 247.

Para a nitretação dos corpos de prova de fluência foi necessário o desenvolvimento de um novo porta amostra onde fosse possível fixar todo o material e realizar o tratamento em um único lote. O desenho do porta amostras é mostrado na Figura 19.

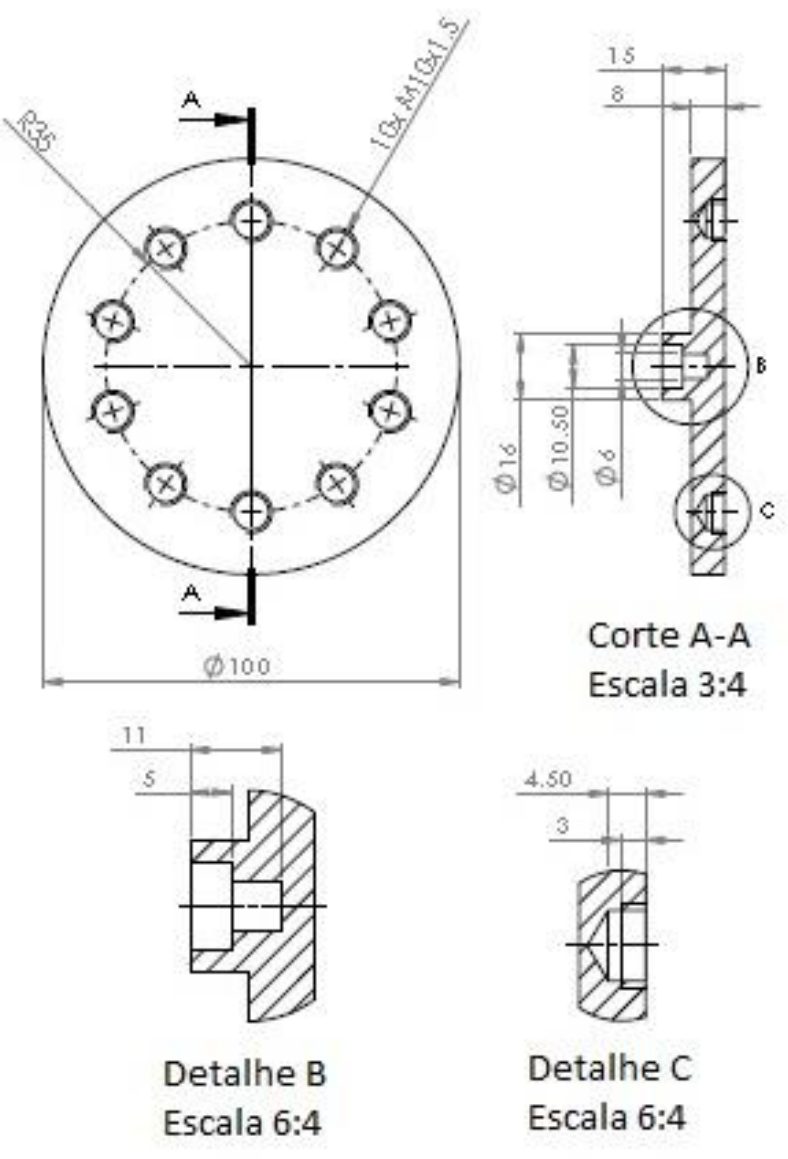

Figura 19 - Desenho do porta amostra utilizado para nitretação. 


\subsubsection{Processo de nitretação}

Foram realizados vários testes para se conseguir um sistema estável o suficiente para começar 0 processo de nitretação propriamente dito. Primeiramente todo o equipamento foi limpo para evitar pontos de descarga elétrica ("arcos") que poderiam desligar o sistema, todas as peças foram lixadas e limpas com álcool isopropílico ou acetona. Para a limpeza e montagem final do equipamento foram utilizadas luvas descartáveis para evitar o contato com qualquer tipo de gordura.

As etapas do processo de nitretação estão descritas no fluxograma da Figura 20 e a imagem deste material sendo nitretado é mostrado na Figura 21.

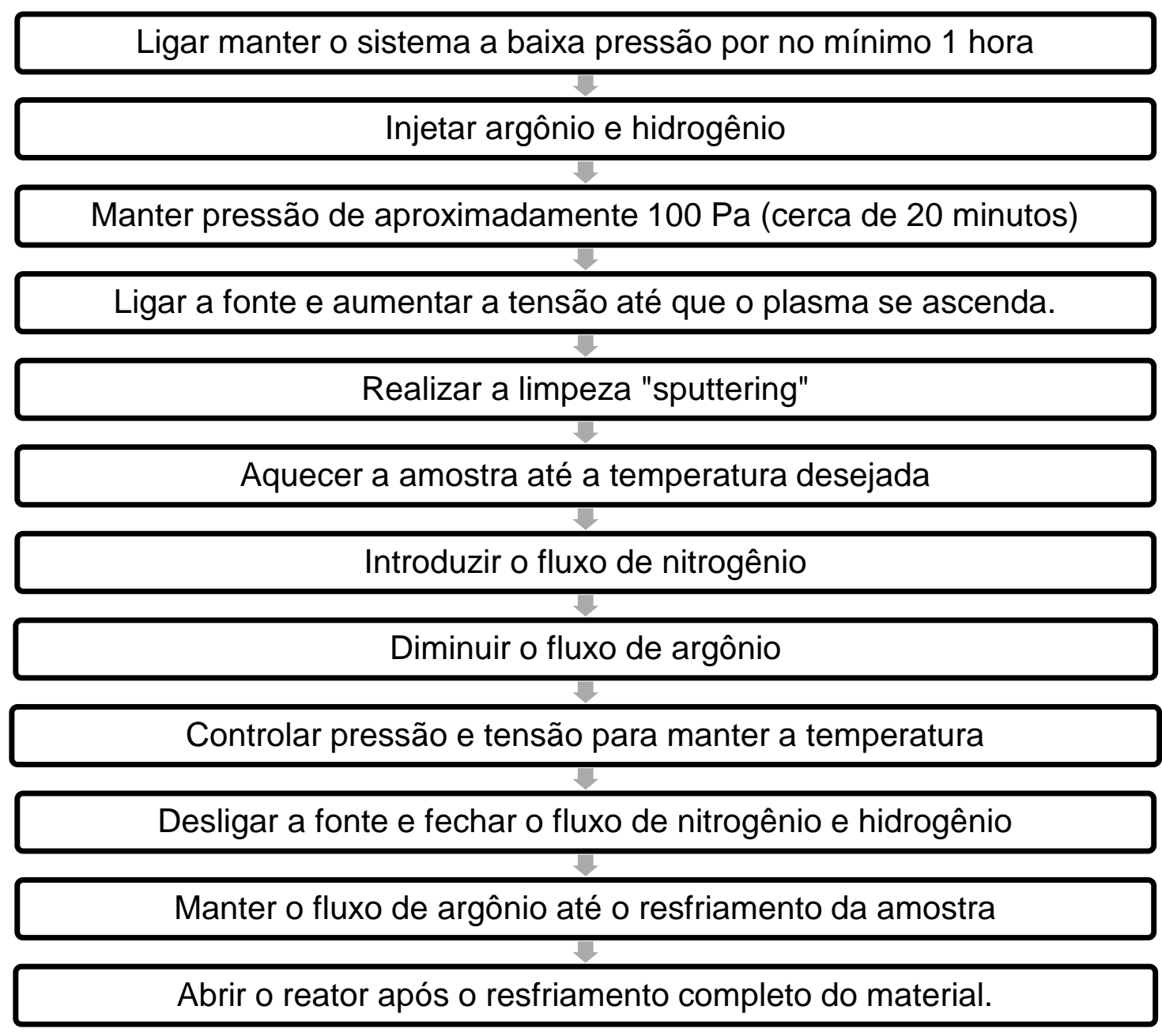

Figura 20 - Fluxograma do processo de nitretação por plasma. 


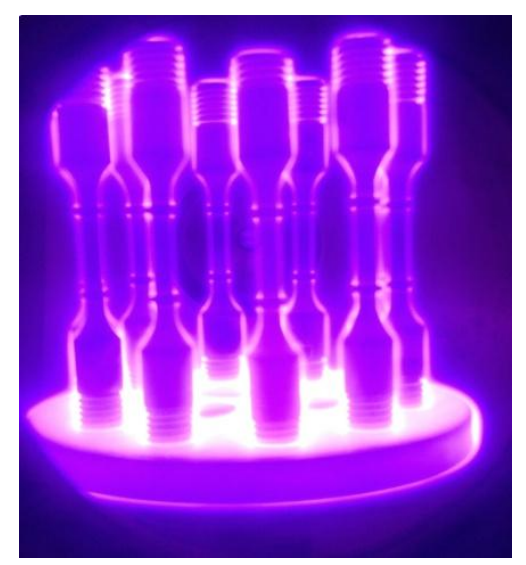

Figura 21 - Imagem dos corpos de prova de fluência sendo nitretados por plasma.

O plasma é gerado aplicando-se uma diferença de potencial entre os eletrodos. No início do processo, enquanto as contaminações estão sendo removida das superfícies a formação de descargas "arcos elétricos" é bastante intensa, sendo necessário um controle da tensão para manter o sistema em funcionamento. No momento que se introduz $\circ \mathrm{N}_{2}$ a temperatura tende a cair, e deve-se aumentar a tensão ou a pressão para manter a temperatura desejada.

$\mathrm{Na}$ Tabela 3 são mostrados os parâmetros utilizados nos principais resultados dos testes realizados para determinar a melhor condição para nitretação dos corpos de prova de fluência. Todas as amostras foram nitretadas por 4 horas. Estes parâmetros tiveram como base valores encontrados na literatura (RAAIF et al., 2007; RAHMAN et al., 2007; LIMA, 2010; HOSSEINI; AHMADI, 2013; POHRELYUK; TKACHUK; PROSKURNYAK, 2013; TANG et al., 2013). O hidrogênio foi adicionado para deixar o plasma mais denso, por melhorar a ionização do mesmo.

Tabela 3 - Parâmetros de Nitretação das amostras

\begin{tabular}{ccccccc}
\hline $\begin{array}{c}\text { Condi- } \\
\text { ção }\end{array}$ & $\begin{array}{c}\text { Temperatura } \\
\left({ }^{\circ} \mathbf{C}\right)\end{array}$ & $\begin{array}{c}\text { Atmosfera } \\
\left(\mathbf{A r} / \mathbf{H}_{\mathbf{2}} / \mathbf{N}_{\mathbf{2}}\right) \\
(\mathbf{s c c m})\end{array}$ & $\begin{array}{c}\text { Pressão } \\
(\mathbf{P a})\end{array}$ & $\begin{array}{c}\text { Tensão } \\
(\mathbf{V})\end{array}$ & $\begin{array}{c}\text { Corrente } \\
(\mathbf{A})\end{array}$ & $\begin{array}{c}\text { Potência } \\
\text { (W) }\end{array}$ \\
\hline $\mathbf{1}$ & $750 \pm 50$ & $50 / 3 / 50$ & $630-760$ & $420-470$ & $1,25-1,52$ & $541-718$ \\
$\mathbf{2}$ & $770 \pm 50$ & $25 / 3 / 75$ & $660-720$ & $440-520$ & $1,24-1,65$ & $543-847$ \\
$\mathbf{3}$ & $720 \pm 50$ & $75 / 3 / 25$ & $500-520$ & $360-480$ & $1,20-1,64$ & $440-786$ \\
\hline
\end{tabular}


Estas amostras foram cortadas ao meio, embutidas, lixadas e polidas para observação no microscópio ótico (MO) e eletrônico de varredura (MEV) e a outra parte de cada uma das amostras foi utilizada para a análise de difração de raios $X(D R X)$. Após análises destes resultados foi definida a condição 1 como a melhor para nitretação dos corpos de prova de fluência.

Devido ao volume maior de peças, para conseguir estabilizar o plasma, a temperatura de nitretação dos corpos de prova de fluência ficou um pouco menor do que a do primeiro teste. A Tabela 4 mostra o resumo dos valores médios utilizados para o processo de nitretação dos corpos de prova.

Tabela 4 - Parâmetros utilizados na nitretação dos corpos de prova de fluência.

\begin{tabular}{cc}
\hline Parâmetros & Faixa \\
\hline Temperatura $\left({ }^{\circ} \mathrm{C}\right)$ & $690 \pm 50$ \\
Atmosfera $\left(\mathrm{Ar} / \mathrm{H}_{2} / \mathrm{N}_{2}\right)(\mathrm{sccm})$ & $50 / 10 / 50$ \\
Pressão (Pascal) & $300-550$ \\
Tensão (V) & $360-590$ \\
Corrente (A) & $1,8-2,6$ \\
Potência (W) & $840-1410$ \\
\hline
\end{tabular}

\subsection{Ensaio de tração a quente}

Os ensaios de tração a quente foram realizados no Laboratório de Ensaios Mecânicos do IPEN-USP conforme a norma ASTM E-21(AMERICAN SOCIETY FOR TESTING AND MATERIALS (ASTM), 2009). Foi utilizada uma máquina universal de ensaios Instron modelo 4400R acoplada a um forno vertical circular com temperatura controlada por zonas. O controle da temperatura de ensaio foi feito utilizando-se dois termopares do tipo Cromel-Alumel encostados nos limites da seção reduzida dos corpos-de-prova. O software Instron Series IX versão 7.5 foi utilizado para aquisição dos dados. Os ensaios foram executados nas temperaturas de $500^{\circ} \mathrm{C}, 600^{\circ} \mathrm{C}$ e $700^{\circ} \mathrm{C}$ com velocidade de deslocamento do travessão de $0,5 \mathrm{~mm} / \mathrm{min}$ na condição nitretada e sem nitretação, ambas com microestrutura Widmanstätten. 


\subsection{Ensaio de Fluência}

O equipamento utilizado para realização dos ensaios de fluência pertence ao Laboratório de Fluência do Instituto Tecnológico de Aeronáutica ITA/DCTA é mostrado na Figura 22. Os fornos da marca MAYES possuem sistemas elétricos e controladores segundo as exigências da norma ASTM E-139 (AMERICAN SOCIETY FOR TESTING AND MATERIALS (ASTM), 2011).

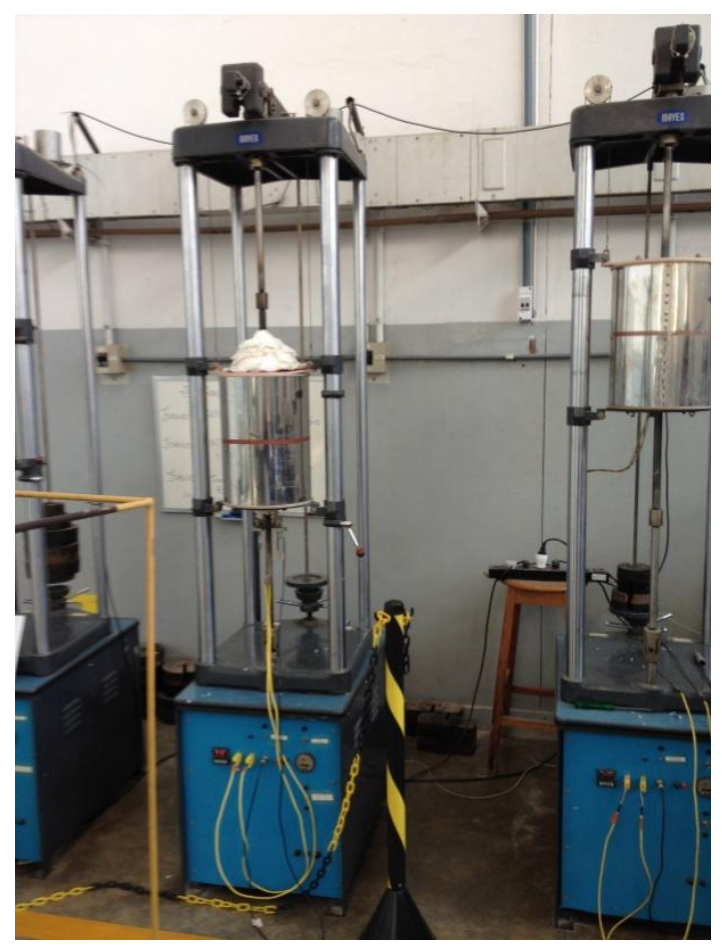

Figura 22 - Equipamento utilizado para realização dos ensaios de fluência.

O software Antares foi utilizado para a coleta dos dados relativos ao alongamento dos corpos de prova e as medidas de temperatura em períodos de tempo pré-determinados. Um transdutor diferencial variável linear (LVDT) da marca Schlumberger foi utilizado para a obtenção das medidas de alongamento e dois termopares tipo Cromel-Alumel AWG24 foram utilizados para o controle de temperatura.

A faixa de temperatura ideal para que ocorra o fenômeno de fluência é de 0,4 a 0,7 da temperatura absoluta de fusão do material (CALLISTER; RETHWISCH, 2012), que para a liga Ti-6Al-4V é de aproximadamente $1.655^{\circ} \mathrm{C}$ ou 1.928 K (BOYER; COLLINGS; WELSCH, 1993). Portanto as temperaturas definidas para os ensaios foram $500^{\circ} \mathrm{C}\left(0,40 \mathrm{~T}_{f}\right), 600^{\circ} \mathrm{C}\left(0,45 \mathrm{~T}_{\mathrm{f}}\right)$ e $700^{\circ} \mathrm{C}(0,50$ $\left.T_{f}\right)$. 
A faixa de tensão definida para os ensaios foi entre $125 \mathrm{MPa}$ e 319 MPa. A tensão de $125 \mathrm{MPa}$ foi definida para que não ocorresse uma predominância do estágio primário da fluência em detrimentos dos demais estágios e para que o tempo de ensaio não superasse mais que 2.000 horas. A tensão de $319 \mathrm{MPa}$ foi definida a baixo do limite de escoamento do material a $600^{\circ} \mathrm{C}$ para não alterar a extensão dos estágios de fluência. (BRIGUENTE, 2015).

Foi aplicada uma pré-carga correspondente a $10 \%$ da carga total por um período de $1 \mathrm{~h}$ para alinhamento do sistema. Durante este período foi ajustado o LVDT. Após ser acrescentada a carga total para o ensaio foi registrado o início do ensaio. A temperatura e a carga aplicada foram mantidas constantes durante todo o ensaio até a ruptura do corpo de prova.

Para testar o efeito da nitretação por plasma foi realizado um ensaio preliminar a $600^{\circ} \mathrm{C}$ e $250 \mathrm{MPa}$. Após o resultado positivo deste ensaio, os demais corpos de prova foram nitretados em um único lote e os parâmetros utilizados nestes ensaios estão descritos na Tabela 5.

Tabela 5 - Parâmetros utilizados para os ensaios de fluência

\begin{tabular}{cccc}
\hline Condições & Temperatura (ㅇ) & Relação com $\mathbf{T}_{\mathbf{f}}$ & Tensão $(\mathbf{M P a})$ \\
\hline 1 & & & 250 \\
2 & 600 & $\mathrm{~T} \cong 0,3$ & 319 \\
3 & & & 125 \\
\hline 4 & 500 & $\mathrm{~T} \cong 0,36$ & 319 \\
\hline 5 & 700 & $\mathrm{~T} \cong 0,42$ & 319 \\
\hline
\end{tabular}

\subsection{Caracterização do material}

\subsubsection{Análise microestrutural por Microscopia}

Após a preparação metalográfica (embutimento, lixamento e polimento com sílica coloidal), foi feito o ataque químico utilizando um reagente com $5 \mathrm{~mL}$ de $\mathrm{HNO}_{3}, 3 \mathrm{~mL}$ de $\mathrm{HF}$ e $100 \mathrm{~mL}$ de água destilada.

As amostras foram analisadas por Microscopia óptica (MO) e eletrônica de varredura (MEV). 
Os equipamentos utilizados para caracterização da microestrutura e também da camada de nitretos, no caso das amostras nitretadas foram um microscópio óptico da marca Olympus (modelo BX 60), com sistema de captura de imagem digital e um microscópio eletrônico de varredura (MEV) da marca Philips (modelo XL-30), com sistema EDS da marca Edax, ambos pertencentes ao Centro de Ciência e Tecnologia de Materiais (CCTM) do IPEN-USP.

\subsubsection{Análise por Difração de Raios X}

As análises foram feitas num difratômetro de raios $X$ da marca Rigaku e modelo Multiflex, pertencente ao IPEN-USP, utilizando radiação CuKa (comprimento de onda $\lambda$ de 1,542 $\AA$ ), varrendo uma faixa de ângulos de 25 a $80^{\circ}$, com uma velocidade de $2^{\circ}$ por minuto e passo de 0,02 . Calcularam-se então as distâncias interplanares (d) dos planos difratados das amostras por meio da Lei de Bragg, $\mathrm{n} \lambda=2$.d. $\operatorname{sen} \theta$, e comparou-se com o arquivo JCPDS (Joint Committee on Powder Diffraction Standards) identificando as fases presentes. 


\section{DISCUSSÃO DOS RESULTADOS}

\subsection{Tratamento térmico}

Devido aos diferentes resultados de resistência a fluência para as diversas microestruturas da liga Ti-6Al-4V encontrados na literatura (CORTEZ et al., 2007; YOGI; SUGAHARA, 2008; DE MELO; REIS; MOURA NETO, 2009; SUGAHARA et al., 2009, 2010; OLIVEIRA, 2010; BRIGUENTE, 2011, 2015; REIS, 2012; CABESTRÉ, 2013), ficou clara a necessidade de um tratamento térmico de todo o material para homogeneização e obtenção da microestrutura de Widmanstätten para realizar a nitretação e subsequentemente os ensaios de fluência.

\subsubsection{Caracterização da microestrutura do material}

Para caracterização da microestrutura obtida no tratamento térmico foram realizadas imagens das amostras por MO. Na Figura 23 são apresentadas imagens da microestrutura equiaxial com grãos menores antes do tratamento térmico (a) e Widmanstätten, estrutura lamelar onde a fase a está localizada na região clara, obtida após o tratamento (b). 


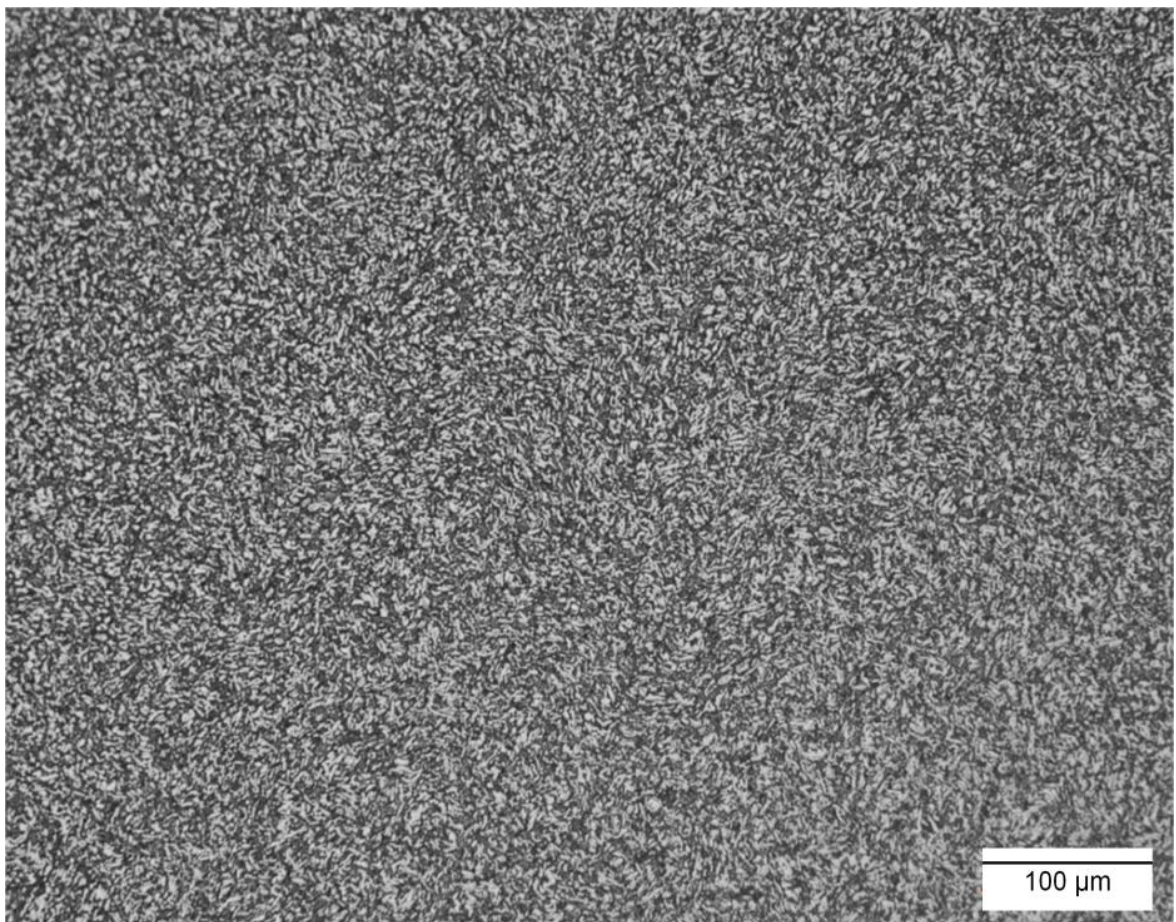

(a)

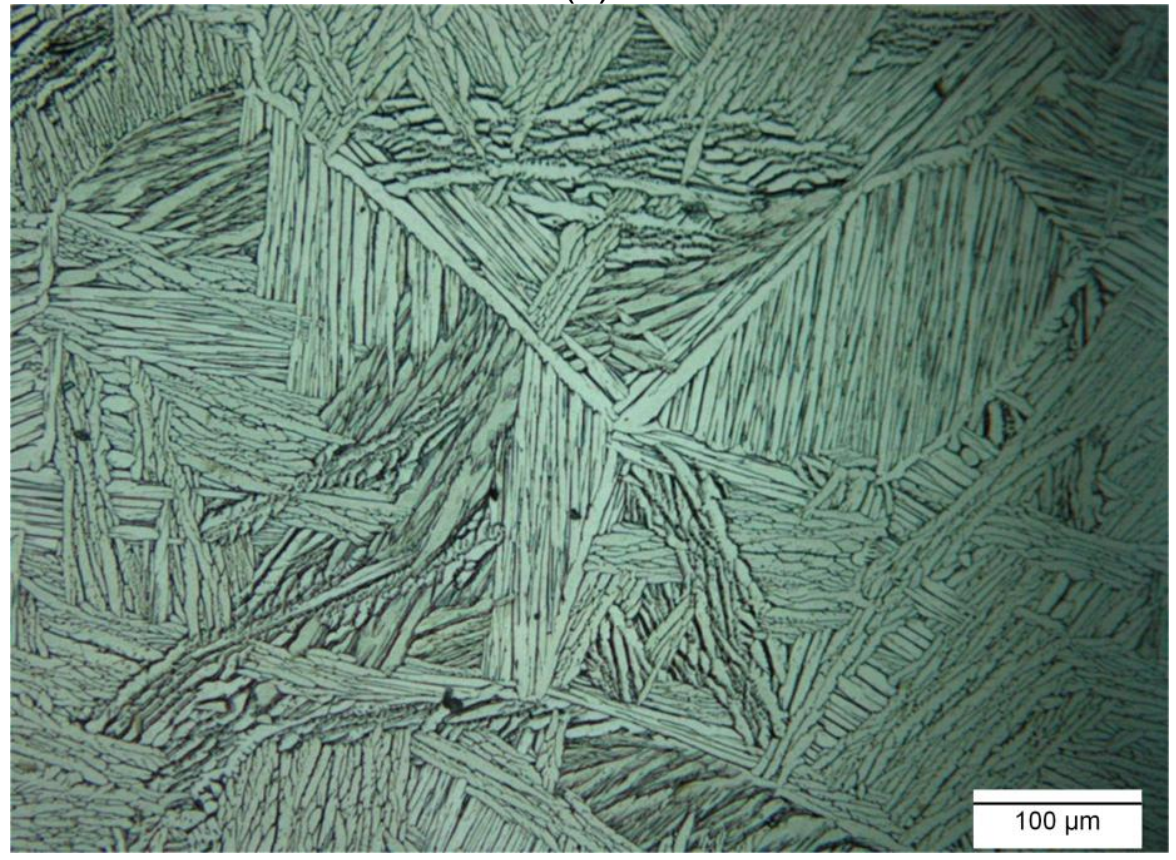

(b)

Figura 23 - Microestrutura da liga Ti-6Al-4V (a) antes e (b) depois do tratamento térmico.

\subsection{Caracterização da camada nitretada}

Para caracterização da camada nitretada foram analisadas imagens das amostras por MO e MEV e realizada a DRX para identificação dos compostos presentes na camada. Após esta caracterização, foi escolhida a melhor condição para realizar a nitretação dos corpos de prova de fluência. 
As amostras que foram nitretadas por plasma com diferentes teores de $\mathrm{N}_{2}$ (50 sccm, 25 sccm e $75 \mathrm{sccm}$ ) apresentaram colorações diferentes de nitretos conforme mostrado na Figura 24 que identifica as amostras pela quantidade de $\mathrm{N}_{2}$ na atmosfera.

50

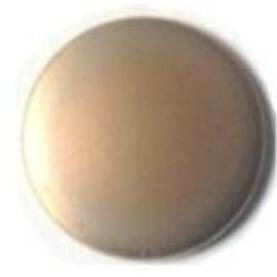

(a)
25

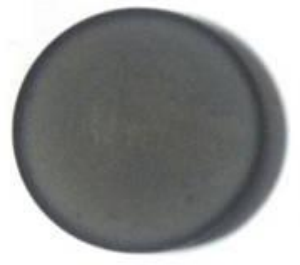

(b)

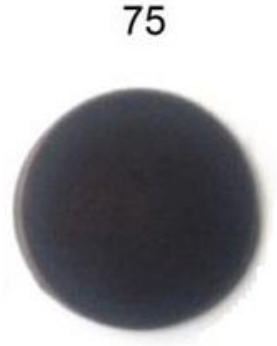

(c)

Figura 24 - Fotografia das amostras nitretadas com diferentes teores de $\mathrm{N}_{2}$ (a) com $50 \%$ (b) com $25 \%$ e (c) com $75 \%$ de $\mathrm{N}_{2}$ na atmosfera nitretante.

Segundo Roquiny é possível associar as cores deste tipo de nitreto e relacionando-as com a estequiometria da camada de $\mathrm{Ti}_{\mathrm{x}} \mathrm{N}_{\mathrm{y}}$. $\mathrm{O}$ dourado indica um valor do padrão estequiométrico (1:1), o cinza abaixo do valor estequiométrico e o vermelho acima (ROQUINY; BODART; TERWAGNE, 1999). As análises de DRX foram realizadas para confirmar os nitretos formados em cada uma das amostras.

\subsubsection{Microscopia Óptica (MO) e Eletrônica de Varredura (MEV)}

A espessura da camada na amostra 1 , nitretada por 4 horas a $750^{\circ} \mathrm{C}$ em uma atmosfera de $50 \%$ de $\mathrm{N}_{2}$ é de aproximadamente $12 \mu \mathrm{m}$, conforme mostrado na

Figura 25 por $\mathrm{MO}$ e na

Figura 26 por MEV. 


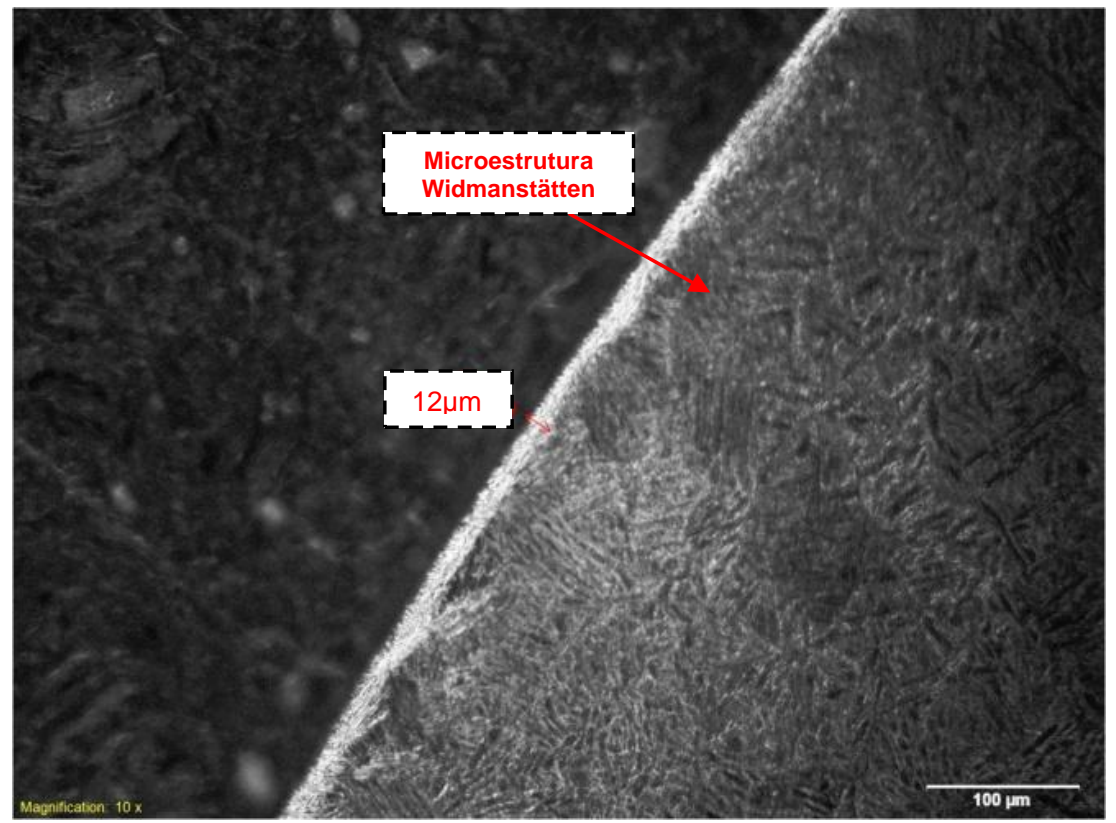

Figura 25 - Micrografia óptica em campo escuro da amostra de Ti-6Al-4V nitretada por plasma.

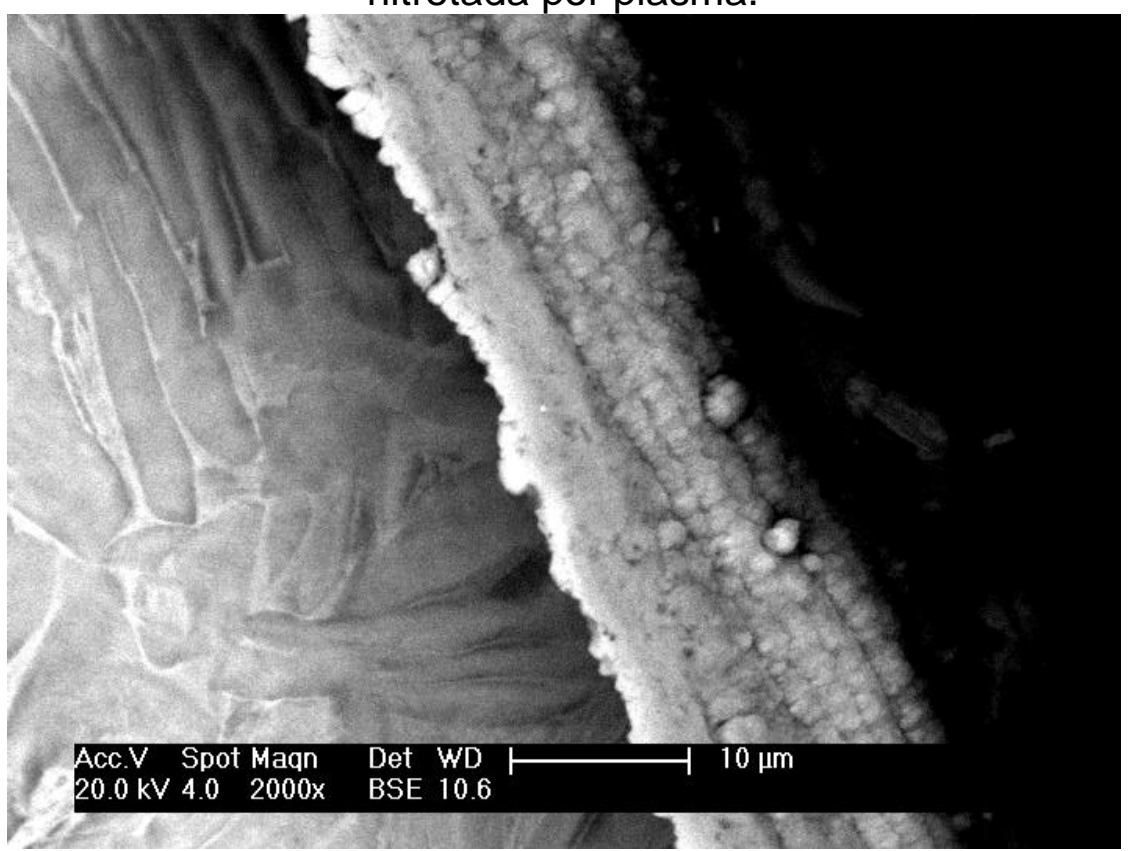

Figura 26 - Micrografia da liga Ti-6Al-4V observada por MEV utilizando elétrons secundários.

Para os corpos de prova de fluência não foi possível atingir uma camada de nitreto com a mesma espessura da primeira amostra, devido a maior quantidade de material e maior tamanho da peça, foi necessário reduzir a temperatura de nitretação de 750 para $690^{\circ} \mathrm{C}$. Os 10 corpos de prova foram nitretados em um único lote por 4 horas em uma atmosfera de $50 \%$ de $\mathrm{N}_{2}$ e a espessura da camada nitretada foi de aproximadamente $1 \mu \mathrm{m}$, conforme é mostrado na Figura 27. 


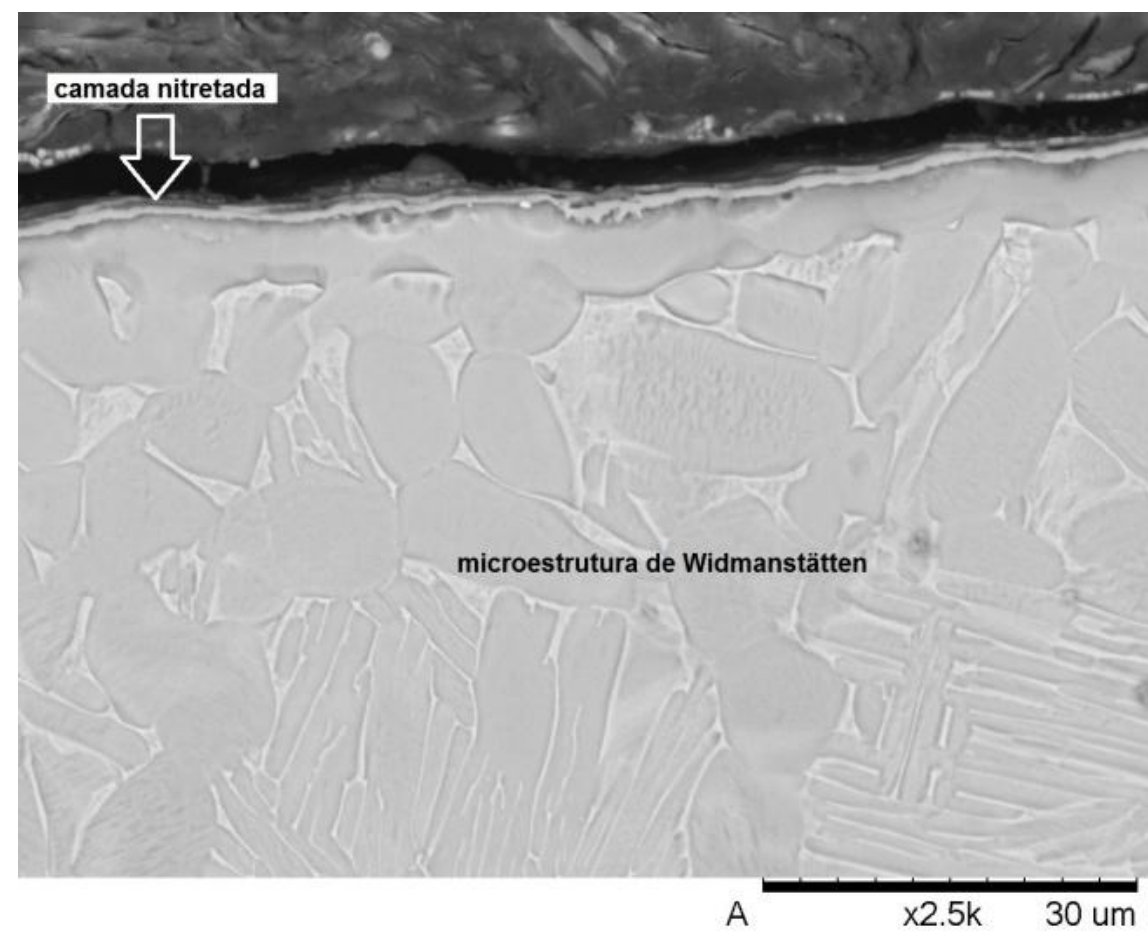

Figura 27 - Micrografia da liga Ti-6Al-4V observada por MEV.

Ao observar a camada nitretada só é possível identificar uma fase presente (cinza mais escuro), isso pode ser explicado devido ao nitrogênio ser um elemento estabilizador da fase $\alpha$ que pode ter causado um envelopamento formando assim uma camada contínua.

A formação desta camada superficial de nitretos gerou uma tensão superficial compressiva que deve ter contribuído para o aumento da resistência do material à fluência. Resultados semelhantes já foram discutidos por outros autores em relação ao aumento da resistência a fadiga desta liga (RAJASEKARAN; RAMAN, 2008; MORITA; ASAKURA; KAGAYA, 2014).

Outro fator importante associado à formação desta camada é a de que ela pode agir como barreira para difusão do oxigênio no material, contribuindo para o aumento da resistência à fluência (PÉREZ, 2005; OLIVEIRA et al., 2014).

\subsubsection{Difração de Raios X}

A Figura 28 apresenta a análise por DRX realizada na amostra como recebida. Nesta figura são indexados os picos de difração com as fases presentes, fase $\alpha$ (JCPDS 44-1294) e fase $\beta$ (JCPDS-44-1288), mesma ficha identificada por diversos autores (DA SILVA et al., 1999; FOUQUET et al., 2004a; FERNANDES et al., 2006; RAHMAN et al., 2007; LIMA, 2010). 


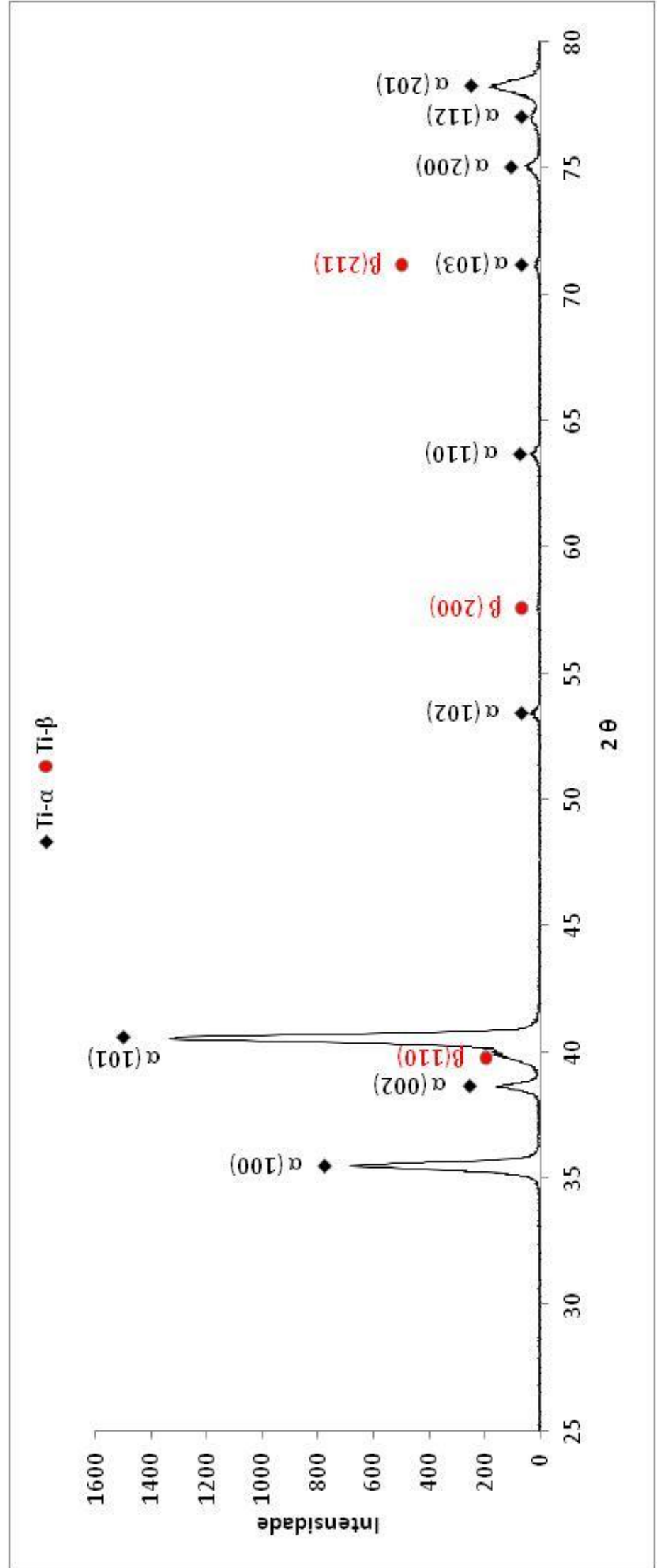

Figura 28 - Difratograma de raios $X$ da amostra como recebida. 
As análises de difração de raios $X$ das amostras nitretadas são mostradas nas figuras 29 a 31 . Além das fases $\alpha$ e $\beta$ detectadas na amostra como recebida (figura 28), observou-se em todas as amostras nitretadas a $750^{\circ} \mathrm{C} \mathrm{com}$ teores de $\mathrm{N}_{2}$ de 25, 50 e 75\% a presença das fases $\mathrm{Ti}_{2} \mathrm{~N}$ (JCPDS 17-0386) com estrutura tetragonal, (fase $\varepsilon$ ), TiN (JCPDS 38-1420) com estrutura cúbica de face centrada (fase $\delta$ ) (MOLARIUS, 1985) e VO (JCPDS 77-2173) com estrutura cúbica simples. A formação destes mesmos nitretos também foi confirmada em outros trabalhos da literatura (FOUQUET et al., 2004a; FERNANDES et al., 2006; LIMA, 2010).

A presença do óxido de vanádio (VO) pode ser explicada devido à presença de até $0,2 \%$ em massa de oxigênio na composição da liga e também a camada de óxido formada na superfície à temperatura ambiente. Parte deste oxigênio pode ser removida fisicamente por pulverização catódica no plasma durante o processo, porém uma parte pode se difundir na superfície na temperatura de tratamento utilizada (BRADING et al., 1992). 


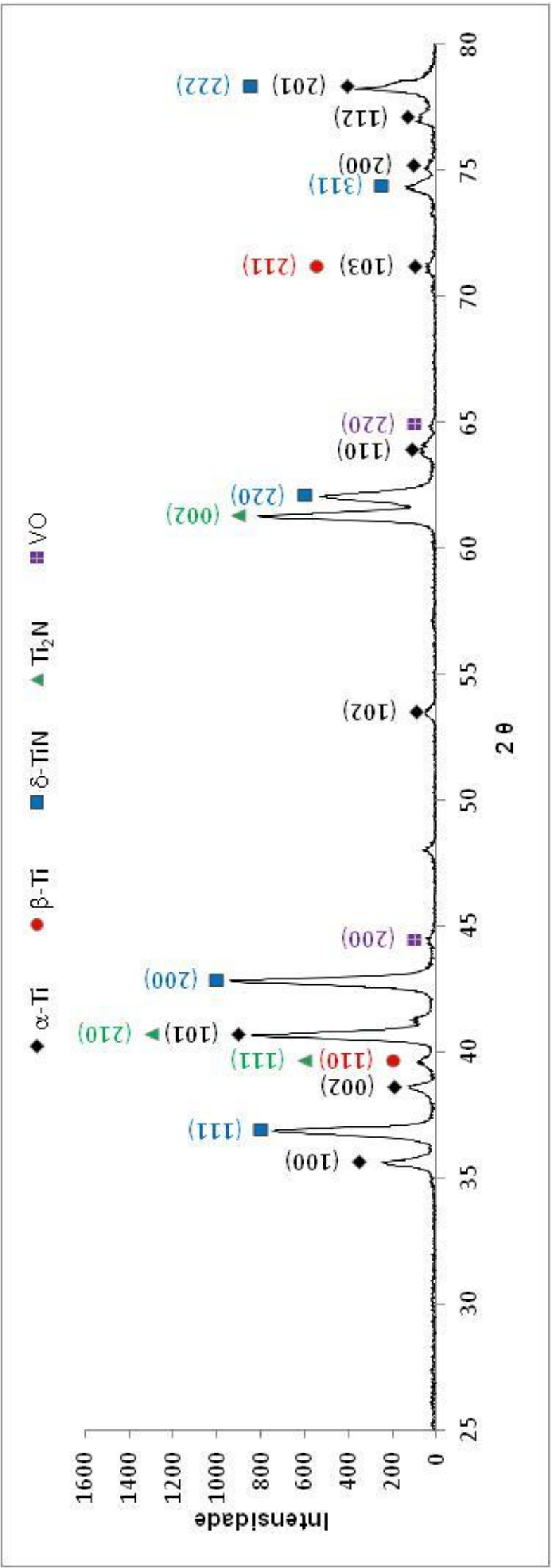

Figura 29 - Difratograma de raios $X$ da amostra tratada por nitretação por plasma em atmosfera com $25 \%$ de $\mathrm{N}_{2}$. 


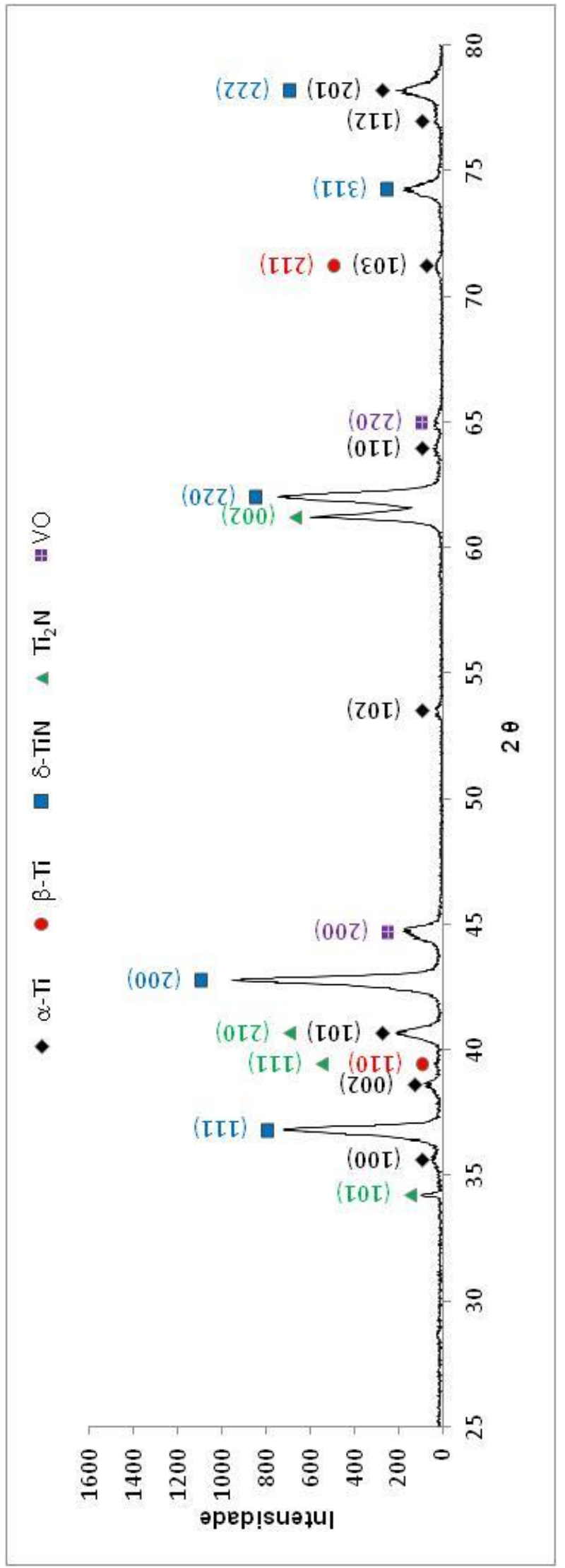

Figura 30 - Difratograma de raios $\mathrm{X}$ da amostra tratada por nitretação por plasma com atmosfera com $50 \%$ de $\mathrm{N}_{2}$. 


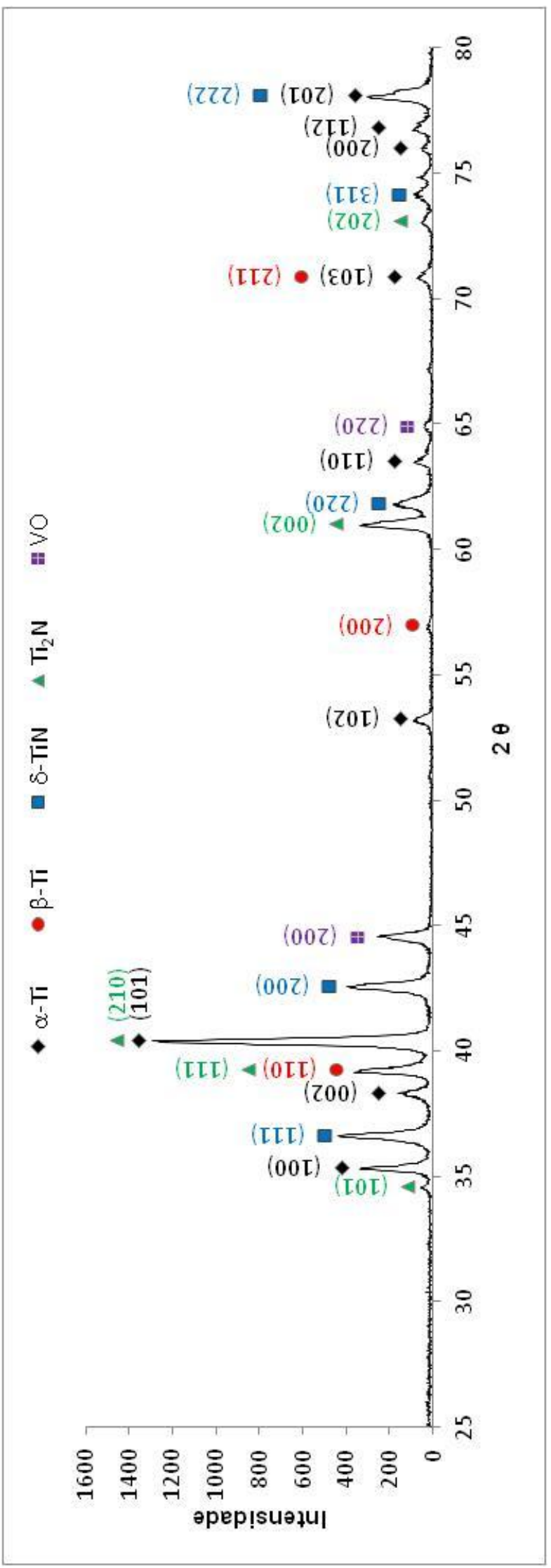

Figura 31 - Difratograma de raios $X$ da amostra tratada por nitretação por plasma com atmosfera com $75 \%$ de $\mathrm{N}_{2}$. 
No difratograma da Figura 29Erro! Fonte de referência não encontrada., pode ser observado aumento na intensidade do pico de $\mathrm{Ti}_{2} \mathrm{~N}$ referente à reflexão (002) comparada com as suas demais reflexões, o que indica que existe uma orientação cristalográfica preferencial, o mesmo foi observado por Brading et al (1992) em nitretações a temperaturas elevadas, acima de $700^{\circ} \mathrm{C}$. Para a fase $\mathrm{Ti}_{2} \mathrm{~N}$, o plano (111) é coincidente com o plano (110) da fase $\beta$ e o plano (210) coincidente com o plano (002) da fase $\alpha$. Para o TiN, os picos identificados foram referente às reflexões (111), (200), (220), (311) e (222) que é coincidente com o pico referente à reflexão (201) da fase $\alpha$.

Rahman et al também observaram em temperaturas acima de $700^{\circ} \mathrm{C}$ os planos de difração (111) e (200) da fase $\delta$-TiN rica em $N_{2}$ (RAHMAN et al., 2007).

Na figura 30 pode-se observar uma redução mais acentuada dos picos de maior intensidade de reflexão da fase $\alpha,(100)$ e (101), amostra nitretada com $50 \%$ de $\mathrm{N}_{2}$, provavelmente devido a maior espessura de camada de nitretos comparada com as outras amostras nitretadas.

Nas amostras nitretadas em atmosfera com 25 e 75\% de $\mathrm{N}_{2}$ (Figura 29 e 31 respectivamente) o pico observado referente à reflexão (002) da fase $\mathrm{Ti}_{2} \mathrm{~N}$ é mais intenso do que na amostra com 50\% de $\mathrm{N}_{2}$ (figura 30). Uma maior intensidade do pico observado referente à reflexão (220) da fase TiN parece indicar uma quantidade maior deste composto na amostra, explicando a sua coloração dourada, típica deste nitreto.

Somente na amostra nitretada com 75\% de $\mathrm{N}_{2}$ (Figura 31) foi identificado o pico referente à reflexão (202) característico da fase $\mathrm{Ti}_{2} \mathrm{~N}$. Nesta mesma amostra, o pico referente à reflexão (210) aparece com grande intensidade e apesar de ser coincidente com o pico referente à reflexão (101) da fase $\alpha$, nota-se que a sua intensidade aumentada deve ser devido à presença do $\mathrm{Ti}_{2} \mathrm{~N}$. Supõe-se que esta amostra tem uma maior quantidade de $\mathrm{Ti}_{2} \mathrm{~N}$ em relação à quantidade de TiN.

Para a fase $\mathrm{Ti}_{2} \mathrm{~N}$ foram identificados os picos referentes às reflexões dos planos (101), (111), (210) e (002). O plano (111) é coincidente com o (110) da fase $\beta$ e o plano (210) com (101) da fase $\alpha$. Os picos identificados para o TiN foram (111), (200), (220) e (311), além do plano (222) que é coincidente com o (201) da fase $\alpha$. 
$\mathrm{Na}$ amostra nitretada por plasma em uma atmosfera com $50 \%$ de $\mathrm{N}_{2}$, difratograma mostrado na Figura 30, para a fase $\mathrm{Ti}_{2} \mathrm{~N}$ foram identificados os picos referente às reflexões dos planos (101), (002) e também (111) que é coincidente com o plano (110) da fase $\beta$ e o (210) que é coincidente com o plano (101) da fase $\alpha$. Os picos identificados referentes às reflexões para o TiN foram dos planos (111), (200), (220) e (311) além do (222) que é coincidente com o pico (201) da fase $\alpha$.

A intensidade do pico referente à reflexão (002) da fase $\alpha-\mathrm{Ti}$ permaneceu praticamente constante nas amostras nitretadas com diferentes teores de $\mathrm{N}_{2}$, ao passo que a reflexão (100) da fase $\alpha$-Ti diminui, sobretudo com o aumento do TiN indica claramente a maior dificuldade para nitretação dos grãos da fase $\alpha$-Ti dos planos basais paralelos à superfície, indicando que o coeficiente de difusão paralelo ao eixo a é conhecidamente maior do que para o eixo c (FOUQUET et al., 2004a). O pico de maior intensidade relativa nas amostras com 25 e $50 \%$ de $\mathrm{N}_{2}$ observado foi referente à reflexão (200) da fase $\delta$-TiN, resultados coerentes com Lakshmi et al. (LAKSHMI; ARIVUOLI; GANGULI, 2002)

A Figura 32 mostra o difratograma de raios $X$ do corpo de prova de fluência nitretada por plasma com atmosfera de $50 \%$ de $\mathrm{N}_{2}$. O alargamento dos picos sugere um maior número de defeitos cristalinos na rede.

Neste difratograma (Figura 32) não foi possível identificar a fase $\beta$ do titânio. Esta dificuldade em identificar é comum nas ligas de titânio quando a fase $\alpha$ também está presente. O plano de reflexão mais intenso da fase da fase $\beta$ (110) tem posição coincidente a um plano de reflexão da fase a (002), mascarando o resultado. Como a quantidade de fase $\beta$ na liga é relativamente pequena e as outras reflexões não coincidentes são de baixa intensidade, fica praticamente impossível garantir a presença da fase $\beta$ somente pela análise por difração de raios X (COUTO et al., 2006; ALMEIDA, 2007). A presença de VO também não foi observada, provavelmente pela redução da quantidade formada deste óxido devido ao pequeno aumento da quantidade de hidrogênio na atmosfera nitretante de 3 para $10 \mathrm{sccm}$. 


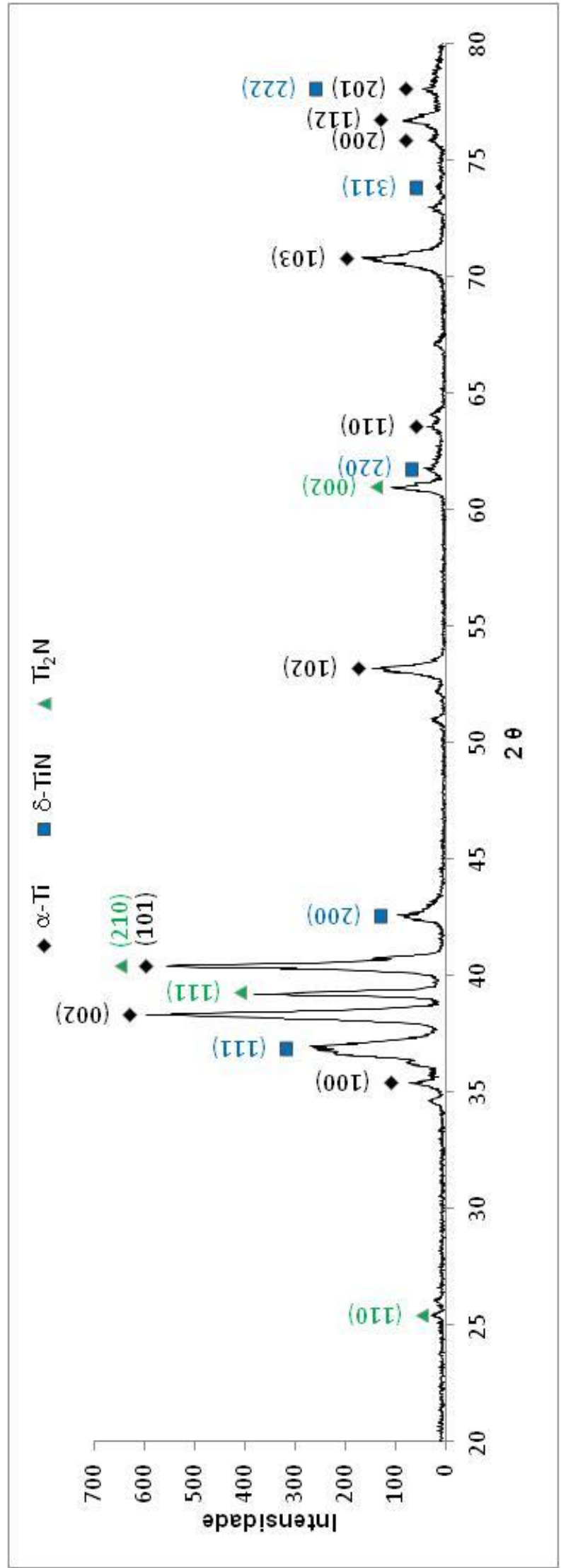

Figura 32 - Difratograma de raios $X$ da amostra tratada por nitretação por plasma com atmosfera com $50 \%$ de $\mathrm{N}_{2}$ (lote dos corpos de prova). 
Em todos os difratogramas (Figuras 28 a 32) observa-se um deslocamento dos picos de Ti-a em relação ao padrão do titânio puro. Este deslocamento é justificado pela presença dos outros elementos químicos da liga, o alumínio e o vanádio.

\subsection{Ensaios de tração a quente}

Os ensaios de tração a quente foram realizados nos corpos de prova da liga Ti-6Al-4V com microestrutura de Widmanstätten nas condições com e sem tratamento superficial de nitretação por plasma.

A Tabela 6 apresenta um resumo dos valores relativos ao limite de escoamento $\left(\sigma_{e}\right)$, limite de resistência $\left(\sigma_{\text {máx }}\right)$, alongamento percentual $\left(A_{p}\right)$ e redução percentual em área (\%RA) para a liga Ti-6Al-4V com e sem tratamento superficial. $O$ ensaio de tração a quente foi realizado para determinação dos parâmetros de tensão e temperatura dos ensaios de fluência.

Tabela 6 - Resultados dos testes de tração a quente.

\begin{tabular}{cccccc}
\hline Temperatura & Condição & $\sigma_{\mathbf{e}}(\mathbf{M P a})$ & $\sigma_{\text {máx }}(\mathbf{M P a})$ & $\mathbf{A}_{\mathbf{p}}(\%)$ & $\mathbf{R A}(\%)$ \\
\hline \multirow{2}{*}{$500^{\circ} \mathrm{C}$} & Sem nitretação & 525 & 576 & 8 & 23,3 \\
& Com nitretação & 679 & 741 & 8 & 40,4 \\
\hline \multirow{2}{*}{$600^{\circ} \mathrm{C}$} & Sem nitretação & 419 & 434 & 9 & 26,9 \\
& Com nitretação & 532 & 587 & 10 & 22,5 \\
\hline \multirow{2}{*}{$700^{\circ} \mathrm{C}$} & Sem nitretação & 281 & 302 & 14 & 51,8 \\
& Com nitretação & 337 & 370 & 16 & 49,0 \\
\hline
\end{tabular}

A Tabela 7 mostra os valores encontrados na literatura para a liga Ti6Al-4V na condição recozido, ou seja, sem o tratamento térmico e não nitretada.

Tabela 7 - Propriedades mecânicas de tração da liga Ti-6Al-4V a temperatura ambiente.

\begin{tabular}{ccccc}
\hline Condição & $\sigma_{\mathrm{e}}(\mathrm{MPa})$ & $\sigma_{\operatorname{máx}}(\mathrm{MPa})$ & $\mathbf{A}_{\mathbf{p}}(\%)$ & $\mathbf{R A}(\%)$ \\
\hline Recozido & $830-924$ & $900-993$ & 14 & 30 \\
\hline Fonte: Adaptado de (ASM INTERNATIONAL, 2001)
\end{tabular}

Fonte: Adaptado de (ASM INTERNATIONAL, 2001) 
Comparando os valores obtidos nos ensaios, houve um aumento significativo no limite de escoamento e no limite de resistência para a condição nitretada. No limite de escoamento o aumento foi de $56 \mathrm{MPa}$ para o teste realizado a $700^{\circ} \mathrm{C}$ e $154 \mathrm{MPa}$ para o realizado a $500^{\circ} \mathrm{C}$, o que representou um ganho de 20 e $29 \%$, respectivamente. No limite de resistência os aumentos foram de $68 \mathrm{MPa}$ para o teste realizado a $700^{\circ} \mathrm{C}$ e $165 \mathrm{MPa}$ para o realizado a $500^{\circ} \mathrm{C}$, o que representou um ganho de 23 e $29 \%$, respectivamente. Já os resultados de alongamento percentual e redução de área não indicaram claramente um efeito devido à nitretação.

O aumento da temperatura do ensaio, em geral provoca uma diminuição na resistência do material (DIETER, 1988), isso pode ser confirmado neste caso, observando tanto a redução do limite de escoamento mostrado na Figura 33, quanto do limite de resistência mostrado na Figura 34.

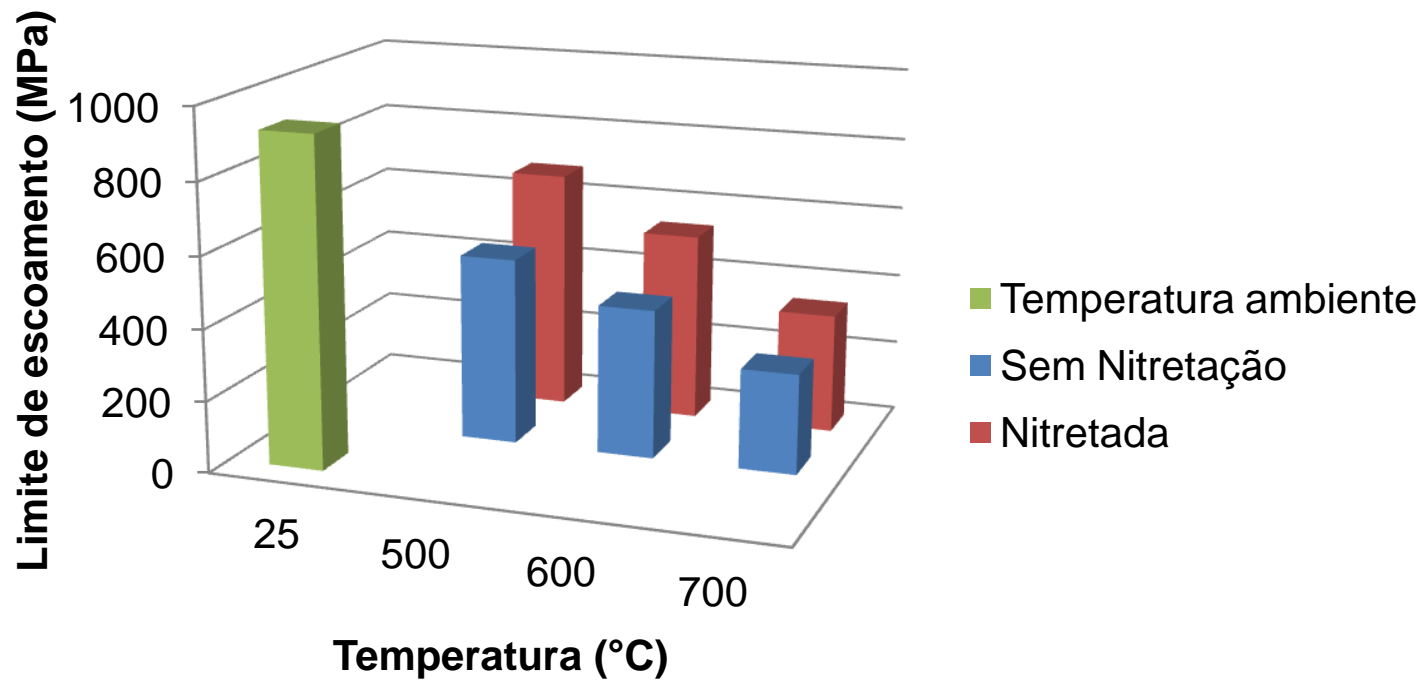

Figura 33 - Influência da temperatura no limite de escoamanto do material 


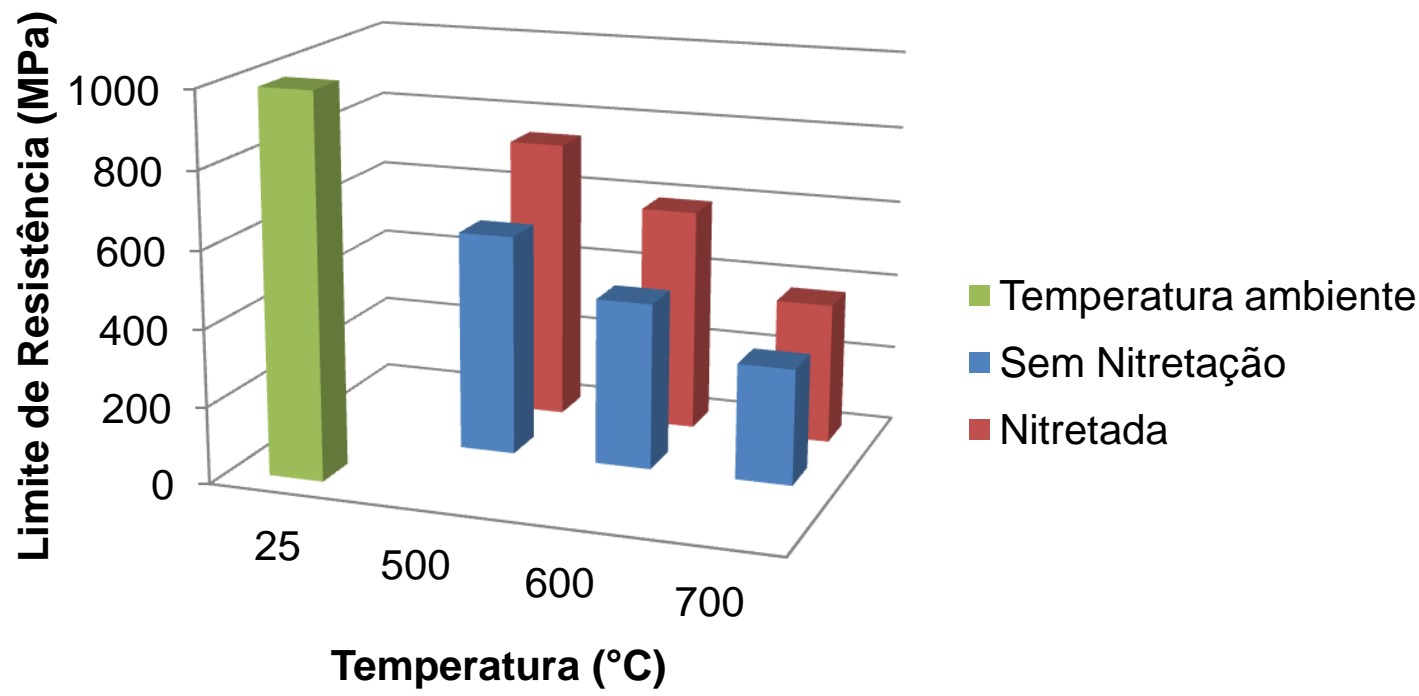

Figura 34 - Influência da temperatura no limite de resistência do material

Comparando a tensão limite de escoamento do material a $700^{\circ} \mathrm{C} \mathrm{com}$ a menor tensão aplicada no ensaio de fluência, que foi de $125 \mathrm{MPa}$ o valor ficou em torno de $40 \%$ deste limite.

Já comparando a tensão limite de escoamento do material a $600^{\circ} \mathrm{C}$ com o maior valor de tensão aplicado que foi $319 \mathrm{MPa}$, temos aproximadamente $76 \%$ e $60 \%$ do limite de escoamento para o material sem nitretação e com nitretação respectivamente conforme mostrado na Tabela 11.

Tabela 8 - Comparação dos valores de tensão obtidos a $600^{\circ} \mathrm{C}$ e as tensões utilizadas no ensaio de fluência.

\begin{tabular}{ccccc}
\hline Temperatura & Condição & $\sigma_{\mathrm{e}}(\mathbf{M P a})$ & $\boldsymbol{\sigma}=\mathbf{1 2 5} \mathbf{~ M P a}$ & $\sigma=\mathbf{3 1 9} \mathbf{~ M P a}$ \\
\hline \multirow{2}{*}{$600^{\circ} \mathrm{C}$} & Sem nitretação & 419 & $30 \%$ & $76 \%$ \\
& Com nitretação & 532 & $23 \%$ & $60 \%$ \\
\hline
\end{tabular}

As figuras 35 a 37 mostram as curvas tensão-deformação obtidas para o material com e sem nitretação nas temperaturas de 500, 600 e $700^{\circ} \mathrm{C}$. 


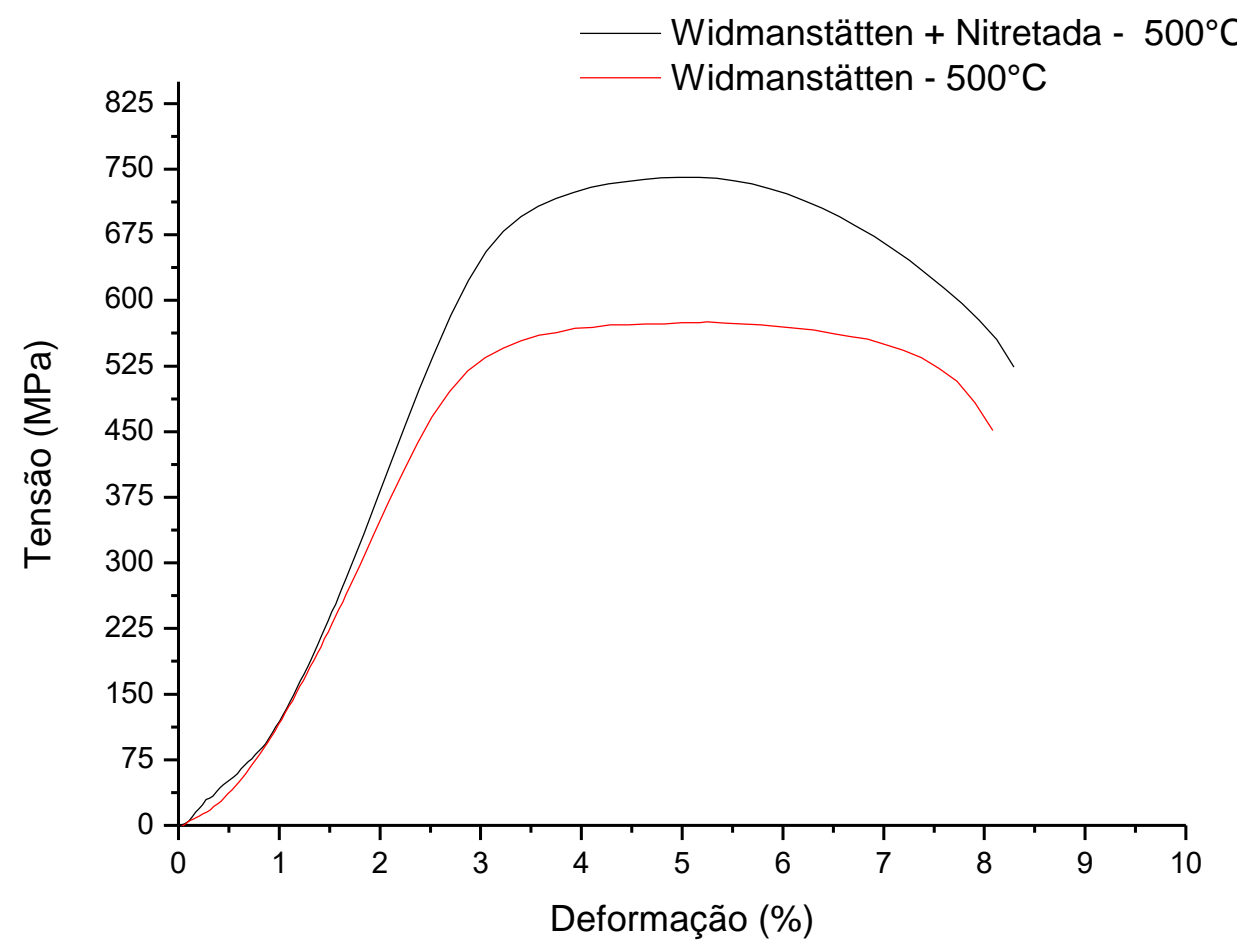

Figura 35 - Curvas de tensão-deformação da liga Ti-6Al-4V obtidas no ensaio de tração a quente a $500^{\circ} \mathrm{C}$.

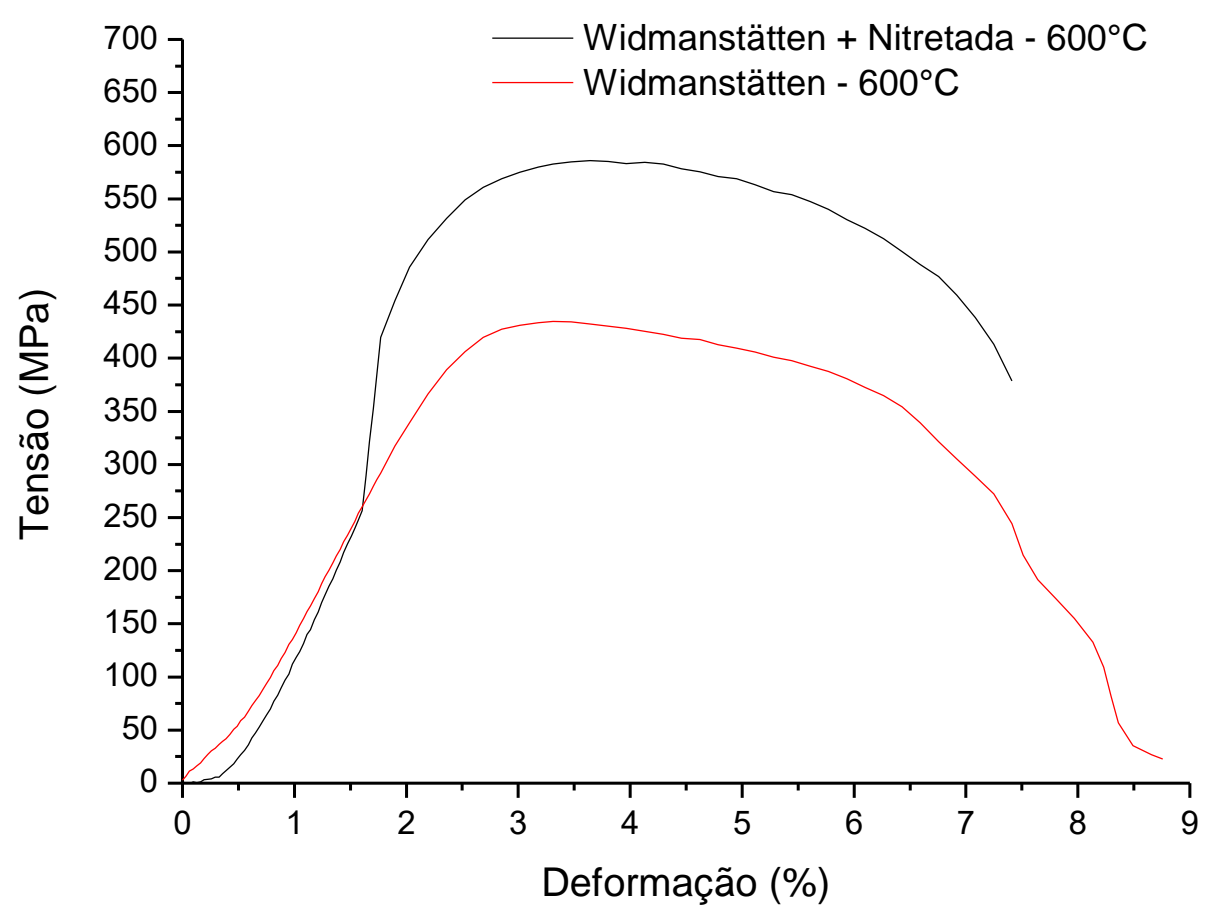

Figura 36 - Curvas de tensão-deformação da liga Ti-6Al-4V obtidas no ensaio de tração a quente a $600^{\circ} \mathrm{C}$. 


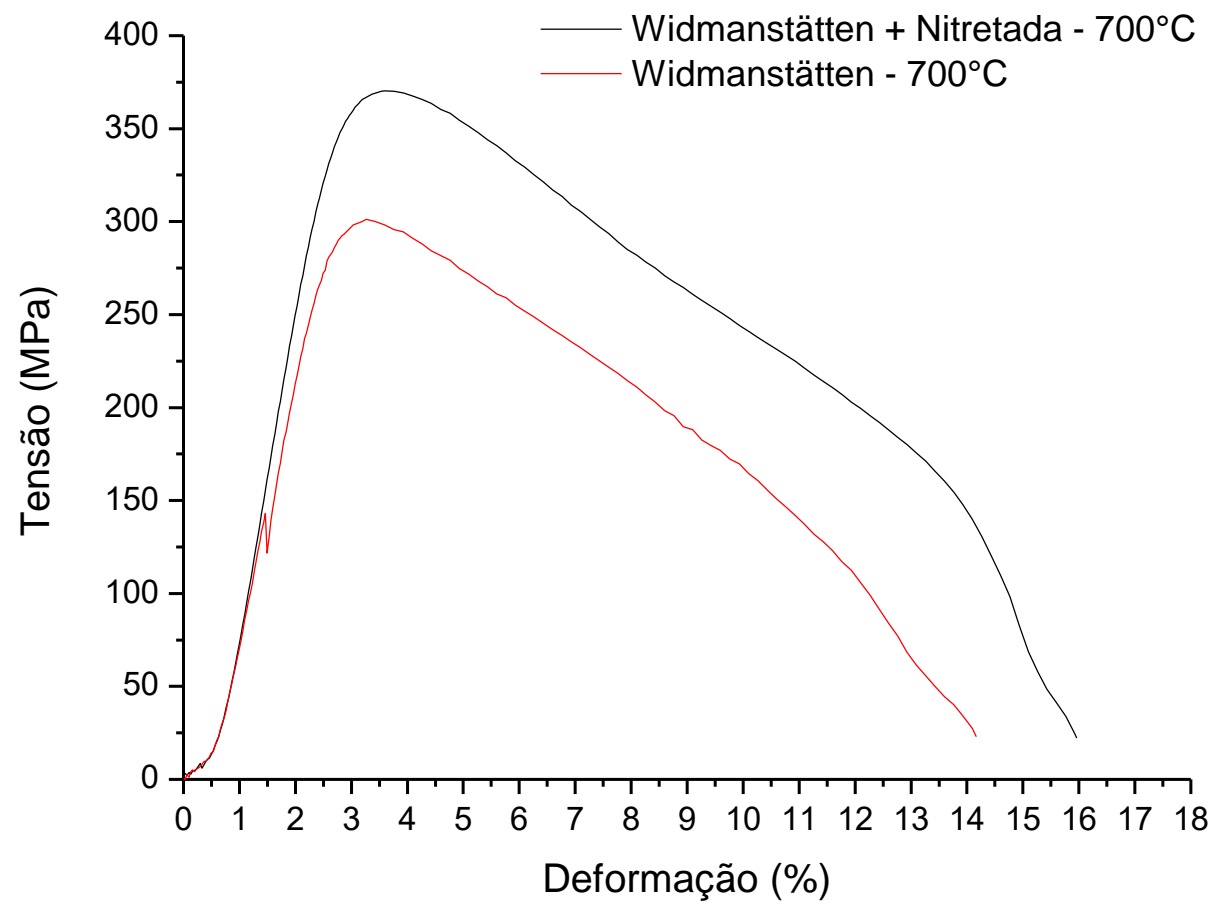

Figura 37 - Curvas de tensão-deformação da liga Ti-6Al-4V obtidas no ensaio de tração a quente a $700^{\circ} \mathrm{C}$.

\subsection{Ensaios de fluência}

Os ensaios de fluência na modalidade carga constante foram realizados em corpos de prova da Ti-6Al-4V com microestrutura de Widmanstätten e tratados superficialmente por nitretação por plasma. Para facilitar a identificação dos resultados do presente trabalho e dos demais utilizados nos comparativos a codificação das amostras mostrada na Tabela 9 será seguida.

Tabela 9 - Codificação utilizada para identificar as amostras dos ensaios de fluência.

\begin{tabular}{cc}
\hline Condições & Código \\
\hline Equiaxial & $\mathrm{Eq}$ \\
Widmanstätten & $\mathrm{Wd}$ \\
Widmanstätten + Nitretada (ensaio preliminar) & $\mathrm{Wd}+\mathrm{N} 1$ \\
Widmanstätten + Nitretada (lote definitivo) & $\mathrm{Wd}+\mathrm{N}$ \\
Widmanstätten+IIIP & $\mathrm{Wd}+$ IIIP \\
\hline
\end{tabular}


5.4.1 Ensaio preliminar de fluência da liga nitretada por plasma

O primeiro ensaio realizado foi com a amostra nitretada por 4 horas a uma temperatura de $750^{\circ} \mathrm{C}$ em uma atmosfera de $50 \%$ de $\mathrm{N}_{2}$.

Na Figura 38 é mostrado a curva de fluência da liga Ti-6Al-4V com e sem nitretação por plasma correspondente à deformação verdadeira, $\varepsilon$, como função do tempo, t, obtidas a $600^{\circ} \mathrm{C}$ e $250 \mathrm{MPa}$.

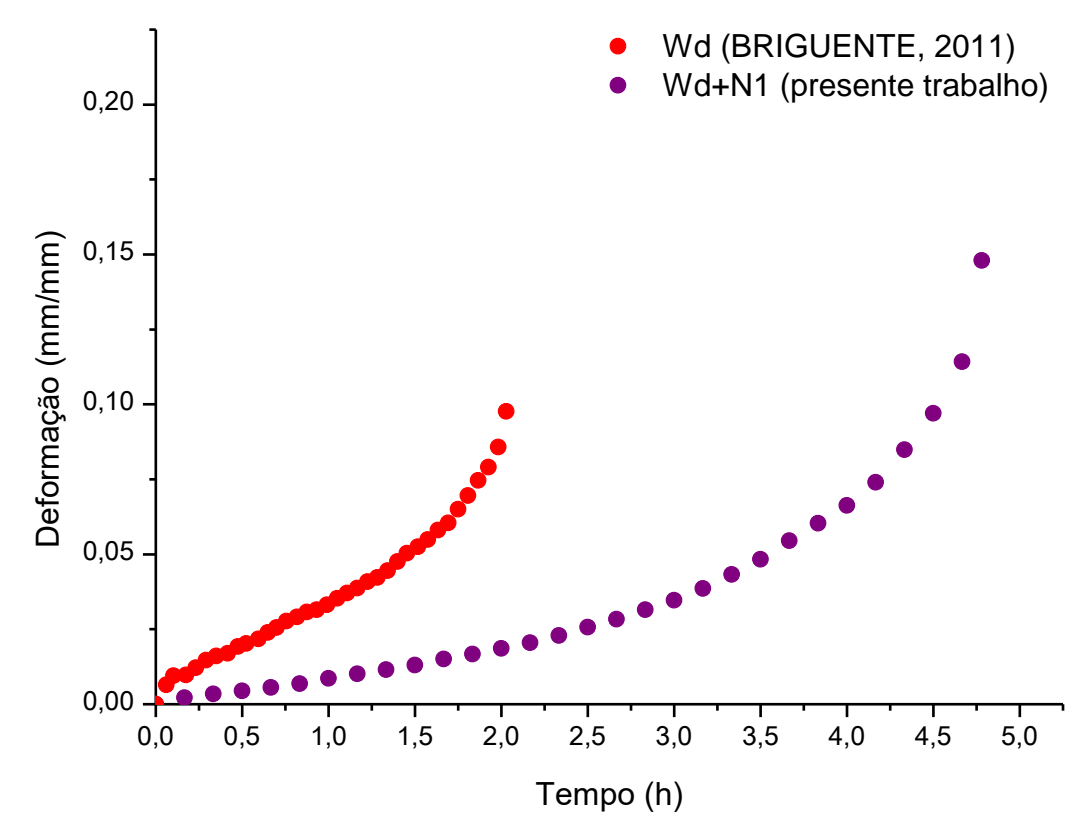

Figura 38 - Curvas de fluência a $600^{\circ} \mathrm{C}$ e $250 \mathrm{MPa}$ para o Ti-6Al-4V com microestrutura de Widmanstätten com e sem nitretação por plasma.

$\mathrm{Na}$ Tabela 10 é apresentada a relação dos principais parâmetros experimentais obtidos a $600^{\circ} \mathrm{C}$ e $250 \mathrm{MPa}$, a partir da curva experimental, em que $\sigma$ é a tensão aplicada, $\dot{\varepsilon}_{s}$ corresponde à taxa de fluência estacionária, obtida a partir da inclinação da região linear na curva de fluência (estágio secundário). $O$ valor de $t_{p}$ corresponde ao tempo relativo ao final do estágio primário e/ou início do estágio secundário. $O$ valor $t_{f}$ é o tempo final de fratura, $\varepsilon_{f}$ corresponde à deformação de fratura para o material com e sem nitretação por plasma.

Tabela 10 - Parâmetros experimentais a $600^{\circ} \mathrm{C}$ e $250 \mathrm{MPa}$ da liga Ti-6Al-4V com e sem nitretação por plasma.

\begin{tabular}{ccccc}
\hline Condições & $\mathbf{t}_{\mathbf{p}}(\mathbf{h})$ & $\dot{\boldsymbol{\varepsilon}}_{\boldsymbol{s}}(\mathbf{1} / \mathbf{h})$ & $\mathbf{t}_{\mathbf{f}}(\mathbf{h})$ & $\boldsymbol{\varepsilon}_{\boldsymbol{f}}(\mathbf{m m} / \mathbf{m m})$ \\
\hline W+N (presente trabalho) & 0,333 & $1,13 \times 10^{-2}$ & 4,78 & 0,148 \\
W (BRIGUENTE, 2011) & 0,350 & $3,04 \times 10^{-2}$ & 2,03 & 0,098 \\
\hline
\end{tabular}


O resultado foi um aumento na resistência à fluência quando comparado com a amostra não nitretada. Isto foi evidenciado tanto pela diminuição da taxa de fluência, como pelo aumento do tempo de ruptura do material.

5.4.2 Ensaios de fluência da liga tratada termicamente e nitretada por plasma

Após o tratamento térmico para homogeneização da microestrutura de Widmanstätten, novos ensaios de fluência foram realizados nas amostras submetidas um único lote de tratamento superficial de nitretação por plasma. A Tabela 11 mostra os resultados experimentais deste lote de material ensaiado em temperaturas de $500^{\circ} \mathrm{C}, 600^{\circ} \mathrm{C}$ e $700^{\circ} \mathrm{C}$ e tensões de $125 \mathrm{MPa}, 250$ e $319 \mathrm{MPa}$.

Tabela 11 - Parâmetros experimentais da liga Ti-6Al-4V nitretada por plasma.

\begin{tabular}{cccccc}
\hline $\begin{array}{c}\text { Temperatura } \\
\left({ }^{\circ} \mathbf{C}\right)\end{array}$ & $\boldsymbol{\sigma}(\mathbf{M P a})$ & $\mathbf{t}_{\mathbf{p}}(\mathbf{h})$ & $\dot{\boldsymbol{\varepsilon}}_{\boldsymbol{s}}(\mathbf{1} / \mathbf{h})$ & $\mathbf{t}_{\mathrm{f}}(\mathbf{h})$ & $\begin{array}{c}\boldsymbol{\varepsilon}_{f} \\
(\mathbf{m m} / \mathbf{m m})\end{array}$ \\
\hline 500 & 319 & 8,300 & $7,93 \times 10^{-5}$ & 251,30 & 0,038 \\
\hline 600 & 125 & 4,000 & $3,80 \times 10^{-4}$ & 112,56 & 0,046 \\
& 250 & 0,417 & $3,67 \times 10^{-3}$ & 6,03 & 0,031 \\
\hline 700 & 319 & 0,042 & $2,07 \times 10^{-2}$ & 1,17 & 0,056 \\
\hline
\end{tabular}

5.4.2.1 Comparação dos resultados de fluência da liga Ti-6Al-4V sem tratamento e após nitretação por plasma

Para se verificar o efeito da nitretação por plasma na resistência a fluência da liga Ti-6Al-4V foram realizadas comparações com os resultados de fluência obtidos da liga Ti-6Al-4V nas mesmas condições de ensaio para diferentes microestruturas e tratamentos superficiais, ensaio realizados pelo grupo de fluência. Na Figura 39 são mostradas as curvas experimentais a $500^{\circ} \mathrm{C}$ e 319 MPa comparativas entre os materiais com estrutura equiaxial (REIS, 2012) e Widmanstätten sem nitretação (BRIGUENTE, 2011), com tratamento IIIP (YOGI, 2012) e nitretado por plasma. 


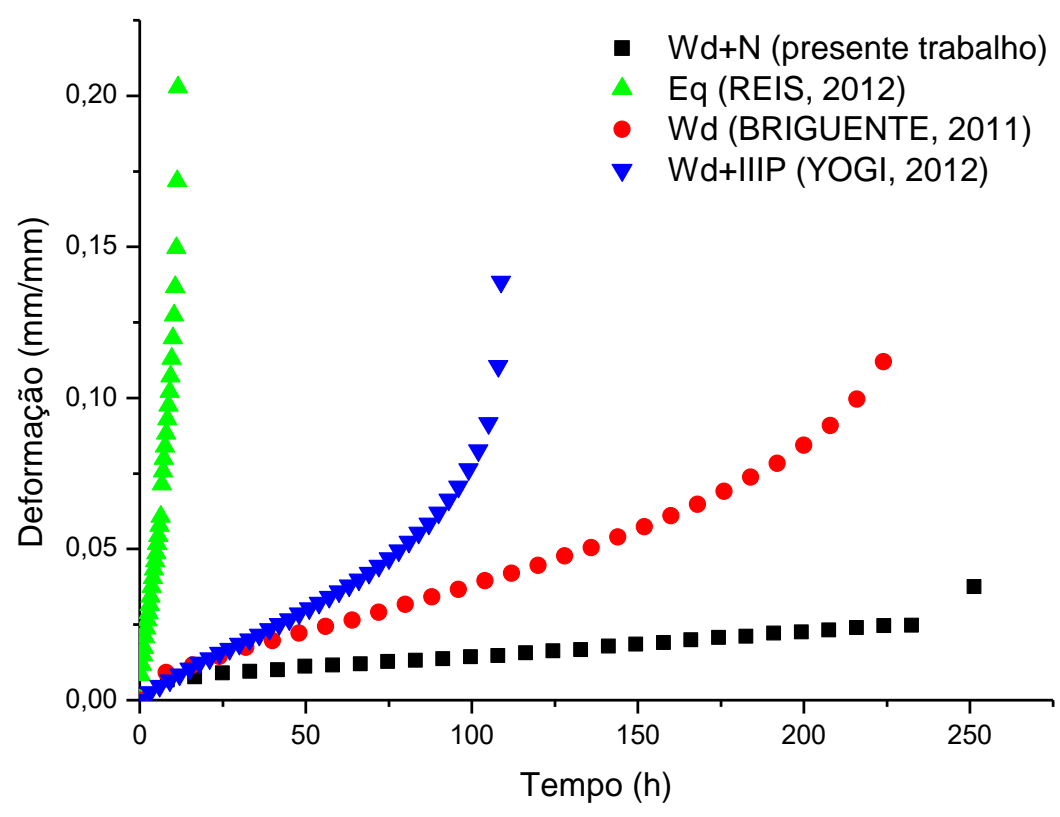

Figura 39 - Curvas de fluência a $500^{\circ} \mathrm{C}$ e $319 \mathrm{MPa}$ para o Ti-6Al-4V com diferentes microestruturas e tratamentos superficiais.

$\mathrm{Na}$ Figura 40 são mostradas as curvas comparativas experimentais a $600^{\circ} \mathrm{C}$ e $125 \mathrm{MPa}$ entre os materiais com estrutura equiaxial (BRIGUENTE et al., 2013) e Widmanstätten sem nitretação (BRIGUENTE, 2011), com tratamento IIIP que foi interrompido (YOGI, 2012) e nitretado por plasma.

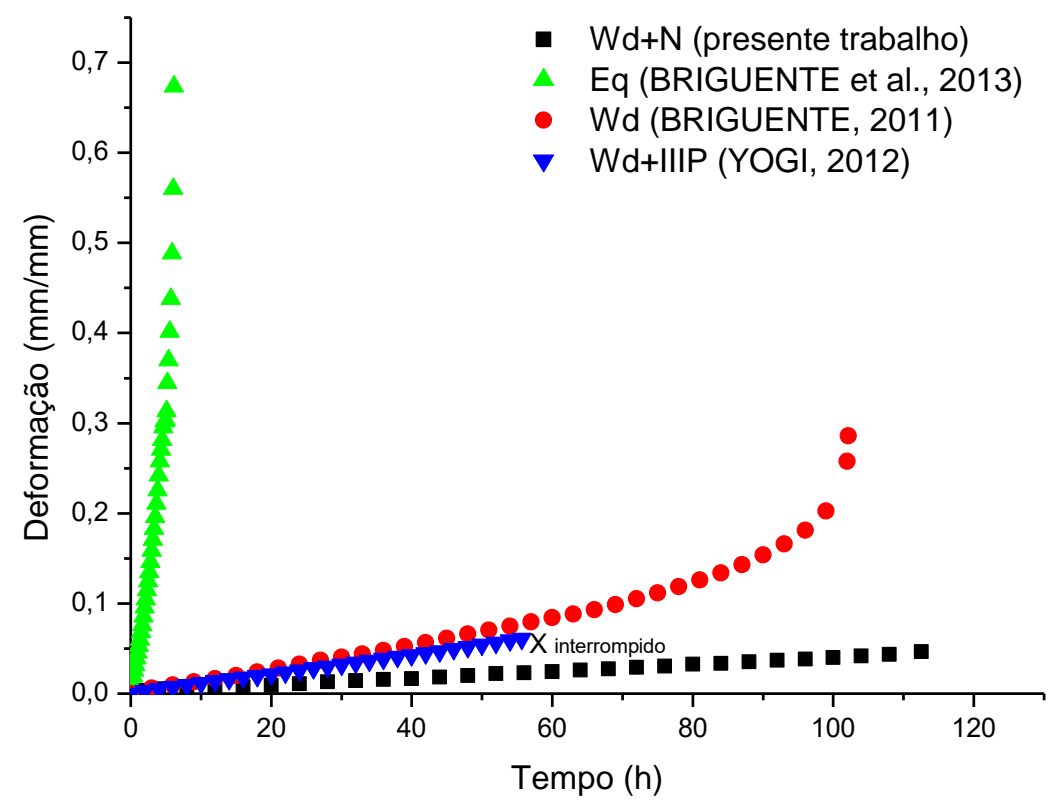

Figura 40 - Curvas de fluência a $600^{\circ} \mathrm{C}$ e $125 \mathrm{MPa}$ para o Ti-6Al-4V com diferentes microestruturas e tratamentos superficiais. 
$\mathrm{Na}$ Figura 41 são mostradas as curvas experimentais a $600^{\circ} \mathrm{C}$ e 250 MPa comparativas entre os materiais com estrutura equiaxial (REIS, 2012) e Widmanstätten sem nitretação (BRIGUENTE, 2011), com tratamento IIIP (YOGI, 2012) e o nitretado por plasma do ensaio preliminar $(\mathrm{Wd}+\mathrm{N} 1)$ e do lote definitivo $(\mathrm{Wd}+\mathrm{N})$.

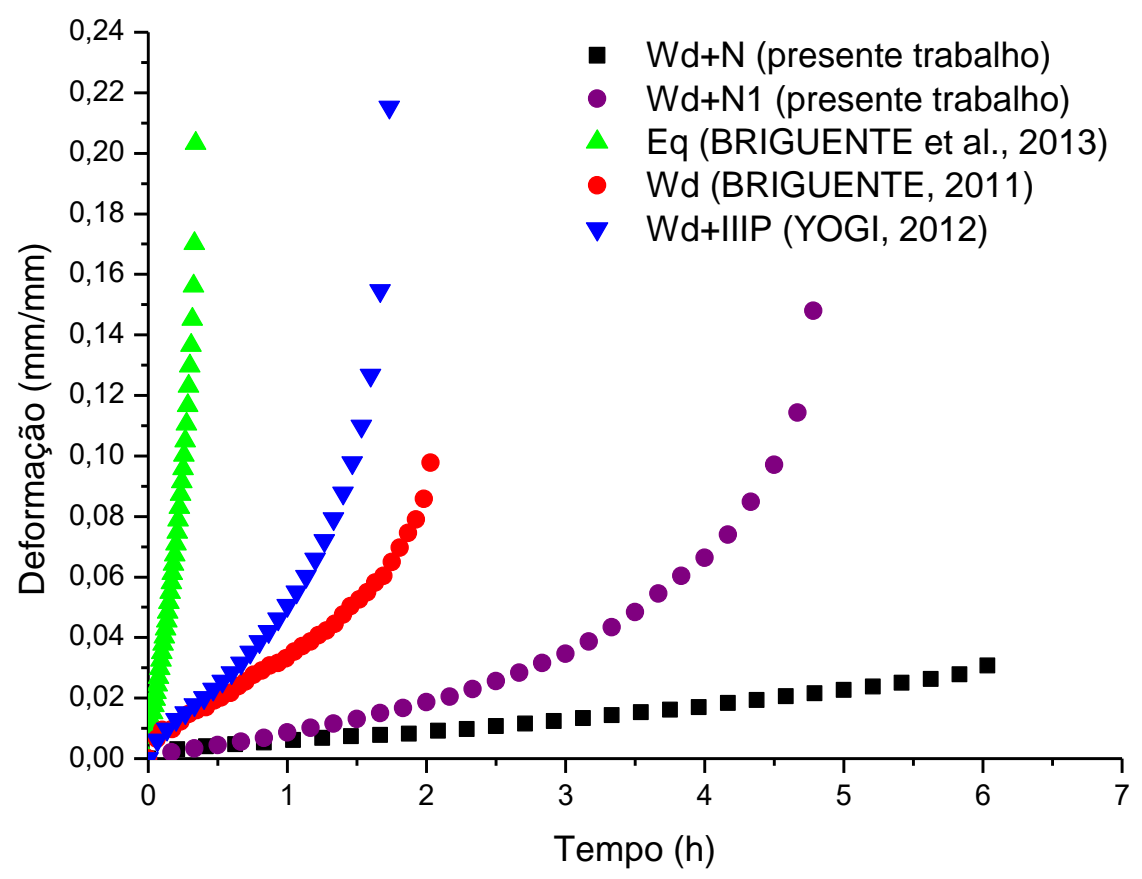

Figura 41 - Curvas de fluência a $600^{\circ} \mathrm{C}$ e $250 \mathrm{MPa}$ para o Ti-6Al-4V com diferentes microestruturas e tratamentos superficiais.

$\mathrm{Na}$ Figura 42 são mostradas as curvas experimentais a $600^{\circ} \mathrm{C}$ e 319 MPa comparativas entre os materiais com estrutura equiaxial (BRIGUENTE et al., 2013) e Widmanstätten sem nitretação (BRIGUENTE, 2011), com tratamento IIIP (YOGI, 2012) e nitretado por plasma que também possui microestrutura de Widmanstätten. 


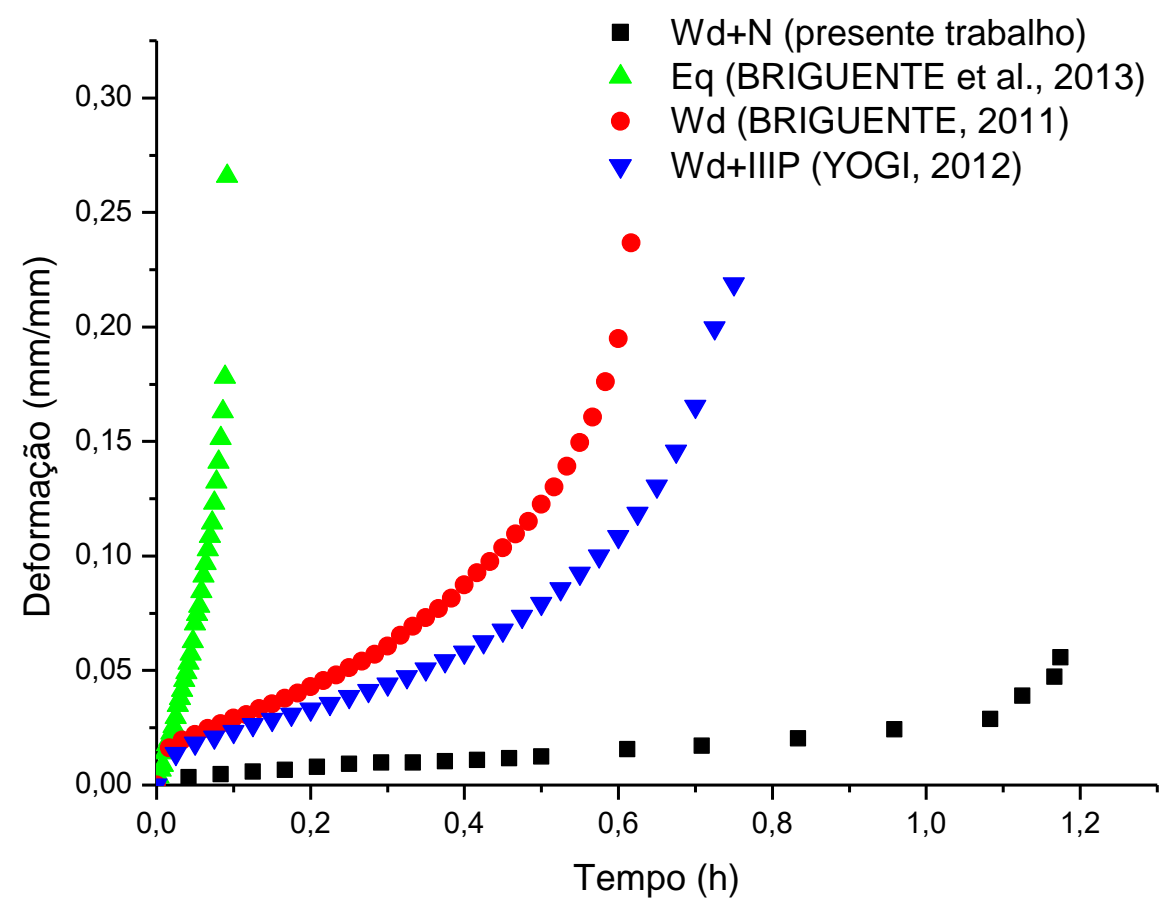

Figura 42 - Curvas de fluência a $600^{\circ} \mathrm{C}$ e $319 \mathrm{MPa}$ para o Ti-6Al-4V com diferentes microestruturas e tratamentos superficiais.

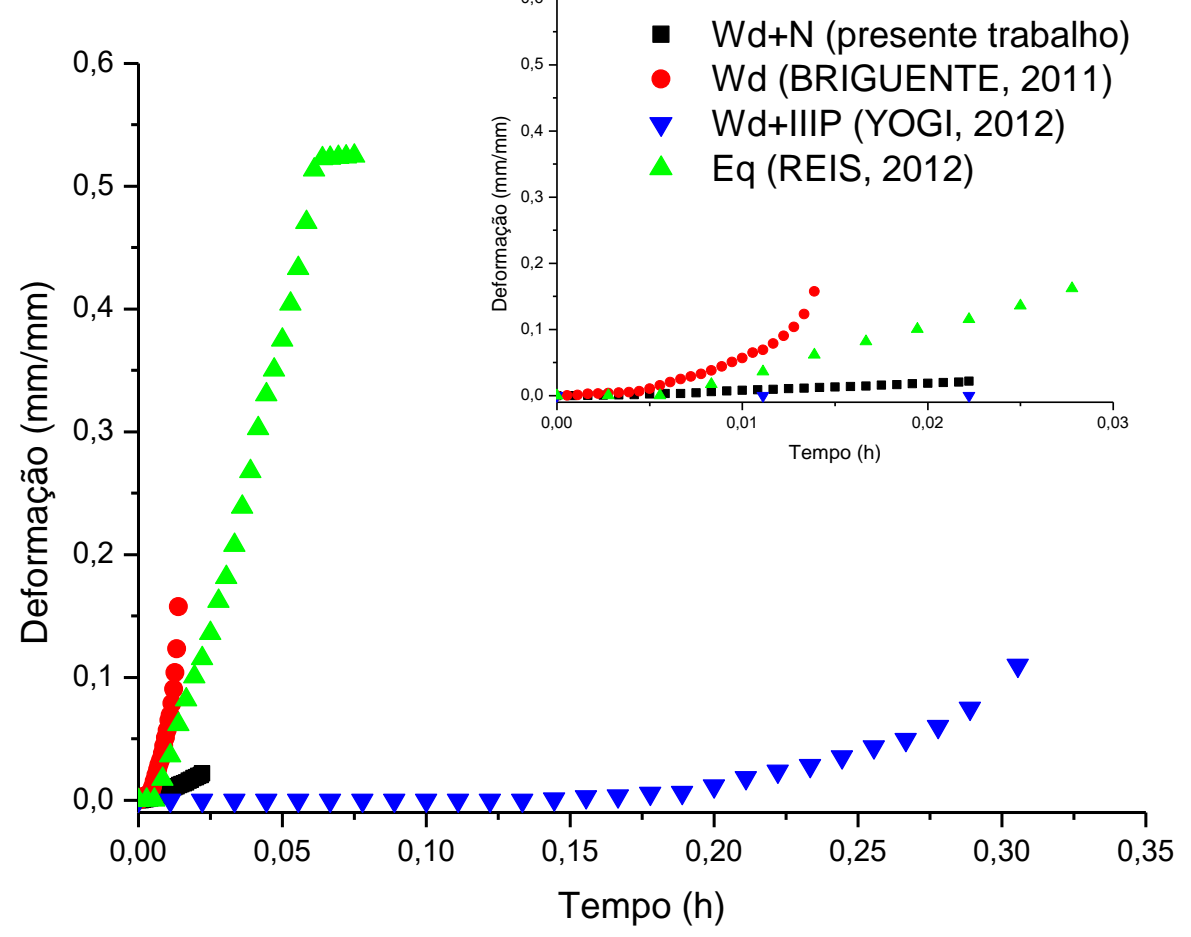

Figura 43 - Curvas de fluência a $700^{\circ} \mathrm{C}$ e $319 \mathrm{MPa}$ para o Ti-6Al-4V com diferentes microestruturas e tratamentos superficiais. 
Os resultados de fluência obtidos a 500, 600 e 700ํㅡ a partir da liga de Ti-6Al-4V sem tratamento superficial com estrutura equiaxial e Widmanstätten, Widmanstätten com tratamento IIIP e Widmanstätten após nitretação por plasma são apresentados na Tabela 12, onde estão resumidos os principais parâmetros experimentais, os valores do tempo de fluência primário $\left(t_{p}\right)$, taxa de fluência secundária $\dot{\varepsilon}_{s}$, tempo de fluência final $\left(\mathrm{t}_{\mathrm{f}}\right)$ e deformação final $\left(\varepsilon_{f}\right)$. 
Tabela 12 - Dados comparativos de fluência a 500, 600 e $700^{\circ} \mathrm{C}$ da liga Ti-6Al-4V com e sem nitretação por plasma e para diferentes microestruturas.

\begin{tabular}{|c|c|c|c|c|c|c|}
\hline $\begin{array}{c}\text { Temperatura } \\
\left({ }^{\circ} \mathbf{C}\right)\end{array}$ & $\begin{array}{c}\sigma \\
(\mathrm{MPa})\end{array}$ & Condições & $t_{p}(h)$ & $\dot{\varepsilon}_{s}(1 / \mathrm{h})$ & $t_{f}(h)$ & $\begin{array}{c}\varepsilon_{\mathrm{f}} \\
(\mathrm{mm} / \mathrm{mm})\end{array}$ \\
\hline \multirow{4}{*}{500} & \multirow{4}{*}{319} & $\mathrm{Wd}+\mathrm{N}^{1}$ & 8,300 & $7,93 \times 10^{-5}$ & 251,27 & 0,038 \\
\hline & & $W d^{2}$ & 16,000 & $3,46 \times 10^{-4}$ & 224,00 & 0,112 \\
\hline & & $W d+I I I P^{3}$ & 9,000 & $5,60 \times 10^{-4}$ & 108,00 & 0,138 \\
\hline & & $\mathrm{Eq}^{4}$ & 1,000 & $8,60 \times 10^{-3}$ & 11,53 & 0,203 \\
\hline \multirow{4}{*}{600} & \multirow{4}{*}{125} & $\mathrm{Wd}+\mathrm{N}^{1}$ & 4,000 & $3,80 \times 10^{-4}$ & 112,56 & 0,046 \\
\hline & & $W^{2}$ & 9,000 & $1,40 \times 10^{-3}$ & 102,12 & 0,286 \\
\hline & & $W d+I I I P^{3}$ & 1,000 & $1,08 \times 10^{-3}$ & \multicolumn{2}{|c|}{ Interrompido } \\
\hline & & $\mathrm{Eq}^{5}$ & 0,830 & $6,30 \times 10^{-2}$ & 6,19 & 0,674 \\
\hline \multirow{5}{*}{600} & \multirow{5}{*}{250} & $\mathrm{Wd}+\mathrm{N}^{1}$ & 0,417 & $3,67 \times 10^{-3}$ & 6,03 & 0,031 \\
\hline & & $\mathrm{Wd}+\mathrm{N} 1^{1}$ & 0,333 & $1,13 \times 10^{-2}$ & 4,78 & 0,148 \\
\hline & & $W d^{2}$ & 0,350 & $3,04 \times 10^{-2}$ & 2,03 & 0,098 \\
\hline & & $W d+I I I P^{3}$ & 0,130 & $4,80 \times 10^{-2}$ & 1,73 & 0,215 \\
\hline & & $\mathrm{Eq}^{5}$ & 0,040 & $3,74 \times 10^{-1}$ & 0,34 & 0,203 \\
\hline \multirow{4}{*}{600} & \multirow{4}{*}{319} & $\mathrm{Wd}+\mathrm{N}^{1}$ & 0,042 & $2,07 \times 10^{-2}$ & 1,17 & 0,056 \\
\hline & & $W d^{2}$ & 0,067 & $1,60 \times 10^{-1}$ & 0,62 & 0,237 \\
\hline & & $W d+I I I P^{3}$ & 0,050 & $1,19 \times 10^{-1}$ & 0,75 & 0,219 \\
\hline & & $\mathrm{Eq}^{5}$ & 0,011 & $1,51 \times 10^{0}$ & 0,09 & 0,266 \\
\hline \multirow{4}{*}{700} & \multirow{4}{*}{319} & $\mathrm{Wd}+\mathrm{N}^{1}$ & 0,008 & $1,08 \times 10^{0}$ & 0,02 & 0,022 \\
\hline & & $W d^{2}$ & 0,003 & $7,54 \times 10^{0}$ & 0,01 & 0,158 \\
\hline & & $W d+I I I P^{3}$ & 0,011 & $3,08 \times 10^{-3}$ & 0,31 & 0,110 \\
\hline & & $\mathrm{Eq}^{4}$ & 0,002 & $7,68 \times 10^{0}$ & 0,05 & 0,404 \\
\hline
\end{tabular}

\footnotetext{
${ }^{1}$ Presente trabalho

2 (BRIGUENTE, 2011)

3 (YOGI, 2012)

${ }^{4}$ (REIS, 2012)

${ }^{5}$ (BRIGUENTE et al., 2013)
} 
Os resultados das curvas de fluência (Figuras 39-43) e da Tabela 12 mostram que a liga Ti-6Al-4V com estrutura Widmanstätten nitretada por plasma apresentou uma maior resistência à fluência devido a redução da taxa de fluência estacionária e maior tempo para ruptura.

Somente na condição mais extrema a $700^{\circ} \mathrm{C}$ e $319 \mathrm{MPa}$ os resultados não seguiram o mesmo padrão e a condição com estrutura Widmanstätten com IIIP apresentou maior resistência, porém por ser uma condição muito severa, onde deformação ocorre praticamente de forma instantânea, este resultado não é tão relevante, porque a fluência normalmente se dá ao longo de um período bem mais elevado de tempo. Portanto, de forma geral, esses dados demonstram que o tratamento de nitretação por plasma é efetivo em relação ao comportamento mecânico da liga em fluência.

Para a liga Ti-6Al-4V com estrutura Widmanstätten a $600^{\circ} \mathrm{C}$ submetida a tensão de $250 \mathrm{MPa}$ também apresentou maior valor de $t_{\mathrm{p}}$. Este aumento de resistência pode ser atribuído ao endurecimento superficial da liga de Ti-6Al-4V pela nitretação por plasma. É um fato bem conhecido que o endurecimento superficial aumenta a resistência à fluência de algumas ligas, aumentando o tempo de vida até a ruptura. Isso está associado ao controle da penetração do oxigênio no titânio devido a formação da camada de nitretos (ROSEN; ROTTEM, 1976).

\subsubsection{Comparação dos tempos de fluência da liga Ti-6Al-4V}

Para todas as condições de temperatura estudadas a liga Ti-6Al-4V nitretada por plasma apresentou os três estágios de uma curva normal de fluência, primário, secundário e terciário bem definidos. Pode-se observar que a predominância de vida em fluência é no estágio secundário, onde a taxa de fluência é constante, o que está associado à configuração constante das discordâncias devido ao processo de encruamento e recuperação (DYSON; MCLEAN, 1990; BARBOZA, 2001; REIS, 2012).

A Tabela 13 mostra os tempos de cada estágio de fluência para a liga Ti-6Al-4V nitretada por plasma, extraídos das curvas de fluência. O tempo de fluência secundária $\left(t_{s}\right)$ foi calculado pela diferença entre o tempo de início do estágio terciário e o tempo do estágio primário $\left(t_{p}\right)$. E o tempo de fluência terciário $\left(t_{t}\right)$ foi calculado pela diferença entre o tempo de fratura $\left(t_{f}\right)$ e o início do estágio 
terciário. O percentual relativo do tempo de cada estágio foi definido pela razão entre o tempo de cada estágio pelo tempo total até a fratura. A Figura 44 mostra o comparativo em percentual.

Tabela 13 - Tempos dos estágios primário, secundário, terciário e percentual relativo do tempo dos estágios de fluência.

\begin{tabular}{ccccccccc}
\hline $\begin{array}{c}\text { Temperatura } \\
\left({ }^{\circ} \mathrm{C}\right)\end{array}$ & $\begin{array}{c}\text { Tensão } \\
(\mathrm{MPa})\end{array}$ & $\mathrm{t}_{\mathrm{p}}(\mathrm{h})$ & $\mathrm{t}_{\mathrm{s}}(\mathrm{h})$ & $\mathrm{t}_{\mathrm{t}}(\mathrm{h})$ & $\mathrm{t}_{\mathrm{f}}(\mathrm{h})$ & $\begin{array}{c}\text { Primário } \\
(\%)\end{array}$ & $\begin{array}{c}\text { Secundário } \\
(\%)\end{array}$ & $\begin{array}{c}\text { Terciário } \\
(\%)\end{array}$ \\
\hline 500 & 319 & 8,300 & 207,500 & 35,467 & 251,267 & $3 \%$ & $83 \%$ & $14 \%$ \\
& 125 & 4,000 & 100,000 & 8,560 & 112,560 & $4 \%$ & $89 \%$ & $8 \%$ \\
600 & 250 & 0,417 & 3,542 & 2,075 & 6,033 & $7 \%$ & $59 \%$ & $34 \%$ \\
& 319 & 0,042 & 0,875 & 0,258 & 1,174 & $4 \%$ & $75 \%$ & $22 \%$ \\
700 & 319 & 0,008 & 0,013 & 0,002 & 0,022 & $34 \%$ & $56 \%$ & $10 \%$ \\
\hline
\end{tabular}

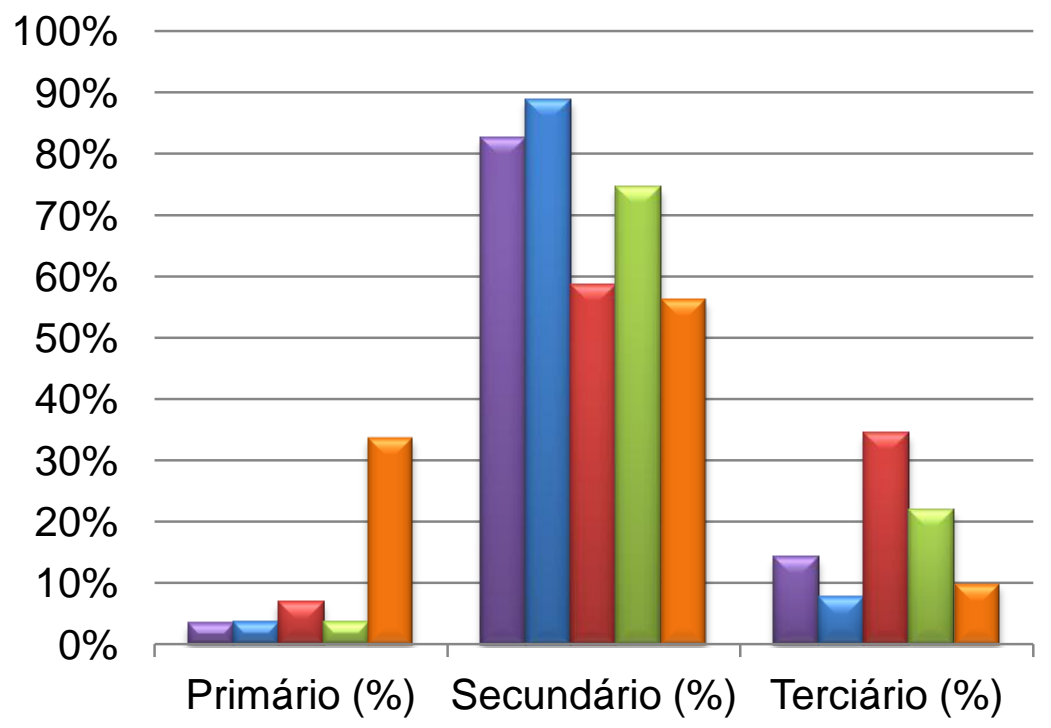

$\square 500^{\circ} \mathrm{C} 319 \mathrm{MPa}$

$\square 600^{\circ} \mathrm{C} 125 \mathrm{MPa}$

$\square 600^{\circ} \mathrm{C} 250 \mathrm{MPa}$

$\square 600^{\circ} \mathrm{C} 319 \mathrm{MPa}$

$\square 700^{\circ} \mathrm{C} 319 \mathrm{MPa}$

Figura 44 - Percentual relativo do tempo dos estágios de fluência dos ensaios realizados na liga Ti-6Al-4V nitretada por plasma.

Uma comparação do tempo de fluência final com as demais condições do material ensaiado com estrutura de Widmanstätten é mostrada na Tabela 14. 
Tabela 14 - Comparação do tempo de fluência final (tf) para condições investigadas

\begin{tabular}{|c|c|c|c|}
\hline Temperatura $\left({ }^{\circ} \mathrm{C}\right)$ & $\sigma(\mathrm{MPa})$ & Condição & Relação \\
\hline \multirow{2}{*}{500} & \multirow{2}{*}{319} & $t_{f} W d+N / t_{f} W d$ & 1,12 \\
\hline & & $t_{f} W d+N / t_{f} W d+I I I P$ & 2,33 \\
\hline 600 & 125 & $t_{f} W d+N / t_{f} W d$ & 1,10 \\
\hline \multirow{2}{*}{600} & \multirow{2}{*}{250} & $t_{f} W d+N / t_{f} W d$ & 2,97 \\
\hline & & $t_{f} W d+N / t_{f} W d+I I I P$ & 3,49 \\
\hline \multirow{2}{*}{600} & \multirow{2}{*}{319} & $t_{f} W d+N / t_{f} W d$ & 1,90 \\
\hline & & $t_{f} W d+N / t_{f} W d+I I I P$ & 1,57 \\
\hline \multirow{2}{*}{700} & \multirow{2}{*}{319} & $t_{f} W d+N / t_{f} W d$ & 1,59 \\
\hline & & $t_{f} W d+N / t_{f} W d+I I I P$ & 0,07 \\
\hline
\end{tabular}

Como pode ser observado quanto ao tempo final de fluência, as amostras nitretadas têm uma resistência à fluência mais elevada do que as amostras não tratadas superficialmente e do que as amostras tratadas com IIIP a temperaturas de 500 e $600^{\circ} \mathrm{C}$.

\subsubsection{Cálculo dos expoentes de tensão e da energia de ativação}

A Figura 45 apresenta a dependência da tensão com o tempo de fluência primária e a Figura 46 a dependência da tensão com a taxa de fluência estacionária para as condições sem tratamento (BRIGUENTE, 2011), nitretada por plasma e tratada com IIIP (YOGI, 2012). Os parâmetros A, B, m e $\mathrm{n}$ do material foram determinados por meio de ensaios de fluência com carga constante. Estes parâmetros dependem da temperatura, composição e microestrutura do material e também do nível de tensão aplicada. 


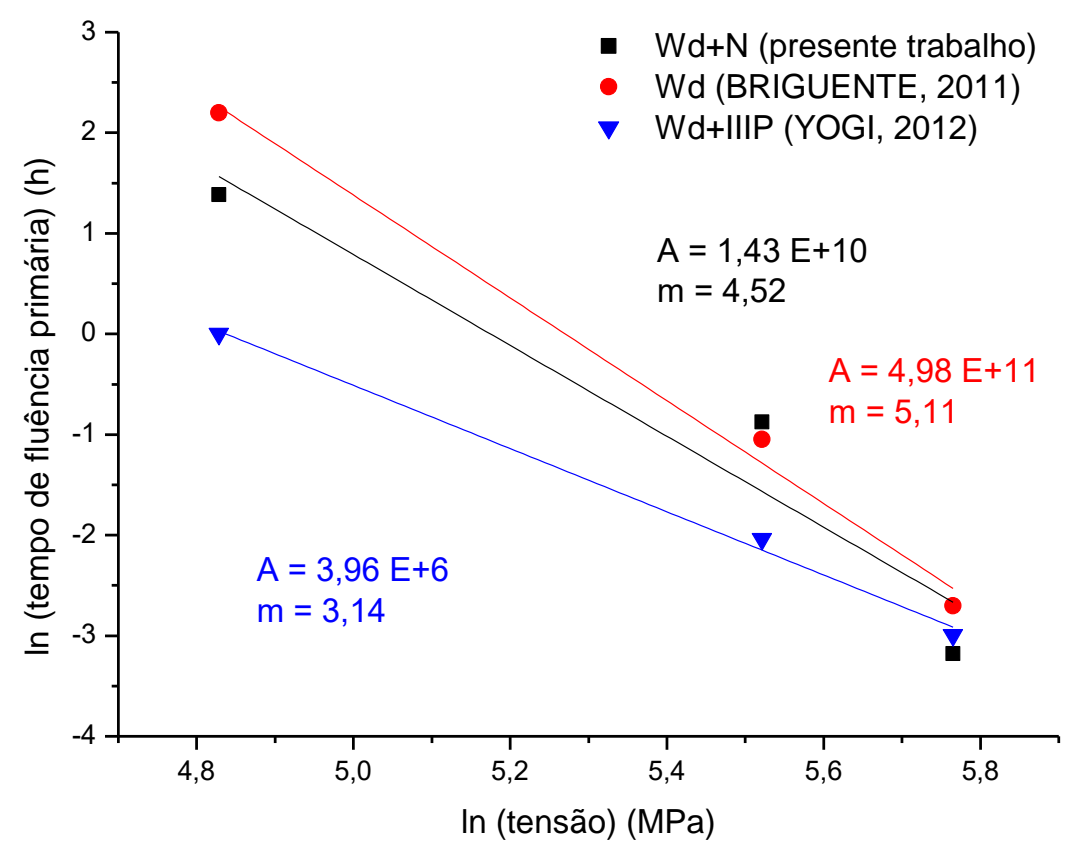

Figura 45 - Dependência do tempo de fluência primária com a tensão aplicada da liga Ti-6Al-4V a $600^{\circ} \mathrm{C}$ sem tratamento, nitretada por plasma e tratada com IIIP.

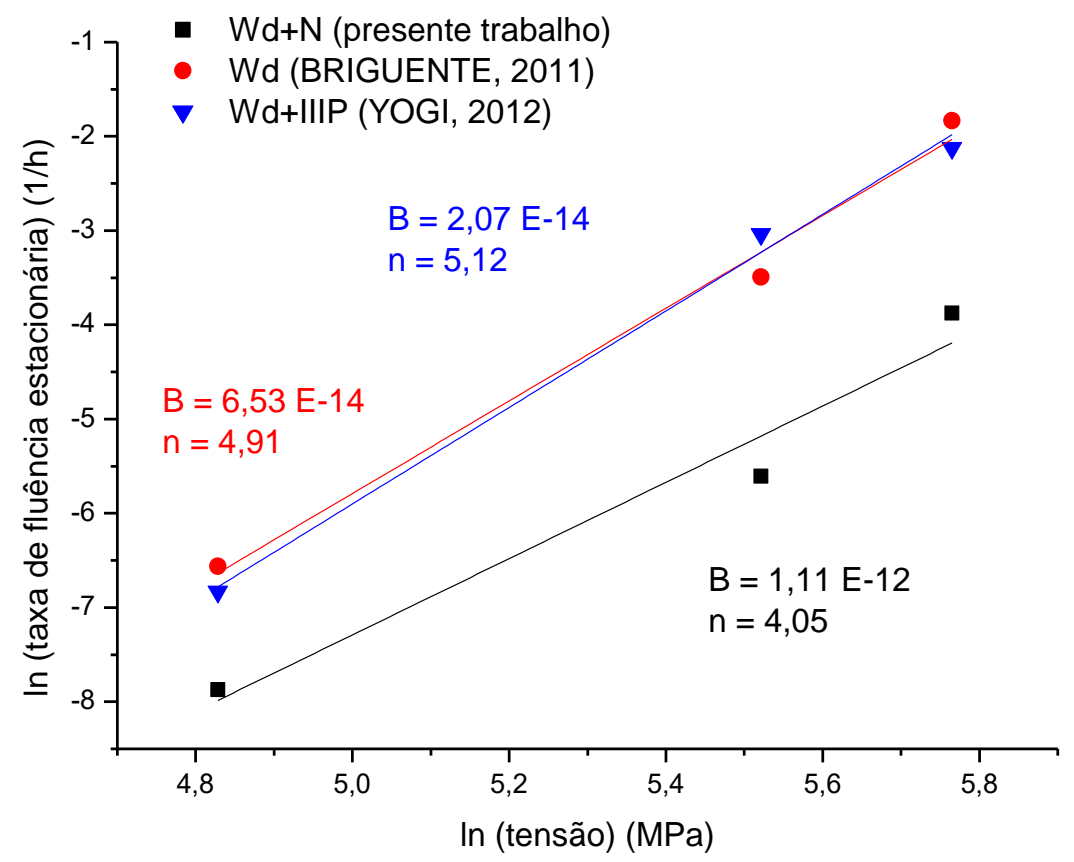

Figura 46 - Dependência da taxa de fluência estacionária com a tensão aplicada da liga Ti-6Al-4V a $600^{\circ} \mathrm{C}$ sem tratamento, nitretada por plasma e tratada com IIIP. 
A Tabela 15 mostra os valores do expoente de fluência primário (m).

Tabela 15 - Valores do expoente de fluência primária m para a liga Ti-6Al-4V.

\begin{tabular}{ccc}
\hline Autores & Condições & m \\
\hline (BARBOZA, 2001) & Equiaxial & 4,58 \\
(PEREZ, 2004) & Equiaxial & 3,41 \\
& Equiaxial & 3,97 \\
(BRIGUENTE, 2015) & Equiaxial + recobrimento metálico & 4,27 \\
(YOGI, 2012) & Equiaxial + TBC ${ }^{6}$ & 4,55 \\
(REIS, 2012) & Equiaxial + IIIP & 3,68 \\
(OLIVEIRA, 2010) & Widmanstätten + IIIP & 3,14 \\
(BRIGUENTE, 2011) & Equiaxial + nitretada a laser & 5,19 \\
Presente trabalho & Widmanstätten + nitretada por plasma & 4,52 \\
\hline
\end{tabular}

Para uma dada temperatura, quanto maior a tensão aplicada menor o valor de $t_{p}$, e, portanto o estágio secundário começa mais rápido. Valores maiores de $\mathrm{m}$ indicam uma maior resistência para o estágio primário e consequentemente valores maiores de $t_{p}$. Comparando o valor de 4,52 para a condição ensaiada, verifica-se que é coerente com o encontrado por outros autores, de 5,11 (BRIGUENTE, 2011) e de 3,14 (YOGI, 2012) sem ganho significativo para a resistência no estágio primário.

$\mathrm{Na}$ Figura 47 foi estimado os valores de energia de ativação para fluência e constante C obtidas a $319 \mathrm{MPa}$ para a liga Ti-6Al-4V nitretada por plasma e também comparado com o material sem tratamento (BRIGUENTE, 2011) e tratado com IIIP (YOGI, 2012).

\footnotetext{
${ }^{6}$ TBC "Thermal Barrier Coating" = recobrimento de barreira térmica
} 


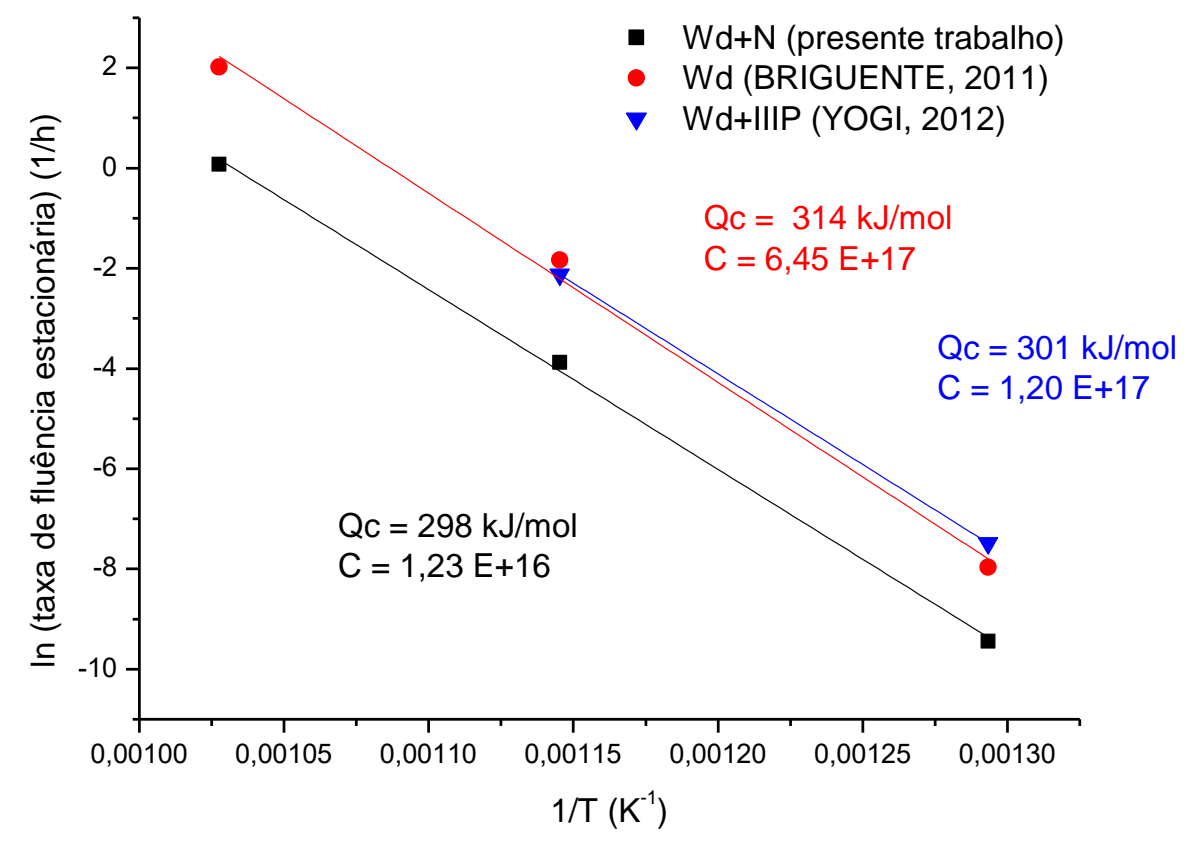

Figura 47 - Diagrama para a determinação da energia de ativação a 319 MPa da liga Ti-6Al-4V sem tratamento, nitretada por plasma e tratada com IIIP.

Os valores da energia de ativação para fluência $\left(Q_{c}\right)$ encontrados próximos dos valores da energia de ativação de autodifusão $\left(Q_{S D}\right)$ e valores de $n$ maiores que 3 em temperaturas entre 0,4 e 0,7 da temperatura de fusão, sob níveis de tensões intermediários ou elevados indicam um mecanismo de fluência por escorregamento de discordâncias (EVANS; WILSHIRE, 1993). A energia de ativação da autodifusão relatada para o $\alpha$-Ti está na faixa de $242-293 \mathrm{~kJ} / \mathrm{mol}$ (PALEHAN; ROSEN, 1978). No $\alpha$-Ti de alta pureza, foram encontradas energias de ativação de 303 e $329 \mathrm{~kJ} / \mathrm{mol}$, respectivamente, para autodifusão do Ti e difusão do Al soluto. Este aumento no valor se justifica pela quantidade e pela natureza das impurezas, particularmente as impurezas de rápida difusão como $\mathrm{Fe}$, Ni e Co, que tiveram diversos efeitos na autodifusão do Ti (KÖPPERS et al., 1997).

$O$ valor encontrado para $Q_{c}$ do Ti-6Al-4V nitretado por plasma foi de $298 \mathrm{~kJ} / \mathrm{mol}$ e para as amostras sem tratamento e tratado com IIIP foram de 314 $\mathrm{kJ} / \mathrm{mol}$ (BRIGUENTE, 2011) e de $301 \mathrm{~kJ} / \mathrm{mol}$ (YOGI, 2012) respectivamente. Os expoentes de tensão obtidos para amostras nitretadas por plasma foram 4,05, ligeiramente inferiores aos da amostra não tratada e tratada com IIIP, que foram respectivamente de 4,91 e 5,12. Estes valores são consistentes com um 
mecanismo de deslocamento de discordâncias. Sendo assim, parece que o mecanismo de fluência na liga Ti-6Al-4V é dominado por um mecanismo de deslocamento semelhante a de muitos metais puros e ligas de soluções sólidas quando testado a aproximadamente 0,5 $\mathrm{T}_{\mathrm{f}}$ (WARREN; HSIUNG; WADLEY, 1995). Os valores de energia de ativação de fluência $\left(Q_{c}\right)$ do Ti-6Al-4V na faixa de temperatura de $600-680^{\circ} \mathrm{C}$ é $240,0 \mathrm{~kJ} / \mathrm{mol}$ e expoente de tensão $(\mathrm{n})$ é de 3,4 (WARREN; HSIUNG; WADLEY, 1995) e 3,8 (HARRIGAN, 1974) respectivamente.

A Tabela 16 mostra os valores do expoente de tensão (n) e da energia de ativação $\left(Q_{c}\right)$ obtidos para a liga Ti-6Al-4V com microestrutura equiaxial e Widmanstätten.

Tabela 16 - Valores do expoente de tensão $n$ e energia de ativação $\left(Q_{c}\right)$ para a liga Ti-6Al-4V.

\begin{tabular}{cccc}
\hline Autores & Condições & $\mathbf{n}$ & Qc (kJ/mol) \\
\hline (BARBOZA, 2001) & Equiaxial & 4,25 & 329 \\
& Equiaxial & 3,59 & \\
(BRIGUENTE, 2015) & Equiaxial + recobrimento metálico & 3,79 & 266 \\
& Equiaxial + TBC & 3,88 & \\
(YOGI, 2012) & Equiaxial + IIIP & 3,23 & 282 \\
& Widmanstätten + IIIP & 5,12 & 301 \\
(REIS, 2012) & Equiaxial + nitretada a laser & 6,46 & 261 \\
(OLIVEIRA, 2010) & Equiaxial + nitretada & 4,82 & 272 \\
(BRIGUENTE, 2011) & Widmanstätten & 4,91 & 314 \\
Presente trabalho & Widmanstätten + nitretada por plasma & 4,05 & 298 \\
\hline
\end{tabular}

Pode-se observar que o valor de $n=4,05$ encontrado para o material com microestrutura de Widmanstätten nitretado por plasma está em concordância com os dos encontrados na literatura conforme mostra a Tabela 16. O valor mais baixo encontrado para $n$ foi de 3,23 para o material com estrutura de grãos equiaxiais + IIIP (YOGI, 2012) e os valores mais altos foram encontrados para 0 material com microestrutura de Widmanstätten + IIIP (YOGI, 2012) e para microestrutura equiaxial nitretada por laser (REIS, 2012), que foram de 5,12 e 6,46 , respectivamente. 
Para os valores de Qc, o menor valor encontrado foi de $261 \mathrm{~kJ} / \mathrm{mol}$ para a microestrutura equiaxial nitretada (REIS, 2012) e o mais alta foi de 329 $\mathrm{kJ} / \mathrm{mol}$ para a microestrutura equiaxial sem tratamento superficial (BARBOZA, 2001). O valor de $298 \mathrm{~kJ} / \mathrm{mol}$ encontrado para a condição nitretada por plasma com microestrutura de Widmanstätten é muito próximo ao da média dos valores encontrados na literatura (Tabela 16).

A Figura 48 apresenta a dependência do tempo de fluência primária com a temperatura a $319 \mathrm{MPa}$. Através da utilização de técnicas de regressão linear, os resultados podem ser descritos pela equação 3 da lei de potência em fluência. O valor de $Q_{p}$ de $223 \mathrm{~kJ} / \mathrm{mol}$ inferior ao valor de Qc que foi de $298 \mathrm{~kJ} / \mathrm{mol}$ pode ser justificado pelo encruamento do material durante o primeiro estágio de fluência (EVANS; WILSHIRE, 1993; ES-SOUNI, 2000).

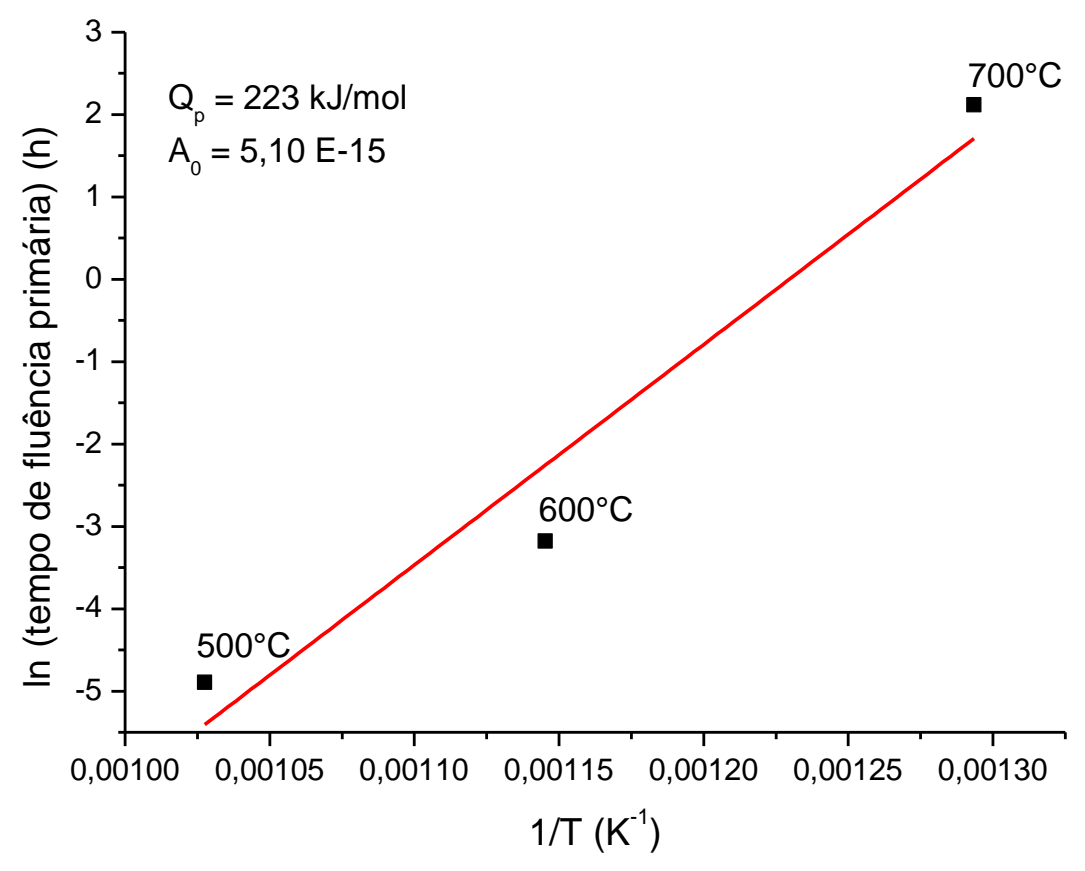

Figura 48 - Dependência do tempo de fluência primária com a temperatura aplicada a $319 \mathrm{MPa}$.

5.4.5 Dependência do tempo de ruptura com a taxa de fluência estacionária (Relação de Monkman-Grant)

As taxas mínimas de fluência obtidas ao longo do estágio secundário foram relacionadas com os tempos de ruptura a tensão de $319 \mathrm{MPa}$. Dessa forma, procurou-se avaliar os parâmetros da relação originalmente proposta por 
Monkman e Grant conforme mostra a Figura 49. Os valores de M e C, foram obtidos por regressão linear. Esta relação pode ser descrita como:

$$
t_{f}\left(\dot{\varepsilon}_{s}\right)^{M}=C
$$

O parâmetro $\mathrm{M}$ corresponde a uma medida da influência da taxa de fluência secundária no tempo de ruptura por fluência e $C$ é uma constante de proporcionalidade característica do material.

Em geral, são encontrados valores de M por volta da unidade para vários materiais, indicando uma proporcionalidade entre o tempo de ruptura e a taxa de deformação no estágio secundário, como proposto por Monkman e Grant (MONKMAN; GRANT, 1956). Apesar das diferenças nas condições de ensaio (não tratadas e nitretada por plasma e tratadas com IIIP), os dados obtidos a 319 MPa seguem a relação de Monkman-Grant, como mostrado na Figura 49.

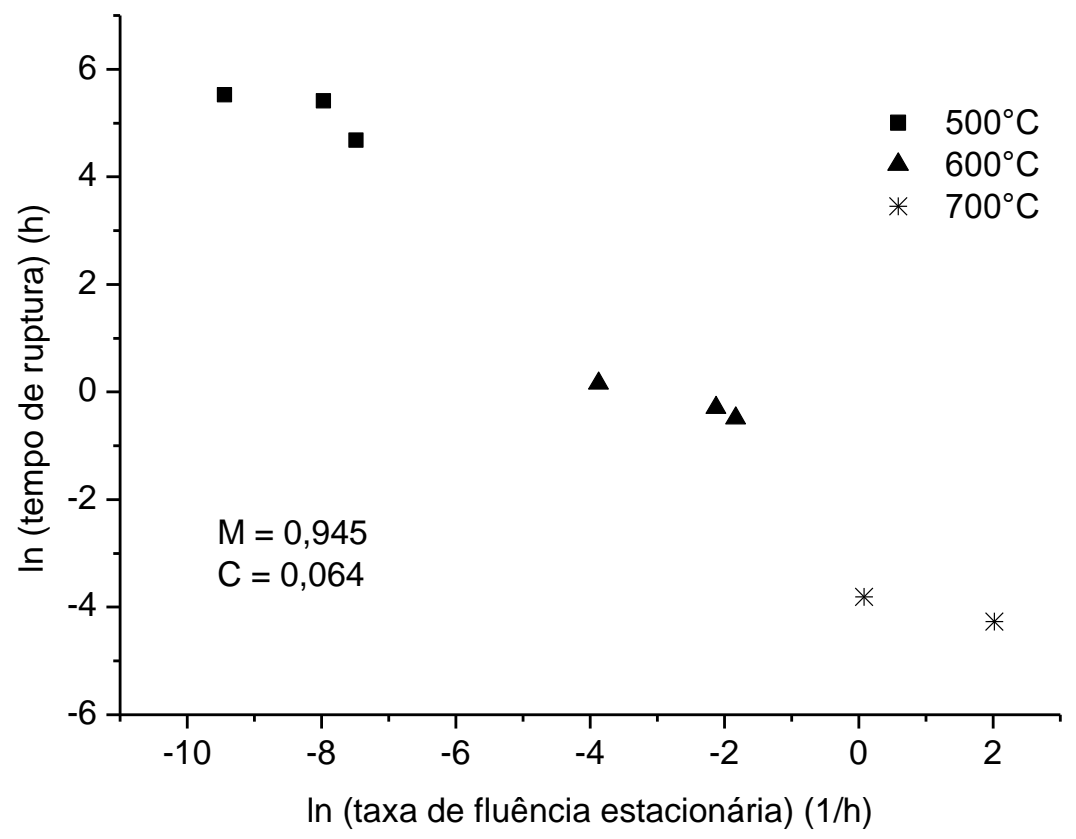

Figura 49 - Dependência da taxa de fluência estacionária com a tensão aplicada de $319 \mathrm{MPa}$ para as condições Widmanstätten (sem tratamento, nitretada por plasma e com IIIP).

Como todas as condições seguem a mesma relação, significa que o processo envolvendo escorregamento e escalagem de discordâncias. A Tabela 17 mostra o resumo dos valores $\mathrm{M}$ e $\mathrm{C}$ encontrados na literatura e neste trabalho para a liga Ti-6Al-4V. 
Tabela 17 - Valores das constantes M e C para a relação Monkman-Grant.

\begin{tabular}{|c|c|c|c|}
\hline Autores & Condições & $\mathbf{M}$ & C \\
\hline $\begin{array}{l}\text { (BARBOZA, } \\
\text { 2001) }\end{array}$ & Microestrutura equiaxial (ensaiado ao ar) & 1,043 & 0,068 \\
\hline (REIS, 2005) & $\begin{array}{l}\text { Microestrutura equiaxial (ensaio ao ar e em } \\
\text { atmosfera de } \mathrm{N}_{2} \text { ) }\end{array}$ & 1,102 & 0,092 \\
\hline $\begin{array}{l}\text { (BRIGUENTE, } \\
\text { 2015) }\end{array}$ & $\begin{array}{l}\text { Microestrutura equiaxial (sem recobrimento, } \\
\text { com recobrimento metálico e com TBC }\end{array}$ & 0,967 & 0,150 \\
\hline (YOGI, 2012) & $\begin{array}{c}\text { Microestrutura equiaxial, Widmanstätten e } \\
\text { martensita (com IIIP) }\end{array}$ & 0,919 & 0,125 \\
\hline (REIS, 2012) & $\begin{array}{c}\text { Microestrutura equiaxial (sem tratamento e } \\
\text { nitretada por laser) }\end{array}$ & 0,933 & 0,069 \\
\hline $\begin{array}{l}\text { (BRIGUENTE, } \\
\text { 2011) }\end{array}$ & $\begin{array}{l}\text { Microestrutura bimodal, martensita e } \\
\text { Widmanstätten (sem recobrimento e com TBC) }\end{array}$ & 1,047 & 0,082 \\
\hline $\begin{array}{l}\text { Presente } \\
\text { trabalho }\end{array}$ & $\begin{array}{c}\text { Microestrutura Widmanstätten (sem tratamento, } \\
\text { nitretada por plasma e com IIIP) }\end{array}$ & 0,945 & 0,064 \\
\hline
\end{tabular}

\subsubsection{Microscopia óptica}

Após os ensaios de fluência, os corpos de prova foram seccionados e as amostras levadas à análise por microscopia óptica. A Figura 50 apresentada a imagem obtida por MO da seção longitudinal do corpo de prova da liga Ti-6Al-4V após ensaio de fluência na condição $500^{\circ} \mathrm{C}$ a $319 \mathrm{MPa}$ e a Figura 51 na condição $700^{\circ} \mathrm{C}$ a $319 \mathrm{MPa}$. Comparando as duas condições, parece que no ensaio a temperatura mais elevada houve uma recristalização dos grãos, evidenciada por grãos menores próximos à fratura e também uma fratura mais lisa.

Comparando a geometria dos corpos de prova de fluência ensaiados na mesma temperatura, a $600^{\circ} \mathrm{C}$, mostrados nas Figuras 52, 53 e 54 a 125, 250 e $319 \mathrm{MPa}$ respectivamente, pode se observar uma seção mais reduzida na amostra ensaiada a $125 \mathrm{MPa}$ (Figura 52), devido a essa geometria a tensão tornou-se mais alta e causou um arrancamento irregular das bordas. 


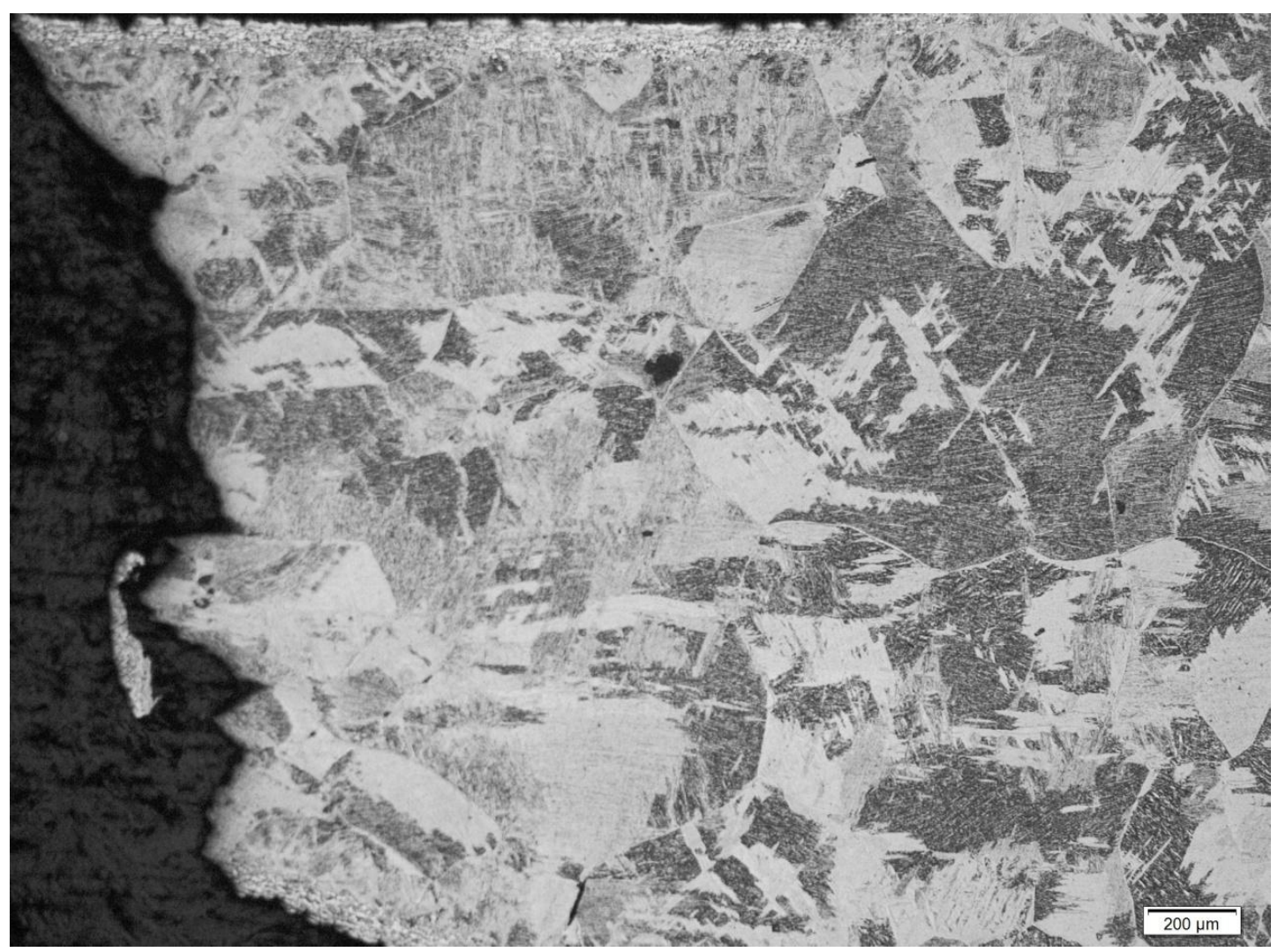

Figura 50 - Microscopia óptica da seção longitudinal do corpo de prova de fluência testado a $500^{\circ} \mathrm{C}$ e $319 \mathrm{MPa}$.

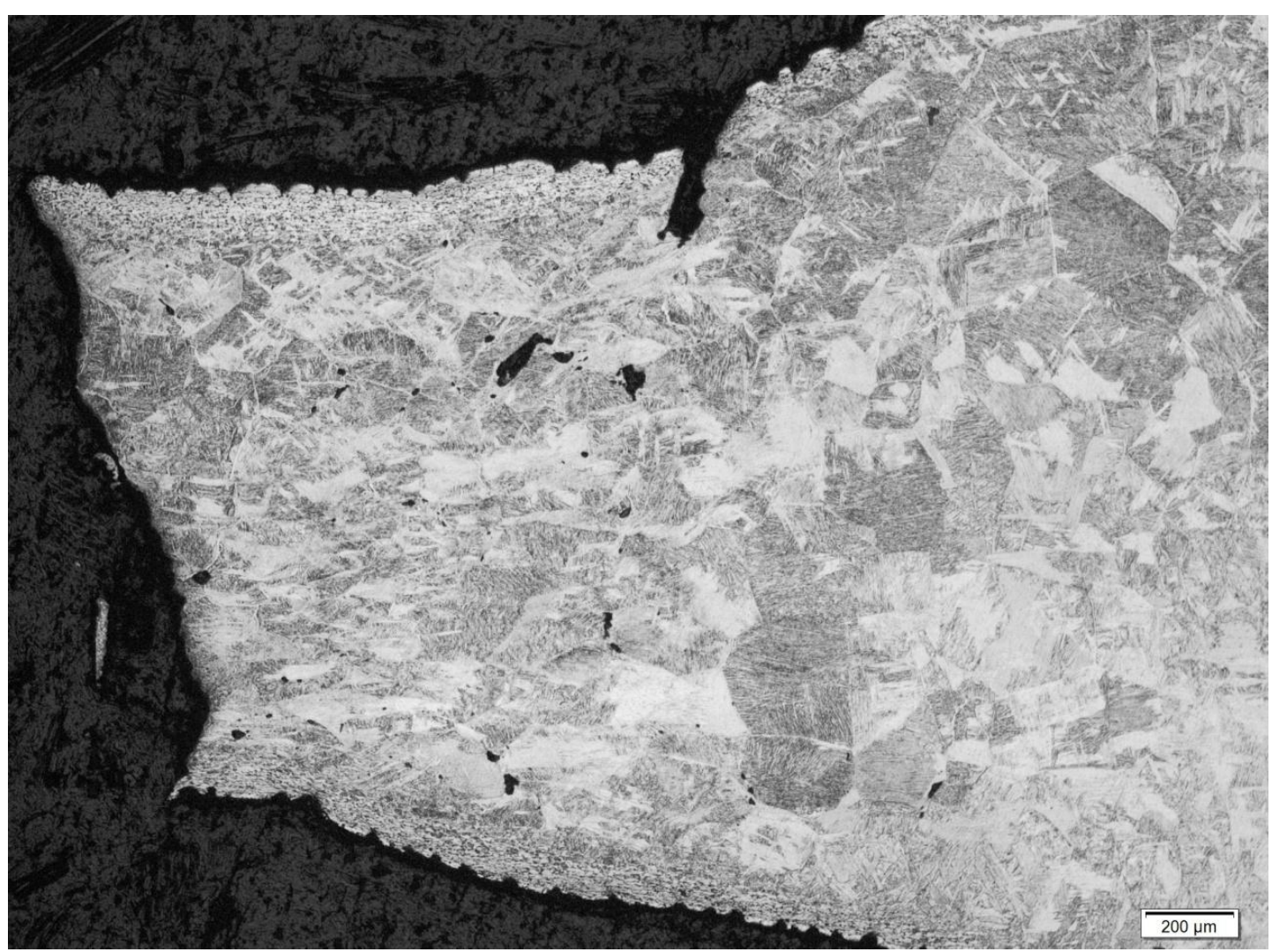

Figura 51 - Microscopia óptica da seção longitudinal do corpo de prova de fluência testado a $700^{\circ} \mathrm{C}$ e $319 \mathrm{MPa}$. 


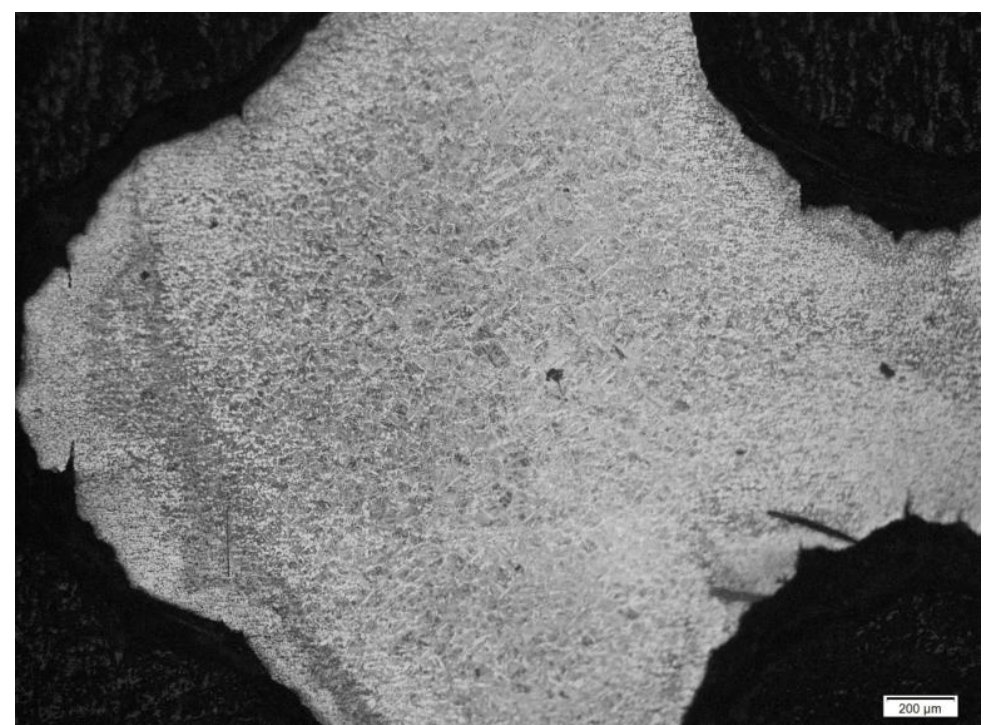

Figura 52 - Microscopia óptica da seção longitudinal do corpo de prova de fluência testado a $600^{\circ} \mathrm{C}$ e $125 \mathrm{MPa}$.

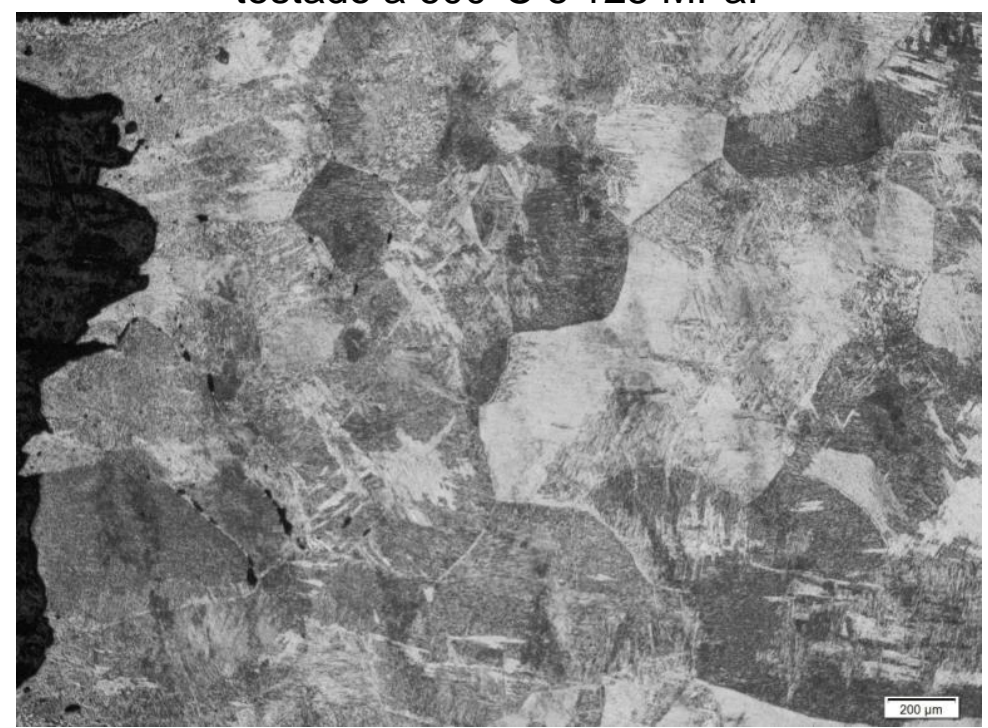

Figura 53 - Microscopia óptica da seção longitudinal do corpo de prova de fluência testado a $600^{\circ} \mathrm{C}$ e $250 \mathrm{MPa}$.

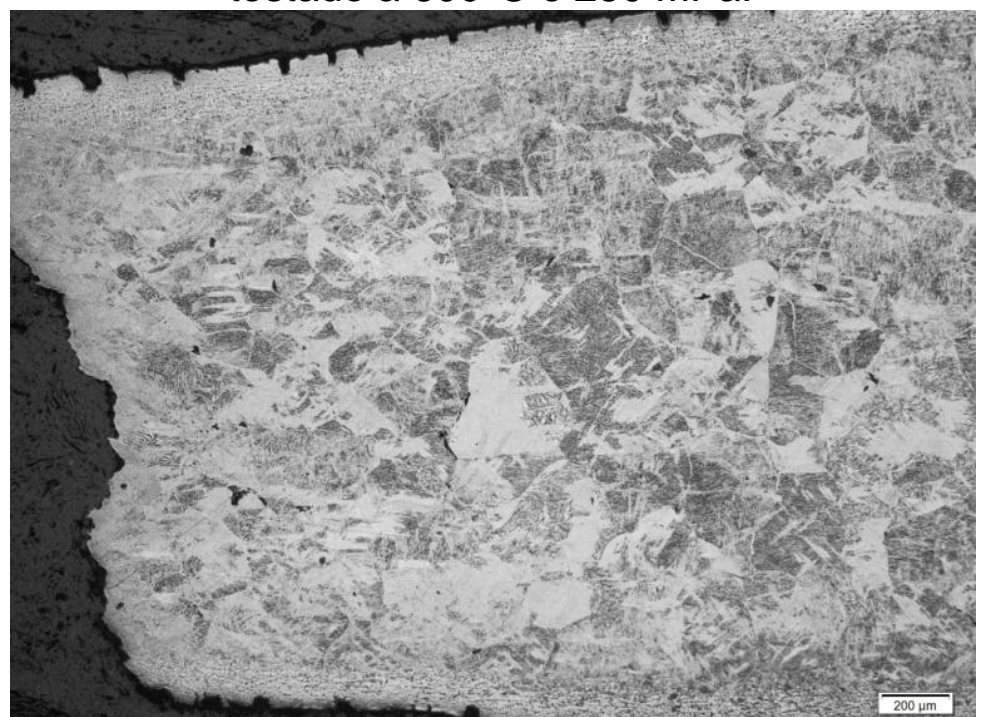

Figura 54 - Microscopia óptica da seção longitudinal do corpo de prova de fluência testado a $600^{\circ} \mathrm{C}$ e $319 \mathrm{MPa}$. 


\subsubsection{Análise fractográfica}

A Figura 55 e a Figura 56 apresentam imagens obtidas por MEV da análise fractográfica da liga Ti-6Al-4V após ensaio preliminar de fluência a $600^{\circ} \mathrm{C}$ e $250 \mathrm{MPa}$. Nestas imagens observa-se a presença de fenômenos de estricção e de microcavidades de pouca profundidade e tamanhos variados, com vazios e membranas alveolares. O que indica que os mecanismos de fratura dúctil foram os que prevaleceram. O mesmo foi observado para parâmetros semelhantes de fluência para o material não nitretado ou com outros tratamentos superficiais por outros autores. (BARBOZA, 2001; SUGAHARA et al., 2008; FREITAS et al., 2010; REIS, 2012; YOGI, 2012; BRIGUENTE, 2015).

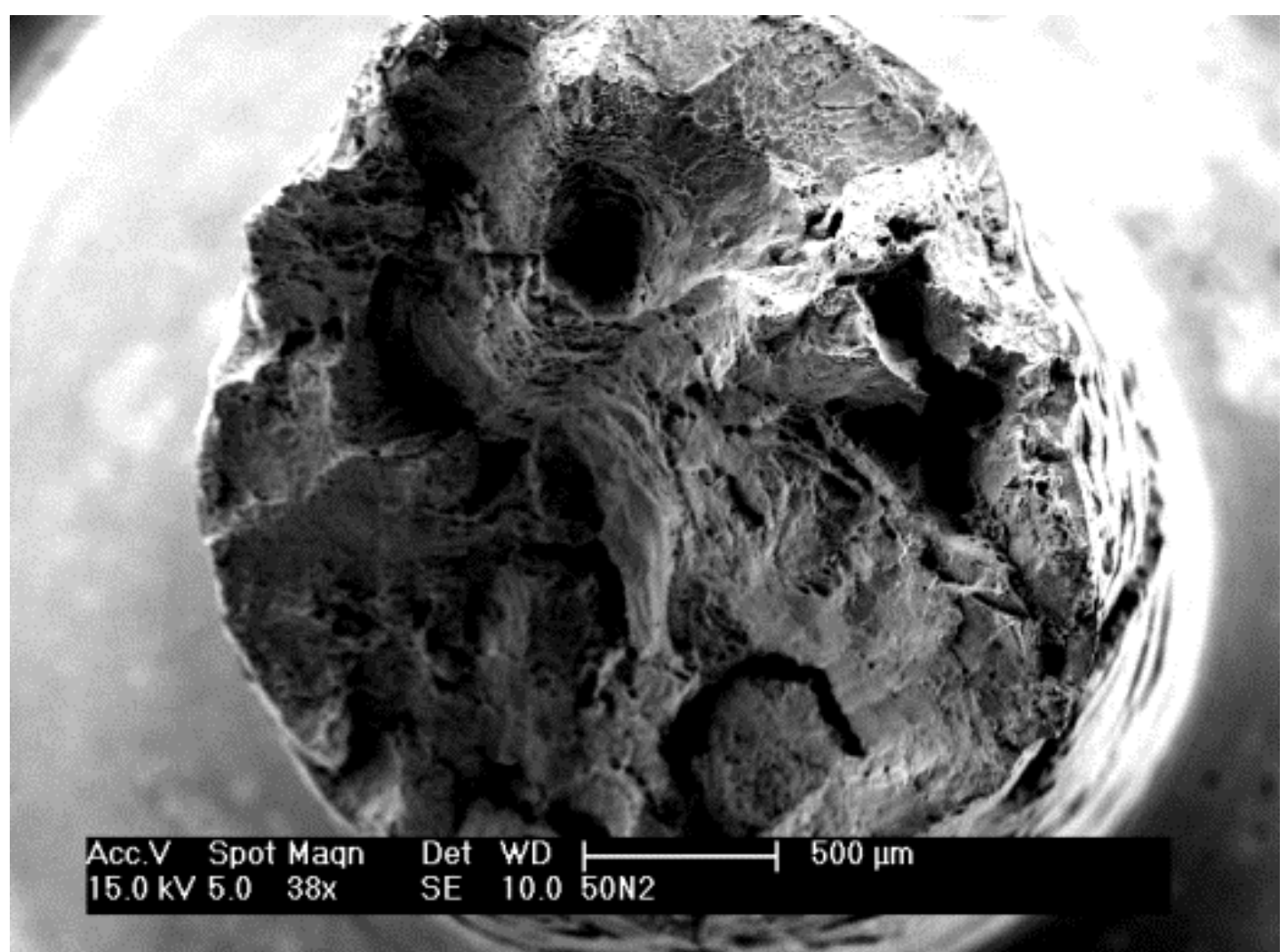

Figura 55 - Aspecto geral da superfície de fratura da liga Ti-6Al-4V com estrutura Widmanstätten após ensaio de fluência a $600^{\circ} \mathrm{C}$ e $250 \mathrm{MPa}$. 


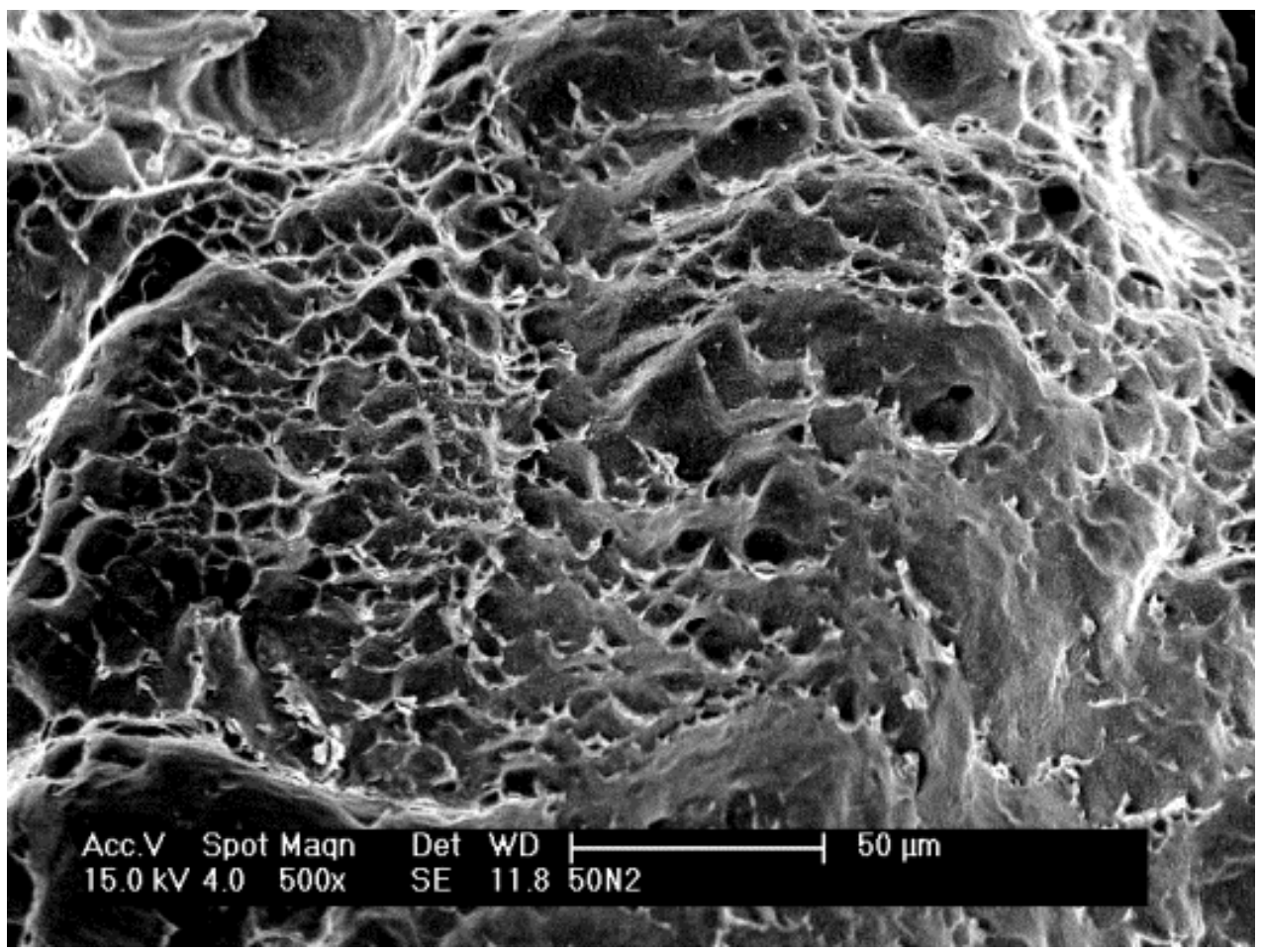

Figura 56 - Análise fractográfica da liga Ti-6Al-4V com estrutura Widmanstätten após ensaio de fluência a $600^{\circ} \mathrm{C}$ e $250 \mathrm{MPa}$ (região interna próxima a borda).

Nas figuras 57 a 59 são apresentadas as imagens obtidas por MEV da análise fractográfica da liga Ti-6Al-4V após ensaio de fluência em todas as condições, que variaram de $500^{\circ}$ a $700^{\circ} \mathrm{C}$ e de $125 \mathrm{MPa}$ até $319 \mathrm{MPa}$.

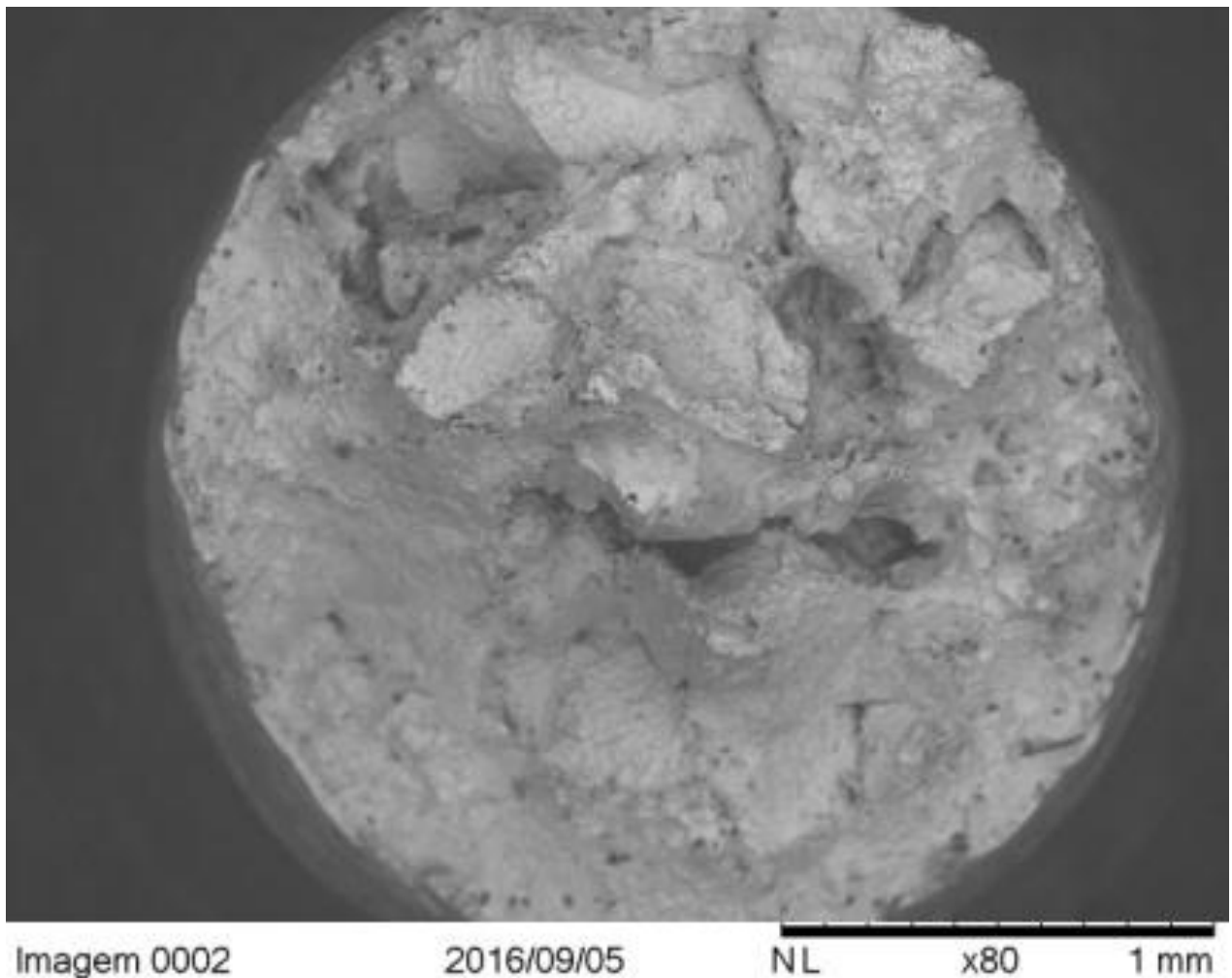

Figura 57 - Aspecto geral da superfície de fratura da liga Ti-6Al-4V após ensaio de fluência a $500^{\circ} \mathrm{C}$ e $319 \mathrm{MPa}$ e analisado por MEV. 


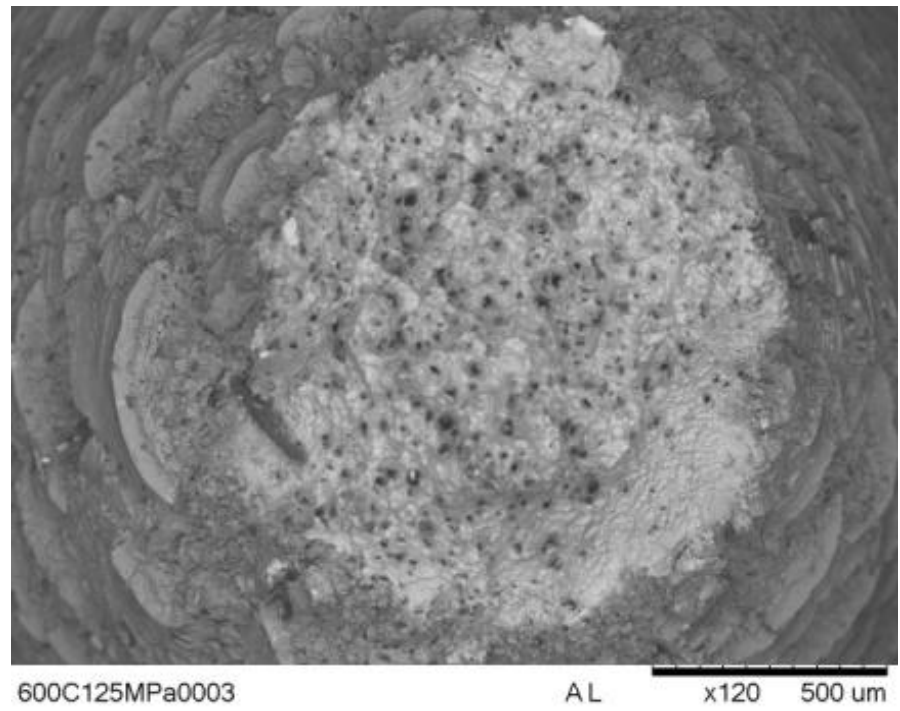

(a)

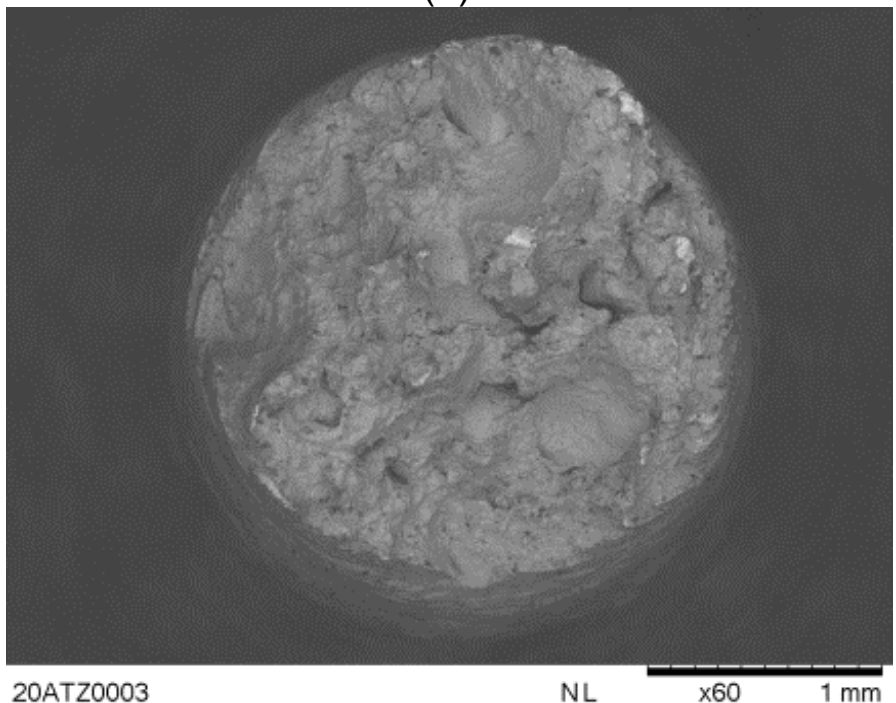

(b)

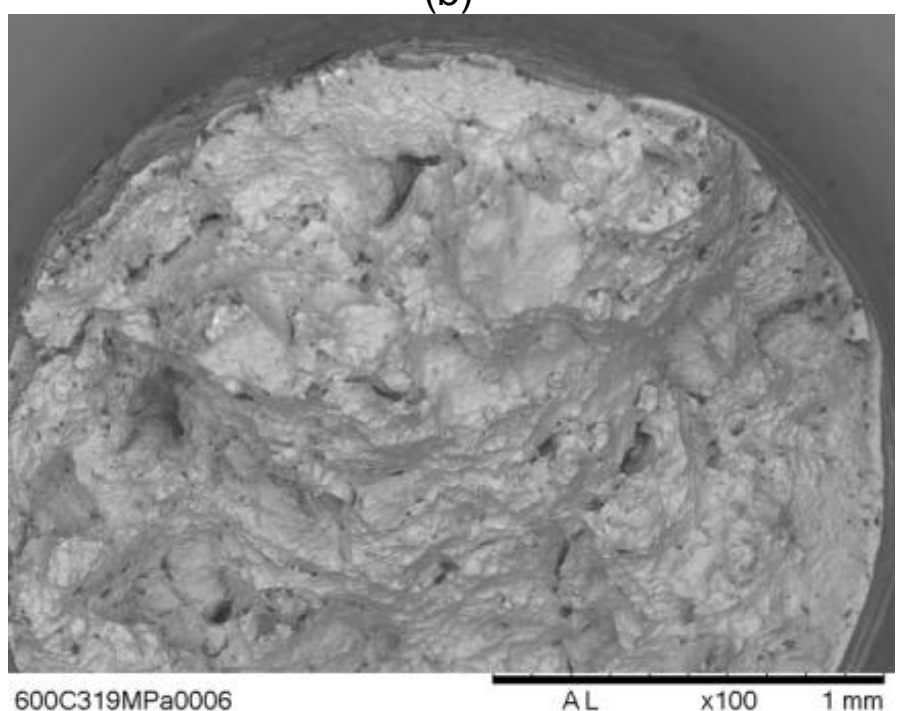

(c)

Figura 58 - Aspecto geral da superfície de fratura da liga Ti-6Al-4V após ensaio de fluência a $600^{\circ} \mathrm{C}$ e (a) $125 \mathrm{MPa}$, (b) $250 \mathrm{MPa}$ e (c) 319MPa e analisado por MEV. 


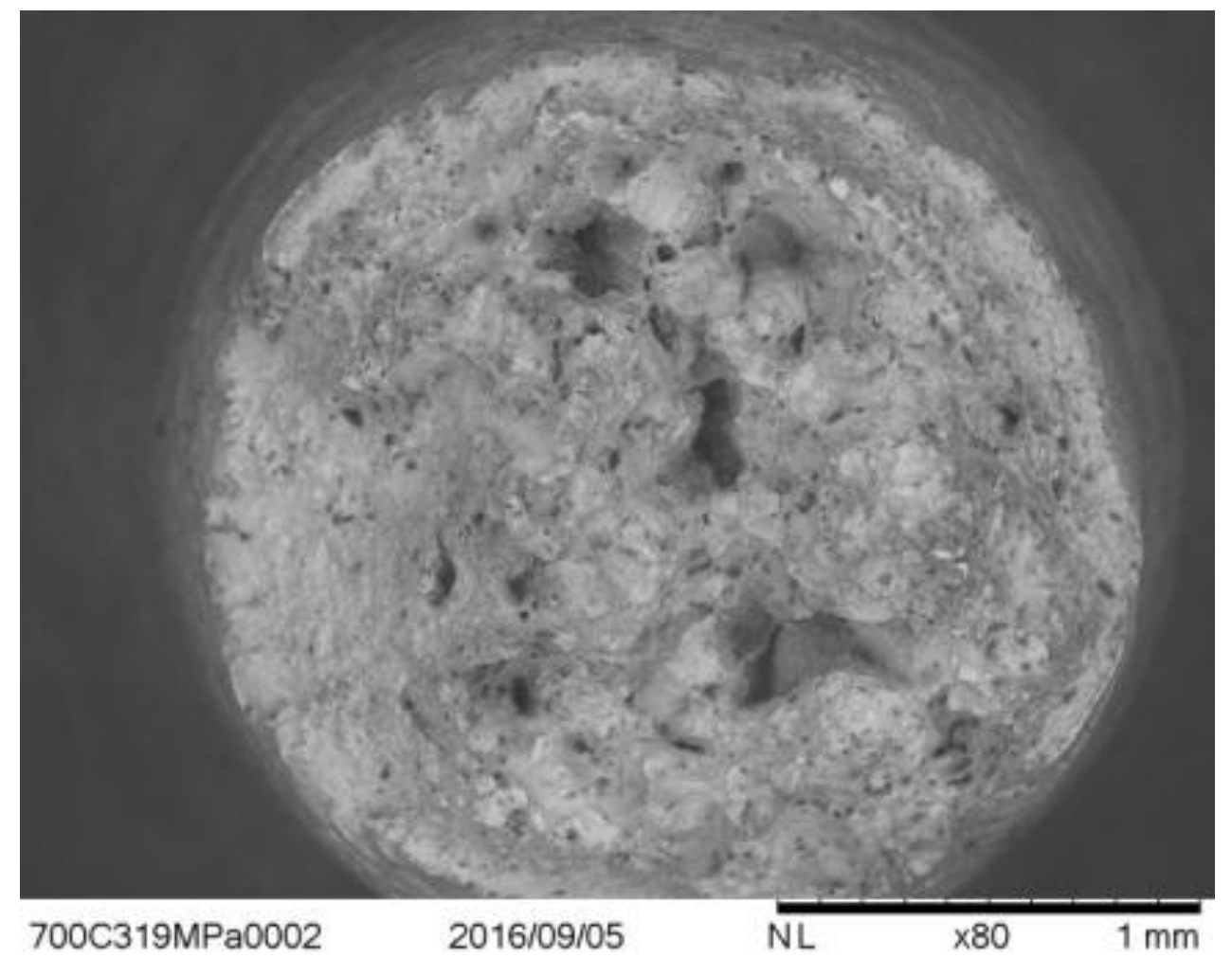

Figura 59 - Aspecto geral da superfície de fratura da liga Ti-6Al-4V após ensaio de fluência a $500^{\circ} \mathrm{C}$ e $319 \mathrm{MPa}$ e analisado por MEV.

Pode-se observar que em todas as condições há indícios de fratura dúctil com a presença de alvéolos ("dimples") e microcavidades. Estes alvéolos são gerados devido ao grande número de heterogeneidades microestruturais, tais como, contornos de grão, partículas, inclusões e discordâncias. O coalescimento destas microcavidades leva a uma ruptura gradual e contínua do material, formando uma fratura do tipo taça e cone. A aparência irregular e fibrosa da superfície de fratura observada indica que houve deformação plástica (STONE et al., 1985; ASM INTERNATIONAL, 1987).

As Figuras 60, 61 e 62 mostram a superfície de fratura analisada por MEV da liga Ti-6Al-4V após ensaio de fluência a 600ㄷ e tensões de 125, 250 e $319 \mathrm{MPa}$ respectivamente. Pode-se observar que em tensões menos elevadas onde o tempo até a fratura foi maior a oxidação superficial é mais elevada. 


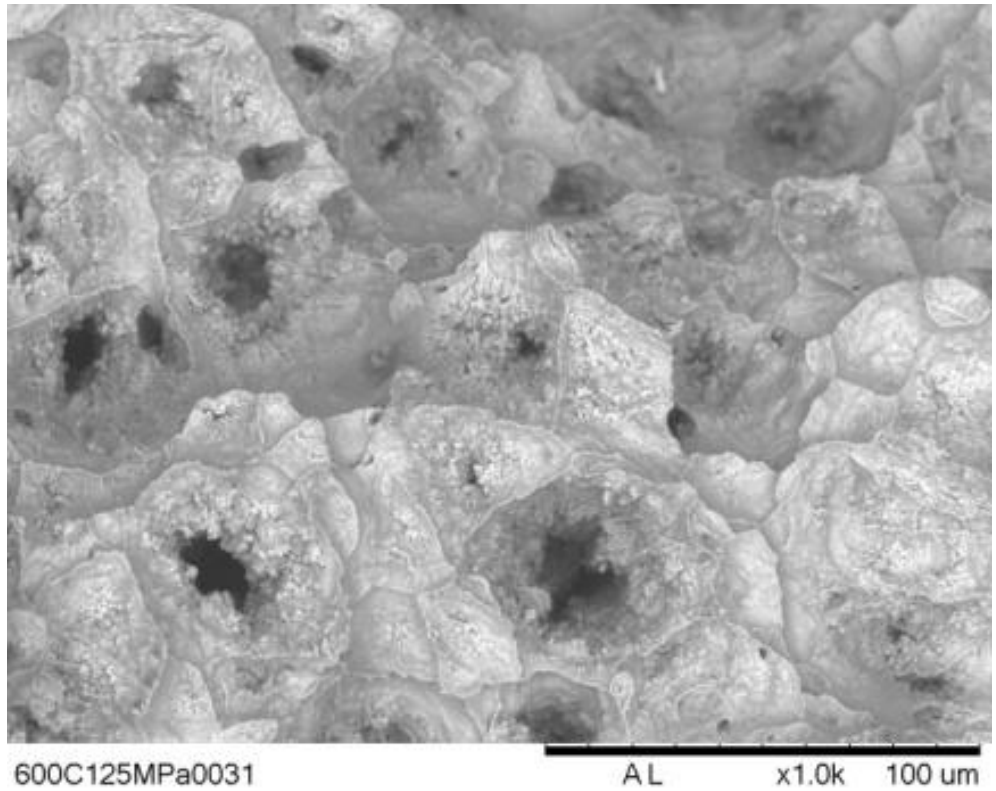

Figura 60 - Análise fractográfica por MEV da liga Ti-6Al-4V ensaiada a $600^{\circ} \mathrm{C}$ e $125 \mathrm{MPa}$.

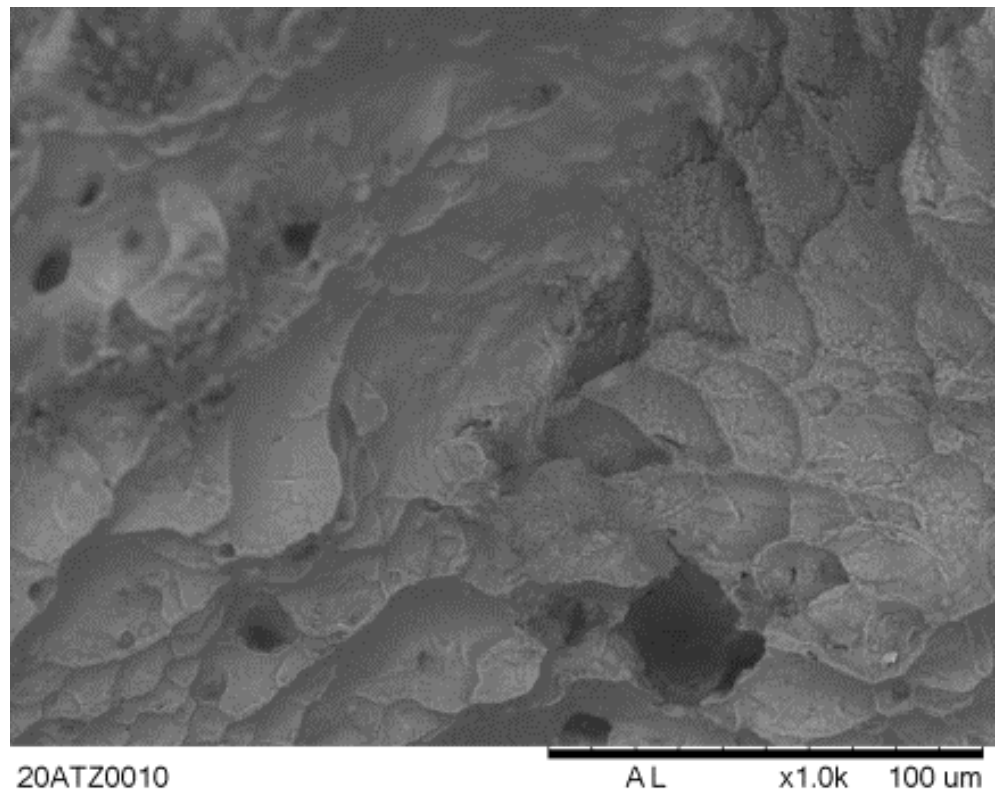

Figura 61 - Análise fractográfica por MEV da liga Ti-6Al-4V ensaiada a $600^{\circ} \mathrm{C}$ e $250 \mathrm{MPa}$. 


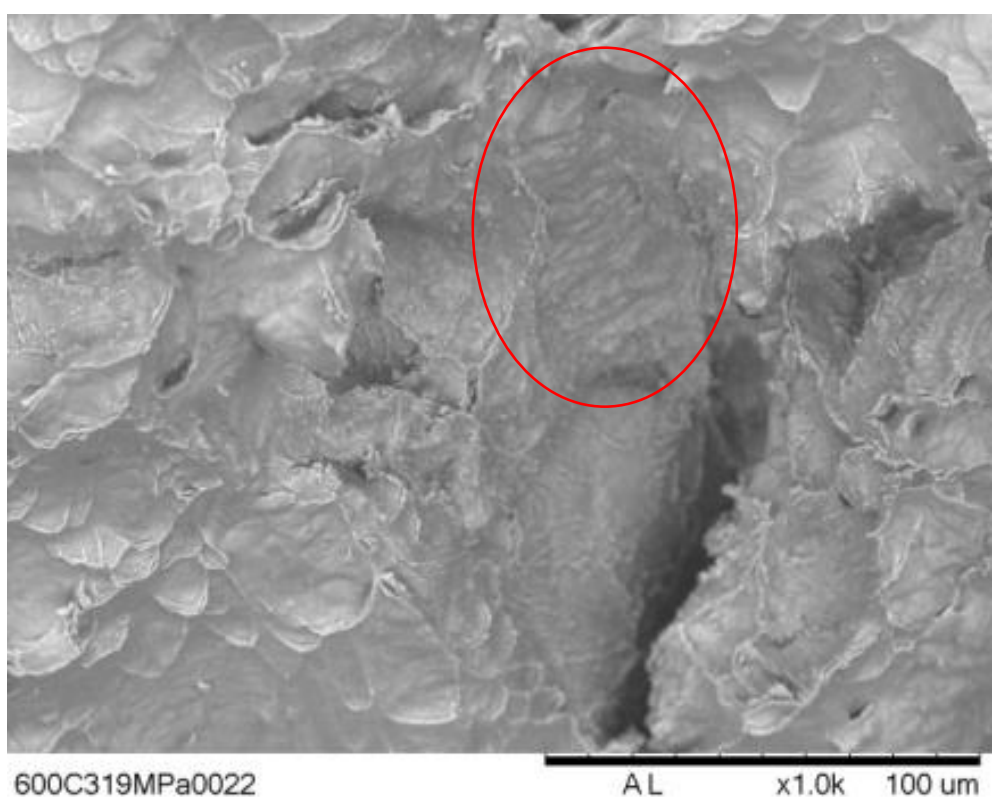

Figura 62 - Análise fractográfica por MEV da liga Ti-6Al-4V ensaiada a $600^{\circ} \mathrm{C}$ e $319 \mathrm{MPa}$.

(a)

(b) (c)

$\mathrm{Na}$ amostra ensaiada a $125 \mathrm{MPa}$ (Figura 60) pode-se observar cavidades "dimples" mais equiaxiais que representam uma típica fratura dúctil, na amostra a $250 \mathrm{MPa}$ (Figura 61) é possível observar cavidades mais alongadas "oval dimples". Na amostra a 319 MPa (Figura 62) a ação da tensão foi mais isolada em relação a oxidação e pode-se observar cavidades "dimples" típicos de cisalhamento. A região com o círculo vermelho nesta imagem (Figura 62) mostra a formação de bandas de escorregamento "slip lines"(ASM INTERNATIONAL, 1987).

Estas bandas de deformações ou de escorregamento também podem ser observadas na Figura 63 (região com círculo vermelho), material ensaiado a $700^{\circ} \mathrm{C}$ e $319 \mathrm{MPa}$. A presença destas bandas de deformação mostra a facilidade de mudança de plano das discordâncias devido à alta temperatura. 


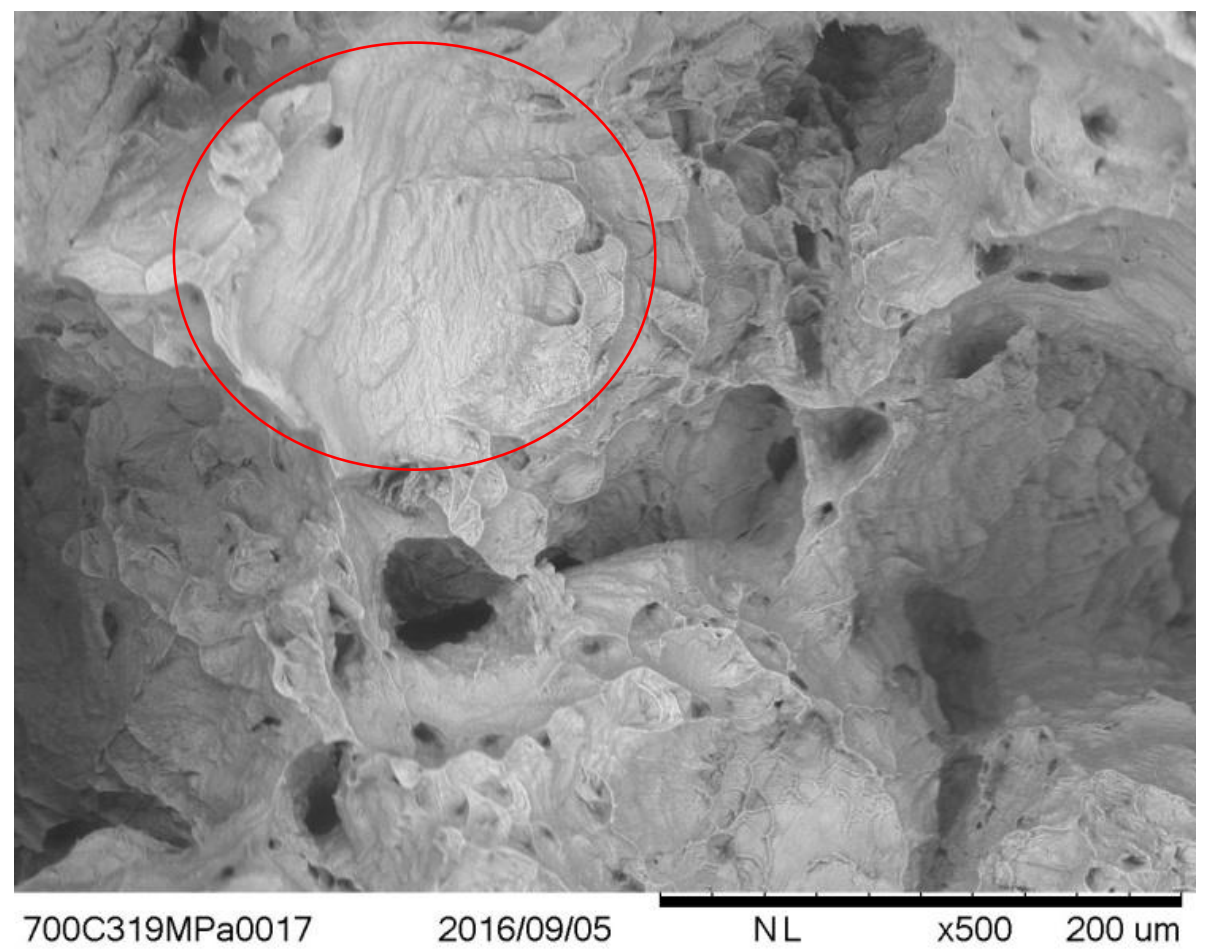

Figura 63 - Análise fractográfica por MEV da liga Ti-6Al-4V ensaiada a $700^{\circ} \mathrm{C}$ e $319 \mathrm{MPa}$ 


\section{CONSIDERAÇÕES FINAIS}

\subsection{Conclusões}

O estudo dos parâmetros de nitretação por plasma e do comportamento em fluência da liga Ti-6Al-4V nitretada permite conduzir as seguintes conclusões:

- Das condições de nitretação de plasma da liga Ti-6Al-4V estudada, variando o teor de $\mathrm{N}_{2}$ na atmosfera nitretante de 25 a $75 \%$, a amostra nitretada durante 4 horas a $750^{\circ} \mathrm{C}$ numa atmosfera contendo $50 \%$ de $\mathrm{N}_{2}$ foi a que teve a maior espessura de camada de nitretos formada, cerca de $12 \mu \mathrm{m}$ de espessura.

- Em todas as condições de nitretação foram encontrados na análise de DRX a formação dos compostos $\varepsilon-\mathrm{Ti}_{2} \mathrm{~N}$ e $\delta$-TiN, além disso, existe a presença da fase $\alpha$, a mesma encontrada na amostra recebida. A condição de nitretação em atmosfera de $50 \%$ de $\mathrm{N}_{2}$, apresentou maior formação do $\delta$-TiN, composto de composição estequiométrica, confirmado pela coloração dourada da amostra.

- Um teste preliminar de fluência realizado a $600^{\circ} \mathrm{C}$ e $250 \mathrm{MPa}$ mostrou um aumento da resistência à fluência, devido ao aumento do tempo final de ruptura e da diminuição da taxa de fluência secundária da amostra nitretada por plasma.

- Os ensaios de tração a quente efetuados após tratamento térmico a $1050^{\circ} \mathrm{C}$ por 30 minutos para obtenção da microestrutura de Widmanstätten numa gama de temperaturas compreendida entre $500^{\circ} \mathrm{C}$ e $700^{\circ} \mathrm{C}$ no material nitretado e não nitretado revelam um aumento da resistência da liga nitretada por plasma.

- Os corpos de prova de fluência com microestrutura de Widmanstätten foram nitretados por plasma a $690^{\circ} \mathrm{C}$ por 4 horas. Para este lote, a camada nitretada formada foi de cerca de $1 \mu \mathrm{m}$ de espessura, a menor espessura desta camada foi devido ao aumento do número de corpos de prova nitretados simultaneamente, aumentando desta forma a massa a ser nitretada e dificultando o aumento da temperatura do tratamento. 
- Os resultados dos ensaios de fluência a $600^{\circ} \mathrm{C}$ e $250 \mathrm{MPa}$ realizados na amostra preliminar nitretada a $750^{\circ} \mathrm{C}$ e do lote definitivo nitretado a $690^{\circ} \mathrm{C}$ no material mostraram uma aumento ainda maior na resistência a fluência da condição nitretada a menor temperatura.

- O estudo do comportamento em fluência da liga Ti-6Al-4V com microestrutura de Widmanstätten nitretada por plasma, nas condições de $500^{\circ} \mathrm{C}$ e $319 \mathrm{MPa}$ e de $600^{\circ} \mathrm{C}$ nas tensões 125 , 250 e $319 \mathrm{MPa}$ e $700^{\circ} \mathrm{C}$ e $319 \mathrm{MPa}$ mostraram um aumento na resistência à fluência quando comparado com as amostras não tratadas e também as tratadas por IIIP. Isto foi evidenciado tanto pela diminuição da taxa de fluência secundária, como pelo aumento do tempo de fluência final e ainda pelo aumento do tempo de fluência primário.

- As energias de ativação de fluência medidas e a dependência da taxa de deformação de fluência no estado estacionário na condição estudada estão dentro da faixa de valores encontradas na literatura. Para a dependência da taxa de tensão de fluência no estado estacionário com tensão segue-se a lei da potência próxima ao modelo de difusão, onde $n$ tem valores aproximadamente entre 4 e 5 . Esta faixa de energia de ativação é corente com os valores de autodifusão do titânio, confirmando o mecanismo predominante de escalagem da discordância durante a fluência. Além disso, a taxa de fluência no estado estacionário e o tempo de ruptura estão relacionados pela relação Monkman-Grant com $\mathrm{M}$ cerca de 1 , o que significa que o que acontece no estágio terciário segue uma relação do estágio secundário.

- A análise fractográfica do material após o ensaio de fluência mostrou que a fratura foi do tipo dúctil com a presença de cavidades "dimples" e forma de taça e cone. Ensaios com maior tempo até a fratura, ou seja, realizados a tensões mais baixas apresentaram uma maior oxidação superficial. 


\subsection{Sugestões para trabalhos futuros}

As seguintes linhas de pesquisa podem ser seguidas para dar continuidade à compreensão dos resultados encontrados neste trabalho:

- Para o melhor entendimento dos micromecanismos de deformação e fratura da liga de Ti-6Al-4V seria necessário uma análise por microscopia de transmissão.

- Poderia também ser realizado um estudo da influência da espessura da camada de nitretos formada variando os parâmetros de nitretação por plasma nas propriedades de fluência da liga Ti-6Al-4V. 


\section{REFERÊNCIAS BIBLIOGRÁFICAS}

ABKOWITZ, S.; BURKE, J. J.; HILTZ JR., R. H. Titanium in industry: technology of structural titanium. New York, USA: D. Van Nostrand Company, 1955.

ALI, M. M.; RAMAN, S. G. S. Effect of Plasma Nitriding Environment and Time on Plain Fatigue and Fretting Fatigue Behavior of Ti-6Al-4V. Tribology letters, v. 38, n. 3, p. 291-299, 2010.

ALI, M. M.; RAMAN, S. G. S.; PATHAK, S. D.; GNANAMOORTHY, R. Influence of plasma nitriding on fretting wear behaviour of Ti-6Al-4V. Tribology International, v. 43, n. 1-2, p. 152-160, jan. 2010.

ALMEIDA, G. F. C. Caracterização microestrutural da liga ti-6al-4v comercial utilizada como biomaterial. 2007. (Trabalho de conclusão de curso) Universidade Presbiteriana Mackenzie, 2007.

ALVES, L. A.; DAMIÃO, A. J.; FONTANA, L. C. Propriedades Óticas de Filmes de TiN Depositados por Triodo Magnetron Sputtering. Revista Matéria, v. 9, n. 4, p. 420 - 425, 2004.

AMERICAN SOCIETY FOR TESTING AND MATERIALS (ASTM). ASTM E21-09 Standard Test Methods for Elevated Temperature Tension Tests of Metallic MaterialsWest Conshohocken, PA, 2009.

AMERICAN SOCIETY FOR TESTING AND MATERIALS (ASTM). ASTM E139-11 Standard Test Methods for Conducting Creep, Creep Rupture, and Stress Rupture Tests of Metallic MaterialsWest Conshohocken, PA, 2011. .

AMERICAN SOCIETY FOR TESTING AND MATERIALS (ASTM). ASTM B265-15 Standard Specification for Titanium and Titanium Alloy Strip, Sheet, and PlateWest Conshohocken, PA, 2015.

ANDRADE, E. N. da C. On the Viscous Flow in Metals, and Allied Phenomena. In: Proceedings of the Royal Society A: Mathematical, Physical and Engineering Sciences, 567, Anais...9 jun. 1910. Disponível em: $<$ http://rspa.royalsocietypublishing.org/content/84/567/1>. Acesso em: $14 \mathrm{fev}$. 2015.

ASM INTERNATIONAL. v.12 Fractography. In: ASM Handbook. Ohio: ASM International, 1987. p. 857.

ASM INTERNATIONAL. V.4 heat treating. Ohio: ASM International, 1991.

ASM INTERNATIONAL. Properties and Selection: Nonferrous Alloys and SpecialPurpose Materials. In: ASM handbook. Ohio: ASM International, 2001. v.2p. 3470.

BARBOZA, M. J. R. Estudo e modelagem sob condições de fluência da liga ti6al-4v. 2001. Tese (Doutorado) - Instituto Tecnológico de Aeronáutica, 2001.

BARBOZA, M. J. R.; MOURA NETO, C.; SILVA, C. R. M. Creep mechanisms and physical modeling for Ti-6Al-4V. Materials Science and Engineering: A, v. 369, n. 1-2, p. 201-209, mar. 2004.

BARBOZA, M. J. R.; PEREZ, E. a. C.; MEDEIROS, M. M.; REIS, D. a. P.; NONO, 
M. C. a.; PIORINO NETO, F.; SILVA, C. R. M. Creep behavior of Ti-6AI-4V and a comparison with titanium matrix composites. Materials Science and Engineering: A, v. 428, n. 1-2, p. 319-326, jul. 2006.

BARSOUM, M. . Fundamentals of ceramics. Bristol and Philadelphia: Institute of Physics Publishing, IOP, 2003.

BELL, T.; BERGMANN, H. W.; LANAGAN, J.; MORTON, P. H.; STAINES, A. M. Surface Engineering of Titanium with Nitrogen. Surface Engineering, v. 2, n. 2, p. 133-143, 19 jan. 1986.

BELL, T.; DONG, H. Proceedings of the. In: 12th IFHT and SE Congress, Anais...2000.

BERBERICH, F.; MATZ, W.; KREISSIG, U.; RICHTER, E.; SCHELL, N.; MÖLLER, W. Structural characterisation of hardening of Ti-Al-V alloys after nitridation by plasma immersion ion implantation. Applied Surface Science, v. 179, n. 1-4, p. 13-19, jul. 2001.

BERBERICH, F.; MATZ, W.; RICHTER, E.; SCHELL, N.; KREISSI, U.; MÖLLER, W. Structural mechanisms of the mechanical degradation of Ti-Al-V alloys: in situ study during annealing. Surface and Coatings Technology, v. 128-129, p. 450454, 2000.

BINGZHONG, X.; YINGZHI, Z. Collision Dissociation Model in lon Nitriding. Surface Engineering, v. 3, n. 3, p. 226-232, 1987.

BLUM, W. Creep of crystalline materials: Experimental basis, mechanisms and models. Materials Science and Engineering A, v. 319-321, p. 8-15, 2001.

BOYER, R.; COLLINGS, E. W.; WELSCH, G. Materials properties handbook: titanium alloys. [s.I.] ASM International, 1993.

BOYER, R. R. An overview on the use of titanium in the aerospace industry. Materials Science and Engineering: A, v. 213, n. 1-2, p. 103-114, ago. 1996.

BRADING, H. J. J.; MORTON, P. H.; BELL, T.; EARWAKER, L. G. The structure and composition of plasma nitrided coatings on titanium. Nuclear Instruments and Methods in Physics Research Section B: Beam Interactions with Materials and Atoms, v. 66, n. 1-2, p. 230-236, 1992.

BRÅTHE, L.; JOSEFSON, L. Estimation of Norton-Bailey Parameters from Creep Rupture Data. Metal Science, v. 13, n. 5, p. 660-664, 1979.

BRIGUENTE, F. P. Estudo dos recobrimentos metálico e cerâmico no comportamento em fluência da liga ti-6al-4v. 2015. Tese (Doutorado) - Instituto Técnológico de Aeronáutica, 2015.

BRIGUENTE, L. A. N. da S. Estudo de tratamento térmico e recobrimento como forma de barreira térmica sobre o comportamento em fluência da liga ti-6al-4v. 2011. Dissertação (Mestrado) - Instituto Tecnológico de Aeronaútica, 2011.

BRIGUENTE, L. A. N. da S.; BRIGUENTE, F. P.; REIS, D. a. P.; MOURA NETO, C.; RESENDE, F. A. Avaliação do Comportamento em fluência da liga Ti-6Al-4V com Estrutura Martensítica e Equiaxial a $600^{\circ} \mathrm{C}$. Tecnologia em Metalurgia, Materiais e Mineração, v. 10, p. 324-328, 2013.

CABESTRÉ, C. R. Evolução microestrutural da liga ti-6al-4v após diferentes tratamentos térmicos. 2013. 2013. 
CALLISTER, W. D.; RETHWISCH, D. G. Fundamentals of materials science and engineering: an integrated approach. edition ed. [s.I.] Hoboken, N.J.: Wiley, 2012.

CORTEZ, L. D.; REIS, D. A. P.; BRIGUENTE, L. A. N. da S.; MOURA NETO, C. Tratamentos Térmicos da Liga TI-6Al-4V para Realização de Ensaio de Fluência. In: XIII ENCITA, Anais...2007. Disponível em: $<$ http://www.bibl.ita.br/xiiiencita/MEC02.pdf>. Acesso em: 8 jun. 2014.

COUTO, A. A.; FALDINI, S. B.; ALMEIDA, G. F. C.; SEKERES, T. S.; KUNIOSHI, C. T.; MORCELLI, A. E.; LIMA, N. B. Caracterização microestrutural da liga Ti-6Al4V comercial utilizada como biomaterial. In: CONGRESSO BRASILEIRO DE ENGENHARIA E CIÊNCIAS DOS MATERIAIS, Foz do Iguaçu - PR. Anais... Foz do Iguaçu - PR: 2006.

CZERWIEC, T.; MICHEL, H.; BERGMANN, E. Low-pressure, high-density plasma nitriding: mechanisms, technology and results. Surface and Coatings Technology, v. 108-109, p. 182-190, out. 1998.

DA SILVA, S. L. R.; KERBER, L. O.; AMARAL, L.; DOS SANTOS, C. A. X-ray diffraction measurements of plasma-nitrided Ti-6Al-4V. Surface and Coatings Technology, v. 116-119, p. 342-346, set. 1999.

DALTON, H. R. Titanium Demand and Trends in the Jet Engine Market. In: Paper Presented on Titanium USA 2013 Conference Proceedings. Titanium USA 2013, Caesars Palace, Las Vegas, Nevada, USA, Las Vegas, Nevada, USA. Anais... Caesars Palace, Las Vegas, Nevada, USA, Las Vegas, Nevada, USA: 2013.

DE MELO, I. G.; REIS, D. A. P.; MOURA NETO, C. ESTUDO MICROESTRUTURAL DALIGA Ti-6AI-4V APÓS ENSAIO DE FLUÊNCIA. 2009.

DIETER, G. E. Mechanical metallurgy. London: McGraw Hill, 1988.

DONACHIE, M. J. Titanium: a technical guide. Ohio: ASM International, 2000.

DUSHMAN, S.; DUNBAR, L. W.; HUTHSTEINER, H. Creep of metals. Journal of Applied Physics, v. 15, n. 1944, p. 108-124, 1944.

DYSON, B. F.; MCLEAN, M. Creep Deformation of Engineering Alloys: Developments from Physical Modelling. ISIJ International, v. 30, n. 10, p. 802811, 1990.

EL-HOSSARY, F. M.; NEGM, N. Z.; KHALIL, S. M.; RAAIF, M. Effect of continuous and cyclic Rf plasma processing time on titanium surface. Applied Surface Science, v. 239, n. 2, p. 142-153, jan. 2005.

EROLA, M. Nitrogen migration and nitride formation during low temperature reactive annealing of titanium. Thin Solid Films, v. 156, n. 1, p. 117-125, jan. 1988.

ES-SOUNI, M. Primary, secondary and anelastic creep of a high temperature near a-Ti alloy Ti6242Si. Materials Characterization, v. 45, p. 153-164, 2000.

ES-SOUNI, M. Creep deformation behavior of three high-temperature near $\alpha-T i$ alloys: IMI 834, IMI 829, and IMI 685. Metallurgical and Materials Transactions A, v. 32, n. 2, p. 285-293, fev. 2001a.

ES-SOUNI, M. Creep behaviour and creep microstructures of a high-temperature titanium alloy Ti-5.8Al-4.0Sn-3.5Zr-0.7Nb-0.35Si-0.06C (Timetal 834). Materials Characterization, v. 46, n. 5, p. 365-379, maio 2001b. 
EVANS, R. W.; WILSHIRE, B. Introduction to creep. London, England: The Institute of Materials, 1993.

EYLON, D.; FUJISHIRO, S.; POSTANS, P.; FROES, F. H. High-Temperature Titanium Alloys-A Review. JOM, v. 36, n. 11, p. 55-62, 1984.

FARÈ, S.; LECIS, N.; VEDANI, M.; SILIPIGNI, A.; FAVOINO, P. Properties of nitrided layers formed during plasma nitriding of commercially pure $\mathrm{Ti}$ and $\mathrm{Ti}-6 \mathrm{Al}-$ 4V alloy. Surface and Coatings Technology, v. 206, n. 8-9, p. 2287-2292, jan. 2012.

FERNANDES, A. C.; VAZ, F.; ARIZA, E.; ROCHA, L. A.; RIBEIRO, A. R. L.; VIEIRA, A. C.; RIVIËRE, J. P.; PICHON, L. Tribocorrosion behaviour of plasma nitrided and plasma nitrided+oxidised Ti6Al4V alloy. Surface and Coatings Technology, v. 200, n. 22-23, p. 6218-6224, jun. 2006.

FOUQUET, V.; PICHON, L.; DROUET, M.; STRABONI, A. Plasma assisted nitridation of Ti-6Al-4V. Applied Surface Science, v. 221, n. 1-4, p. 248-258, jan. 2004a.

FOUQUET, V.; PICHON, L.; STRABONI, A.; DROUET, M. Nitridation of Ti6AI4V by PBII: study of the nitrogen diffusion and of the nitride growth mechanism. Surface and Coatings Technology, v. 186, n. 1-2, p. 34-39, ago. 2004b.

FREITAS, F. E. de; SILVA, M. M.; SUGAHARA, T.; REIS, D. A. P.; MOURA NETO, C.; UEDA, M. Efeito do Tratamento de Implantação lônica por Imersão em Plasma nas Propriedades da Liga Ti-6Al-4V à Altas Temperaturas. Revista Brasileira de Aplicações de Vácuo, v. 28, n. 3-4, p. 55-58, 2010.

FU, Y.; ZHU, X.; TANG, B.; HU, X.; HE, J.; XU, K.; BATCHELOR, A. W. Development and characterization of $\mathrm{CrN}$ films by ion beam enhanced deposition for improved wear resistance. Wear, v. 217, n. 2, p. 159-166, maio 1998.

GALLIANO, F.; GALVANETTO, E.; MISCHLER, S.; LANDOLT, D. Tribocorrosion behavior of plasma nitrided $\mathrm{Ti}-6 \mathrm{Al}-4 \mathrm{~V}$ alloy in neutral $\mathrm{NaCl}$ solution. Surface and Coatings Technology, v. 145, n. 1-3, p. 121-131, ago. 2001.

GARCÍA-ALONSO, M. C.; SALDAÑA, L.; VALLÉS, G.; GONZÁLEZ-CARRASCO, J. L.; GONZÁLEZ-CABRERO, J.; MARTÍNEZ, M. E.; GIL-GARAY, E.; MUNUERA, L. In vitro corrosion behaviour and osteoblast response of thermally oxidised Ti6Al4V alloy. Biomaterials, v. 24, n. 1, p. 19-26, 2003.

GARDNER, A. Tight times for titanium. Metal Bulletin Monthly, v. v. 286, p. 3435, 1994.

GIL, F. J. J.; GINEBRA, M. P. P.; MANERO, J. M. M.; PLANELL, J. A. a. Formation of $\alpha$-Widmanstätten structure: effects of grain size and cooling rate on the Widmanstätten morphologies and on the mechanical properties in Ti6Al4V alloy. Journal of Alloys and Compounds, v. 329, n. 1-2, p. 142-152, nov. 2001.

GOLDEN, P. J.; HUTSON, A.; SUNDARAM, V.; ARPS, J. H. Effect of surface treatments on fretting fatigue of Ti-6Al-4V. International Journal of Fatigue, $v$. 29, n. 7, p. 1302-1310, jul. 2007.

GRILL, A.; RAVEH, A.; AVNI, R. Layer structure and mechanical properties of low pressure r.f. plasma nitrided Ti-6Al-4V alloy. Surface and Coatings Technology, v. 43-44, p. 745-755, dez. 1990.

GÜLERYÜZ, H.; CIMENOĞLU, H. Surface modification of a Ti-6Al-4V alloy by 
thermal oxidation. Surface and Coatings Technology, v. 192, n. 2-3, p. 164170, mar. 2005.

HARRIGAN, W. C. Creep fracture characteristics of weld-repaired cast Ti-6AI-4V. Metallurgical Transactions, v. 5, n. March, p. 565-572, 1974.

HAYES, R. W. Minimum strain rate and primary transient creep analysis of a fine structure orthorhombic titanium aluminide. Scripta Materialia, v. 34, p. 10051012, 1996.

HOSSEINI, S. R.; AHMADI, A. Evaluation of the effects of plasma nitriding temperature and time on the characterisation of Ti $6 \mathrm{Al} 4 \mathrm{~V}$ alloy. Vacuum, v. 87, p. 30-39, jan. 2013.

INTERNATIONAL TITANIUM ASSOCIATION. Titanium - The Infinite Choice. Disponível em: <http://c.ymcdn.com/sites/www.titanium.org/resource/resmgr/Docs/TiUltimate.pdf> . Acesso em: 23 jul. 2014.

ITOH, Y.; ITOH, A.; AZUMA, H.; HIOKI, T. Improving the tribological properties of Ti-6Al-4V alloy by nitrogen-ion implantation. Surface and Coatings Technology, v. 111, n. 2-3, p. 172-176, jan. 1999.

JANUSZEWICZ, B.; SINIARSKI, D. The glow discharge plasma influence on the oxide layer and diffusion zone formation during process of thermal oxidation of titanium and its alloys. Vacuum, v. 81, n. 3, p. 215-220, out. 2006.

JOSHI, V. A. Titanium alloys: an atlas of structures and fracture features. [s.l.] CRC Press, 2006.

KASHAEV, N.; STOCK, H.-R.; MAYR, P. Assessment of the application potential of the intensified glow discharge for industrial plasma nitriding of Ti-6Al-4V. Surface and Coatings Technology, v. 200, n. 1-4, p. 502-506, out. 2005.

KEARNS, M. W.; RESTALL, J. E. Sixth World Conf. On titanium. (L. U. Les Editions de Physique, Ed.) In: Cannes. Anais... Cannes: 1988.

KÖPPERS, M.; HERZIG, C.; FRIESEL, M.; MISHIN, Y. Intrinsic self-diffusion and substitutional Al diffusion in $\alpha-T i$. Acta Materialia, v. 45, n. 10, p. 4181-4191, out. 1997.

LAKSHMI, S. G.; ARIVUOLI, D.; GANGULI, B. Surface modification and characterisation of Ti-Al-V alloys. Materials Chemistry and Physics, v. 76, n. 2, p. 187-190, ago. 2002.

LANGDON, T. G. Dislocations and creep. (Proceedings of the Conference to Celebrate the fiftieth Anniversary of the Concept of Dislocation in Crystals, Ed.) In: Dislocations and Properties of Real Materials, London. Anais... London: The Institute of Metals, 1984.

LIMA, S. C. Desenvolvimento de um sistema de nitretação a plasma e investigação da atmosfera na nitretação da liga ti-6al-4v. 2010. Dissertação (Mestrado) - Universidade Federal do Rio Grande do Sul, 2010.

LISIECKI, A.; KLIMPEL, A. Diode laser gas nitriding of Ti6Al4V alloy. Archives of Materials Science and ..., v. 31, n. 1, p. 53-56, 2008.

MA, S.; XU, K.; JIE, W. Wear behavior of the surface of Ti-6AI-4V alloy modified by treating with a pulsed d.c. plasma-duplex process. Surface and Coatings Technology, v. 185, n. 2-3, p. 205-209, jul. 2004. 
MATHISEN, M. B. In-situ tensile testing combined with ebsd analysis of ti6al-4v samples from components fabricated by additive layer manufacture. 2012. Master's Thesis - Norwegian University of Science and Technology, 2012.

MATSUMOTO, H.; YONEDA, H.; SATO, K.; KUROSU, S.; MAIRE, E.; FABREGUE, D.; KONNO, T. J.; CHIBA, A. Room-temperature ductility of Ti-6Al$4 \mathrm{~V}$ alloy with $\alpha^{\prime}$ martensite microstructure. Materials Science and Engineering: A, v. 528, n. 3, p. 1512-1520, jan. 2011.

MEETHAM, G. W.; VAN DE VOORDE, M. H. Materials for high temperature engineering applications. Berlin, Heidelberg: Springer Berlin Heidelberg, 2000.

MEYERS, M. A.; CHAWLA, K. K. Princípios de metalurgia mecânica. [s.I.] Editora E. Blücher, 1982.

MICHEL, H.; CZERWIEC, T.; GANTOIS, M. Progress in the analysis of the mechanisms of ion nitriding. Surface and Coatings ..., v. 72, p. 103-111, 1995.

Mineral Commodity Summaries 2014. U.S. Geological Survey, 2014U.S. Geological Survey, , $2014 . \quad$. Disponível em: <http://minerals.usgs.gov/minerals/pubs/mcs/2014/mcs2014.pdf>. Acesso em: 24 jul. 2014.

MISHRA, S. .; NAYAK, B. .; MOHANTY, B. .; MILLS, B. Surface nitriding of titanium in arc plasma. Journal of Materials Processing Technology, v. 132, n. 1-3, p. 143-148, jan. 2003.

MOLARIUS, J. M. Ti-N phases formed by reactive ion plating. Journal of Vacuum Science \& Technology A: Vacuum, Surfaces, and Films, v. 3, n. 6, p. 2419-2425, nov. 1985.

MOLINARI, A.; STRAFFELINI, G.; TESI, B.; BACCI, T.; PRADELLI, G. Effects of load and sliding speed on the tribological behaviour of Ti-6Al-4V plasma nitrided different temperatures. Wear, v. 203-204, n. 96, p. 447-454, 1997.

MONKMAN, F. C.; GRANT, N. J. An empirical relationship between rupture life and minimum creep rate in creep-rupture tests. ASTM Proceedings, v. 56, 1956.

MORITA, T.; ASAKURA, K.; KAGAYA, C. Effect of combination treatment on wear resistance and strength of Ti-6Al-4V alloy. Materials Science and Engineering: A, v. 618, p. 438-446, 2014.

NABARRO, F. R. N. Creep at very low rates. Metallurgical and Materials Transactions A, v. 33, n. 2, p. 213-218, fev. 2002.

NISHIMURA, T.; MIZOGUCHI, T.; ITOH, Y. Titanium Materials for Cryogenic Service. Kobe Res. Dev., v. 34, n. 3, p. 63-66, 1984.

NORRIS, G. Feeling the heat. Metal Bulletin Monthly, v. v. 386, p. 36-39, 1994.

OHRING, M. Materials science of thin films: depositation \& structure. [s.l.] Academic Press, 2002.

OLIVEIRA, A. C.; OLIVEIRA, R. M.; REIS, D. A. P.; CARRERI, F. C. Effect of nitrogen high temperature plasma based ion implantation on the creep behavior of Ti-6Al-4V alloy. Applied Surface Science, v. 311, p. 239-244, ago. 2014.

OLIVEIRA, R. M.; MELLO, C. B.; SILVA, G.; GONÇALVES, J. A. N.; UEDA, M.; PICHON, L. Improved properties of Ti6Al4V by means of nitrogen high temperature plasma based ion implantation. Surface and Coatings Technology, 
v. 205, p. S111-S114, jul. 2011.

OLIVEIRA, V. M. Estudo do fenômeno da fluência da liga ti-6al-4v submetida a tratamentos de nitretação e carbonetação a plasma. 2010. Dissertação (Mestrado) - Escola de Engenharia de Lorena - USP, 2010.

OLIVEIRA, H. S. de; REIS, D. A. P. Caracterização mecânica e microestrutural da liga Ti-6Al-4V após tratamento superficial com laser pulsado Nd: YAG. In: Anais do $15^{\circ}$ Encontro de Iniciação Científica e Pós Graduação do ITA, São José dos Campos, SP. Anais... São José dos Campos, SP: 2009. Disponível em: <http://www.bibl.ita.br/xvencita/MEC04.pdf>. Acesso em: 22 mar. 2014.

PALEHAN, I.; ROSEN, A. History dependent creep of Ti-6Al-4V alloy. Metal Science, v. 12, n. 3, p. 163-165, 1978.

PAULA, J. R.; BARBOZA, M. J. R.; SILVA, C. R. M.; MOURA NETO, C.; PIORINO NETO, F.; SILVA, F. J. Avaliação dos Estágios Primário e Secundário da Liga Ti6Al-4V sob Condições de Fluência. In: $57^{\circ}$ Congresso Anual da ABM, São Paulo. Anais... São Paulo: Congresso Internacional da ABM, 2002.

PEREZ, E. A. C. Influência da microestrutura no comportamento em fluência da liga ti-6al-4v. 2004. Dissertação (Mestrado) Faculdade de Engenharia Química de Lorena, 2004.

PÉREZ, P. Influence of nitriding on the oxidation behaviour of titanium alloys at $700{ }^{\circ} \mathrm{C}$. Surface and Coatings Technology, v. 191, n. 2-3, p. 293-302, fev. 2005.

PITT, F.; RAMULU, M. Influence of Grain Size and Microstructure on Oxidation Rates in Titanium Alloy Ti-6Al-4V Under Superplastic Forming Conditions. Journal of Materials Engineering and Performance, v. 13, n. 6, p. 727-734, 1 dez. 2004.

POHRELYUK, I. M.; TKACHUK, O. V.; PROSKURNYAK, R. V. Corrosion Behaviour of Ti-6Al-4V Alloy with Nitride Coatings in Simulated Body Fluids at $36^{\circ} \mathrm{C}$ and $40^{\circ} \mathrm{C}$. ISRN Corrosion, v. 2013, n. I, p. 1-7, 2013.

RAAIF, M.; EL-HOSSARY, F. M.; NEGM, N. Z.; KHALIL, S. M.; SCHAAF, P. Surface treatment of Ti-6Al-4V alloy by rf plasma nitriding. Journal of Physics: Condensed Matter, v. 19, n. 39, p. 1-12, 3 out. 2007.

RAHMAN, M.; REID, I.; DUGGAN, P.; DOWLING, D. P.; HUGHES, G.; HASHMI, M. S. J. Structural and tribological properties of the plasma nitrided Ti-alloy biomaterials: Influence of the treatment temperature. Surface and Coatings Technology, v. 201, n. 9-11, p. 4865-4872, fev. 2007.

RAJASEKARAN, B.; RAMAN, S. G. S. Plain fatigue and fretting fatigue behaviour of plasma nitrided Ti-6Al-4V. Materials Letters, v. 62, n. 16, p. 2473-2475, jun. 2008.

RAVEH, A.; BUSSIBA, A.; BETTELHEIM, A.; KATZ, Y. Plasma-nitrided $\alpha-\beta$ Ti alloy: layer characterization and mechanical properties modification. Surface and Coatings Technology, v. 57, n. 1, p. 19-29, abr. 1993.

REED-HILL, R. E.; ABBASCHIAN, R.; ABBASCHIAN, L. Physical metallurgy principles. Stanford, CT: Cengage Learning, 2009.

REIS, A. G. Avaliação do comportamento em fluência da liga ti-6al-4v submetida a tratamento superficial de nitretação por laser. 2012. Dissertação 
(Mestrado) - Instituto Tecnológico de Aeronáutica, 2012.

REIS, D. A. P. Efeito do recobrimento cerâmico e da atmosfera de ensaio na fluência de liga metálica refratária de titânio. 2005. Tese (Doutorado) - Instituto Nacional de Pesquisas Espaciais, 2005.

REIS, D. A. P.; PIORINO NETO, F.; BARBOZA, M. J. R.; NONO, M. C. A.; SILVA, C. R. M. Influence of the oxidation in creep of Ti-6Al-4V Alloy. Acta Microscopica, v. 12, n. September, p. 219-220, 2003.

REIS, D. A. P.; SILVA, C. R. M.; NONO, M. C. A.; BARBOZA, M. J. R.; PIORINO NETO, F.; PEREZ, E. A. C. Plasma-Sprayed Coatings for Oxidation Protection on Creep of the Ti-6Al-4V Alloy. Materials at High Temperatures, v. 22, n. 3-4, p. 449-452, 2 jan. 2005.

RODRIGUEZ, D.; MANERO, J. M.; GIL, F. J.; PLANELL, J. A. Low cycle fatigue behavior of Ti6Al4V thermochemically nitrided for its use in hip prostheses. Journal of Materials Science: ..., v. 2, p. 935-937, 2001.

ROLIŃSKI, E. Surface properties of plasma-nitrided titanium alloys. Materials Science and Engineering: A, v. 108, p. 37-44, fev. 1989.

ROLINSKI, E.; SHARP, G.; COWGILL, D. F.; PETERMAN, D. J. Ion nitriding of titanium alpha plus beta alloy for fusion reactor applications. Journal of Nuclear Materials, v. 252, n. 3, p. 200-208, fev. 1998.

ROQUINY, P.; BODART, F.; TERWAGNE, G. Colour control of titanium nitride coatings produced by reactive magnetron sputtering at temperature less than $100^{\circ} \mathrm{C}$. Surface and Coatings Technology, v. 116-119, p. 278-283, set. 1999.

ROSEN, A.; ROTTEM, A. The effect of high temperature exposure on the creep resistance of Ti-6Al-4V alloy. Materials Science and Engineering, v. 22, p. 2329, jan. 1976.

SECO, F. J.; IRISARRI, A. M. Creep failure mechanisms of a Ti-6AI-4V thick plate. Fatigue \& Fracture of Engineering Materials and Structures, v. 24, n. 11, p. 741-750, 18 nov. 2001.

SHA, W.; HAJI MAT DON, M. A.; MOHAMED, A.; WU, X.; SILIANG, B.; ZHECHEVA, A. X-ray diffraction, optical microscopy, and microhardness studies of gas nitrided titanium alloys and titanium aluminide. Materials Characterization, v. 59, n. 3, p. 229-240, mar. 2008.

SHACKELFORD, J. F. Ciência dos materiais. $6^{\text {a }}$ ed. São Paulo: PEARSON Education do Brasil, 2012.

SILVA, H. R.; REIS, D. A. P.; SUGAHARA, T.; MOURA NETO, C.; PIORINO NETO, F.; BARBOZA, M. J. R. Estudo do recobrimento cerâmico no comportamento em fluência da liga Ti-6Al-4V. In: Anais do XVI Encontro de Iniciação Científica e Pós-Graduação do ITA, São José dos Campos, SP. Anais... São José dos Campos, SP: 2010. Disponível em: <http://www.bibl.ita.br/xviencita/IEM-8.pdf>. Acesso em: 22 mar. 2014.

SRIVATSAN, T. S. A review of: "Oxidation of High Temperature Intermetallics" edited by T. Grobstein and J. Doychak TMS, Warrendale, Pennsylvania 295 pages, hardcover, 1988. Materials and Manufacturing Processes, v. 5, n. 4, p. 677-679, jan. 1990.

STONE, R. H. Van; COX, T. B.; LOW, J. R.; PSIODA, J. A. Microstructural 
aspects of fracture by dimpled rupture. International Metals Reviews, v. 30, n. 1, p. 157-180, 18 jan. 1985.

SUGAHARA, T.; MOURA NETO, C.; REIS, D. A. P.; PIORINO NETO, F. Caracterização Mecânica e Microestrutural da Liga Ti-6Al-4V Tratada Termicamente. Revista Brasileira de Aplicações de Vácuo, v. 27, n. n.4, p. 195-199, 2008.

SUGAHARA, T.; REIS, D. A. P.; MOURA NETO, C.; BARBOZA, M. J. R.; PEREZ, E. A. C.; PIORINO NETO, F.; HIRSCHMANN, A. C. O. The Effect of Widmanstätten and Equiaxed Microstructures of Ti-6Al-4V on the Oxidation Rate and Creep Behavior. Materials Science Forum, v. 636-637, p. 657-662, 10 jan. 2010.

SUGAHARA, T.; YOGI, L. M.; OLIVEIRA, G. L. F. de; REIS, D. A. P.; SILVA, M. M.; MOURA NETO, C.; BARBOZA, M. J. R. Influence of Heat Treatment in Creep Resistance of Titanium Alloy. In: 20th International Congress of Mechanical Engineering, Gramado, RS. Anais... Gramado, RS: 2009.

TANG, F.; NAKAZAWA, S.; HAGIWARA, M. Transient creep of Ti-Al-Nb alloys. Materials Science and Engineering: A, v. 325, n. 1-2, p. 194-201, fev. 2002.

TANG, J. G.; LIU, D. X.; TANG, C. B.; ZHANG, X. H. Surface Modification of Ti6AI-4V Alloy by Cathode Assiting Discharge Setup and Conventional Plasma Nitriding Methods. Science China Technological Sciences, v. 56, n. 8, p. 18581864, 18 ago. 2013.

TEOH, S. H. Fatigue of biomaterials: a review. International Journal of Fatigue, v. 22, n. 10, p. 825-837, 2000.

VENKATESH, T. A.; CONNER, B. P.; SURESH, S.; GIANNAKOPOULOS, A. E.; LINDLEY, T. C.; LEE, C. S. An Experimental Investigation of Fretting Fatigue in Ti6Al-4V: The Role of Contact Conditions and Microstructure. Metallurgical and Materials Transactions A, v. 32, n. 5, p. 1131-1146, 2001.

VISWANATHAN, R.; FOULDS, J. Accelerated Stress Rupture Testing for Creep Life Prediction-Its Value and Limitations. Journal of Pressure Vessel Technology, v. 120, p. 105, 1998.

WARREN, J.; HSIUNG, L. M.; WADLEY, H. N. G. High temperature deformation behavior of physical vapor deposited Ti-6Al-4V. Acta Metallurgica et Materialia, v. 43, n. 7, p. 2773-2787, 1995.

YANG, R.; HAO, Y. L. Estimation of $(Y+\alpha 2)$ equilibrium in two-phase Ti-Al-X alloys by means of sublattice site occupancies of $X$ in TiAl and Ti3Al. Scripta Materialia, v. 41, n. 3, p. 341-346, jul. 1999.

YASAVOL, N.; MAHBOUBI, F. The effect of duplex plasma nitriding-oxidizing treatment on the corrosion resistance of AISI 4130 steel. Materials \& Design, v. 38, p. 59-63, jun. 2012.

YETIM, A. F.; YILDIZ, F.; VANGOLU, Y.; ALSARAN, A.; CELIK, A. Several plasma diffusion processes for improving wear properties of Ti6Al4V alloy. Wear, v. 267 , n. 12 , p. $2179-2185$, dez. 2009.

YILBAS, B. S.; SHUJA, S. Z.; HASHMI, M. S. J. A numerical solution for laser heating of titanium and nitrogen diffusion in solid. Journal of Materials Processing Technology, v. 136, n. 1-3, p. 12-23, maio 2003. 
YILDIZ, F.; YETIM, A. F.; ALSARAN, A.; ÇELIK, A. Plasma nitriding behavior of Ti6Al4V orthopedic alloy. Surface and Coatings Technology, v. 202, n. 11, p. 2471-2476, fev. 2008.

YOGI, L. M. Estudo da fluência da liga ti-6al-4v após tratamento térmico e implantação iônica por imersão em plasma. 2012. Dissertação (Mestrado) Instituto Tecnológico de Aeronáutica, 2012.

YOGI, L. M.; PIORINO NETO, F.; REIS, D. A. P.; MOURA NETO, C. Avaliação do Tratamento Térmico na Fluência da Liga Ti-6Al-4V por Caracterização Microestrutural. ( $14^{\circ}$ ENCITA, Ed.) In: $14^{\circ}$ Encontro de Iniciação Científica e PósGraduação do ITA, São José dos Campos, SP. Anais... São José dos Campos, SP: Instituto Tecnológico de Aeronáutica, 2008. Disponível em: <http://www.bibl.ita.br/xivencita/MEC03.pdf>. Acesso em: 8 jun. 2014.

YOGI, L. M.; SUGAHARA, T. Efeito do Tratamento Térmico na Fluência da Liga Ti-6Al-4V. Revista Brasileira de Aplicações de Vácuo, v. 27, n. 4, p. 189-194, 2008.

ZHECHEVA, A.; MALINOV, S.; SHA, W. Titanium alloys after surface gas nitriding. Surface and Coatings Technology, v. 201, n. 6, p. 2467-2474, dez. 2006.

ZHECHEVA, A.; SHA, W.; MALINOV, S.; LONG, A. Enhancing the microstructure and properties of titanium alloys through nitriding and other surface engineering methods. Surface and Coatings Technology, v. 200, n. 7, p. 2192-2207, dez. 2005. 